UNIVERSIDADE DE SÃO PAULO

FACULDADE DE ECONOMIA, ADMINISTRAÇÃO E CONTABILIDADE DEPARTAMENTO DE CONTABILIDADE E ATUÁRIA

PROGRAMA DE PÓS-GRADUAÇÃo EM CONTROLADORIA E CONTABILIDADE

DIANE ROSSI MAXIMIANO REINA

COMPARABILIDADE DOS DEMONSTRATIVOS

FINANCEIROS, ACURÁCIA E INFORMATIVIDADE NO BRASIL

SÃo PAULO 
Prof. Dr. Marco Antônio Zago

Reitor da Universidade de São Paulo

Prof. Dr. Adalberto Américo Fischmann

Diretor da Faculdade de Economia, Administração e Contabilidade

Prof. Dr. Ariovaldo dos Santos

Chefe do Departamento de Contabilidade e Atuária

Prof. Dr. Luiz Paulo Lopes Fávero

Coordenador do Programa de Pós-Graduação em Controladoria e Contabilidade 
DIANE ROSSI MAXIMIANO REINA

\section{COMPARABILIDADE DOS DEMONSTRATIVOS FINANCEIROS, ACURÁCIA E INFORMATIVIDADE NO BRASIL}

Tese de Doutoramento apresentada ao Departamento de Contabilidade e Atuária da Faculdade de Economia, Administração e Contabilidade da Universidade de São Paulo, como requisito parcial para a obtenção do grau de Doutor em Ciências.

Orientador: Prof. Dr. Luiz Nelson Guedes de Carvalho

\section{Versão Corrigida}

(versão original disponível na Biblioteca da Faculdade de Economia, Administração e Contabilidade)

São Paulo 


\section{FICHA CATALOGRÁFICA}

Elaborada pela Seção de Processamento Técnico do SBD/FEA/USP

\section{Reina, Diane Rossi Maximiano}

Comparabilidade dos demonstrativos financeiros, acurácia e informatividade no Brasil / Diane Rossi Maximiano Reina. - São Paulo, 2017.

$135 \mathrm{p}$.

Tese(Doutorado) - Universidade de São Paulo, 2017.

Orientador: Luiz Nelson Guedes de Carvalho.

1. Contabilidade financeira 2. Demonstrativos financeiros 3. Comparabilidade 4. Informatividade 5. Acurácia I. Universidade de São Paulo. Faculdade de Economia, Administração e Contabilidade. II. Título.

CDD -657.48 
Nome: Diane Rossi Maximiano Reina

Título: Comparabilidade dos demonstrativos financeiros, acurácia e informatividade no Brasil.

Tese de Doutoramento apresentada ao Departamento de Contabilidade e Atuária da Faculdade de Economia, Administração e Contabilidade da Universidade de São Paulo, como requisito parcial para a obtenção do grau de Doutor em Ciências. 

Dedico.

A Deus e à minha família 



\section{AGRADECIMENTOS}

Agradeço a Deus, pela força, persistência e discernimento, entretanto, a realização deste trabalho não seria possível sem o auxílio daqueles, que direta ou indiretamente, colaboraram e me apoiaram nesta trajetória.

Ao Donizete, em especial, pelo incentivo, apoio, paciência e conforto nos momentos difíceis, além de compartilhar as alegrias e angústias deste desafio.

Aos meus familiares pela compreensão e apoio.

Agradeço imensamente ao Professor e Orientador Dr. Luiz Nelson Guedes de Carvalho pelo tempo dispensado, pela paciência, pelos ensinamentos durante o processo de orientação e também no período de monitoria didática.

Aos Professores Antonio Lopo Martinez e José Elias Feres de Almeida, pela pronta disposição em participar da banca de qualificação e de defesa, bem como pelos questionamentos e sugestões que contribuíram para o desenvolvimento desta tese. $\mathrm{O}$ mesmo agradecimento estendo também aos Professores Fernando Dal-Ri Murcia e Guillermo Oscar Braunbeck por participarem da banca de defesa.

Aos professores, Dr. Alexandro Broedel Lopes, Dr. Bruno Salotti, Dr. Edgar Cornachione Junior, Dr. Fernando Dal-Ri Murcia, Dr. Gilberto Martins, Dr. Luiz Paulo Fávero, Dr. Luiz João Corrar, e Dra. Tânia Regina Sordi Relvas pelos ensinamentos.

Aos amigos, Sérgio Lemos Duarte, Sandro Vieira Soares pelo auxílio e companheirismo. Agradeço a todas as pessoas as quais convivi na FEA/USP especialmente: Patrícia Romualdo de Almeida; Carlos Alberto Kuhl; Raquel Wille Sarquis; Verônica de Fátima Santana; André Carlos de Souza; Talles Vianna Brugni; Ana Lúcia Carvalho Santos; Eduardo Alves de Oliveira; Sayuri Unoki de Azevedo; Edmilson Patrocínio de Sousa; Eduardo da Silva Flores; Iracema Raimunda Brito Neves Aragão, muito obrigada pela convivência e ajuda. Aos funcionários da FEA/USP, pelo auxilio e por serem sempre prestativos. 



\section{RESUMO}

Reina, D. R. M. (2017). Comparabilidade dos demonstrativos financeiros, acurácia e informatividade no Brasil. Tese de Doutorado, Departamento de Contabilidade e Atuária, Faculdade de Economia, Administração e Contabilidade, Universidade de São Paulo, São Paulo.

O aumento da comparabilidade entre os países é uma das principais motivações para o apoio permanente à convergência aos padrões globais de contabilidade (SEC, 2010; Hail, Leuz \& Wysocki, 2010). As informações contábeis são importantes na formação das expectativas do mercado, e, segundo Sarlo Neto, Lopes e Dalmácio (2009) tal importância influencia o valor das empresas e é conhecida como informatividade. A Comparabilidade afeta os usuários finais das demonstrações financeiras, porque as empresas pares servem como referência na análise das informações contábeis de uma empresa. Assim, o objetivo principal desta pesquisa foi investigar o impacto da comparabilidade dos demonstrativos financeiros sobre a acurácia na previsão de consenso dos analistas de investimento do mercado brasileiro e na informatividade das empresas listadas na BM\&FBovespa no período de 2005 a 2015. Esta pesquisa é quantitativa, utiliza-se de dados secundários e é descritiva por investigar a influência da comparabilidade dos demonstrativos financeiros sobre a acurácia e previsão dos analistas de investimento do mercado brasileiro. Os dados foram coletados a partir do banco de dados dos sistemas Thomson ONE Analytics, Economática, e, Comdinheiro. Para tanto utilizou-se a técnica econométrica de regressão múltiplaA classificação por setor foi realizada utilizando-se o North American Classification System - NAICS nível 2; e para testar o comportamento das variáveis foi utilizada a abordagem estatística de dados em painel. Os principais resultados obtidos foram: a comparabilidade individual média entre empresas diferentes não apresentou variações significativas no período após adoção do IFRS, entretanto a comparabilidade da mesma empresa ao longo do período apresentou melhora. Em relação à acurácia não foram observadas alterações significativas nos períodos antes e após a transição regulatória. No entanto, observou-se que as variáveis COMPM e COMPT influenciam a acurácia de forma significativa e negativa. As variáveis COMPM e COMPT mostraram-se positivas e estatisticamente significativas, como principais variáveis que impactam no retorno das ações.

Palavras-chave: Contabilidade Financeira. Demonstrativos Financeiros. Comparabilidade. Informatividade. Acurácia. 


\section{ABSTRACT}

Reina, D. R. M. (2017). Comparability of financial statements, accuracy and informativeness in Brazil. Ph.D Dissertation, Department of Accounting and Actuarial Sciences, School of Economics, Business Administration and Acconting, University of Sao Paulo, Sao Paulo.

Increasing comparability across countries is one of the main motivations for continuing support for convergence to global accounting standards (SEC, 2010; Hail, Leuz \& Wysocki, 2010). Accounting information is important in shaping market expectations, and according to Sarlo Neto, Lopes and Dalmácio (2009) such importance influences the value of companies and is known as information. Comparability affects the end users of financial statements because peer companies serve as a benchmark in analyzing a company's accounting information. The main objective of this research was to investigate the impact of the comparability of the financial statements on the accuracy in the consensus forecast of investment analysts in the Brazilian market and in the informativeness of the companies listed on BM \& FBovespa between 2005 and 2015. This research is quantitative, we used secondary and descriptive data to investigate the influence of the comparability of financial statements on the accuracy and prediction of investment analysts in the Brazilian market. The data were collected from the Thomson ONE Analytics System Database, the Economics System Database, and Comdinheiro. For that, the econometric technique of multiple regression was used with the aid of Stata ${ }^{\circledR}$ and SPSS ${ }^{\circledR}$ Software. The classification by sector was made using the classification of the North American Classification System - NAICS level 2; and to test the behavior of the variables the statistical approach of panel data was used. As the main results: the average individual comparability between different companies did not show significant variations in the period after adoption of IFRS, however the comparability of the same company during the period showed an improvement in the period. Regarding the accuracy, no significant changes were observed in the periods before and after the regulatory transition. However, it was observed that the COMPM and COMPT variables influence the accuracy significantly and negatively. The variables COMPM and COMPT were positive and statistically significant, as the main variables that impact on stock returns.

Keywords: Financial Accounting. Financial Statements. Comparability. Informativeness Accuracy. 


\section{SUMÁRIO}

1 INTRODUÇÃO ...................................................................................................................... 19

2 FUNDAMENTAÇÃO TEÓRICA ............................................................................... 27

2.1 CONCEITO DE COMPARABILIDADE DOS DEMONSTRATIVOS CONTÁBEIS E SUAS PRINCIPAIS

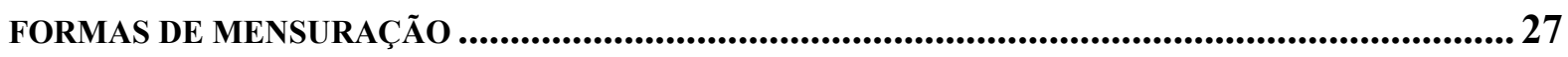

2.2 FORMAS DE MENSURAÇÃO DA COMPARABILIDADE......................................................... 32

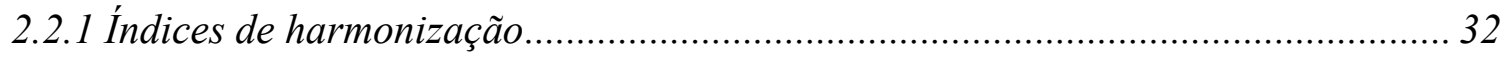

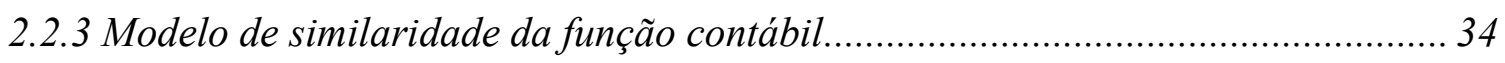

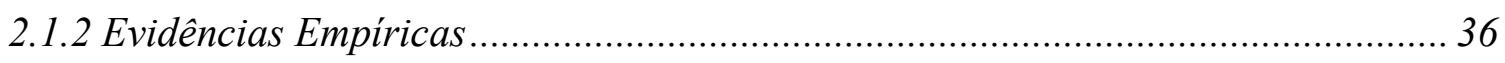

2.2 PREVISÃo doS ANALISTAS E A COMPARABILIDAdE ..................................................... 39

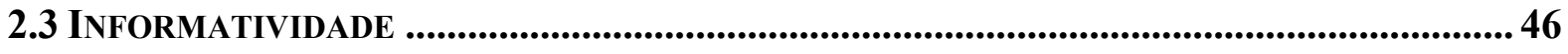

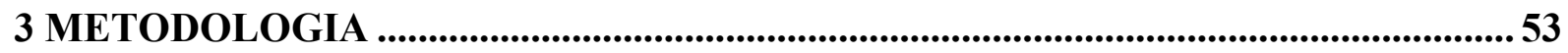

3.1 ENQUAdRAMENTO METOdOLÓGICO .......................................................................5 53

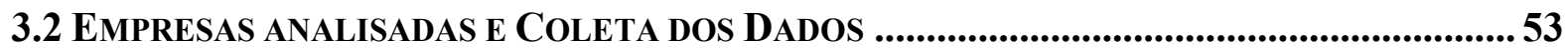

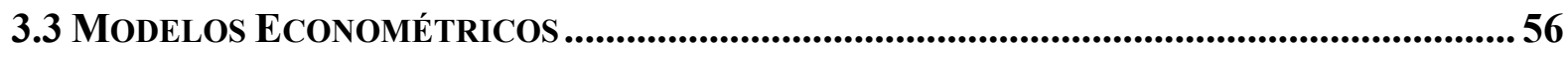

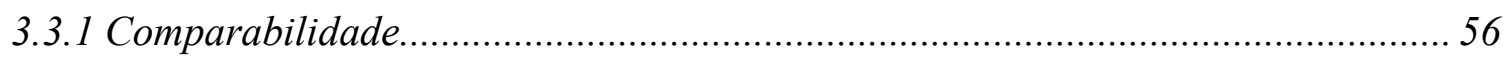

3.3.1.1 Medida de comparabilidade individual média (COMPM) .............................57

3.3.1.2 Medida de comparabilidade intertemporal (COMPT) .................................... 58

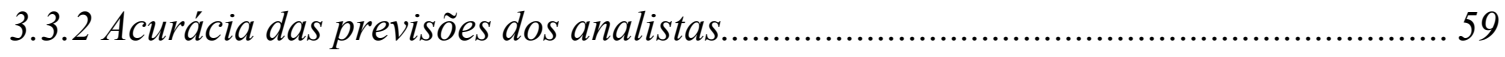

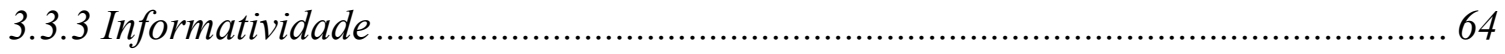

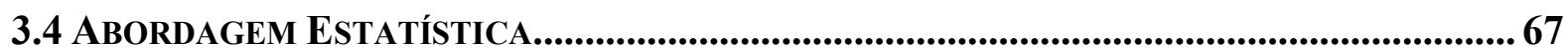

4 APRESENTAÇÃO E ANÁLISE DOS RESULTADOS ............................................. 73

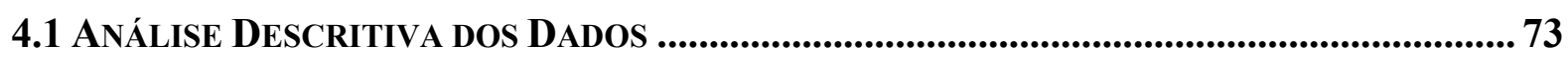

4.1.2 Análise comparabilidade da mesma empresa ao longo do tempo .......................... 80

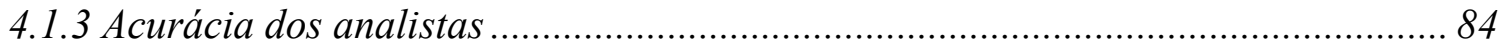

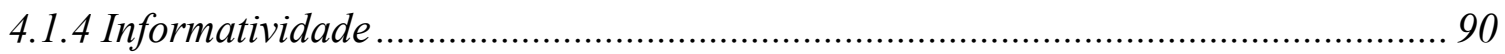

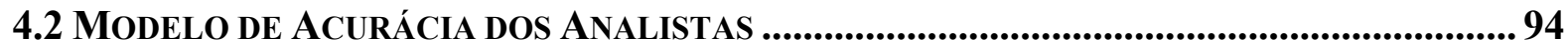

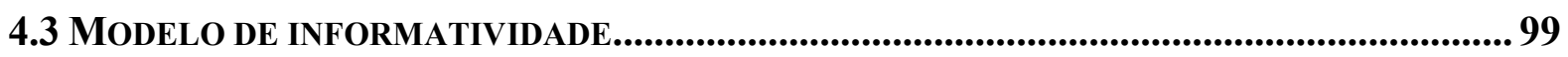

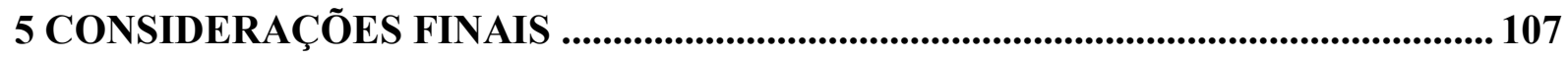

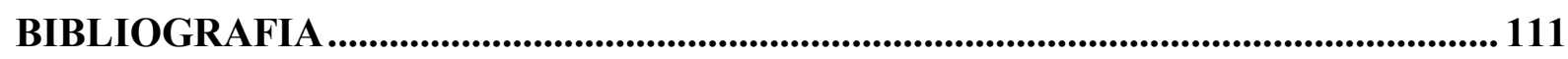

APÊNDICE 1 - RESULTADOS DOS MODELOS ESTIMADOS .............................. 119 



\section{LISTA DE TABELAS}

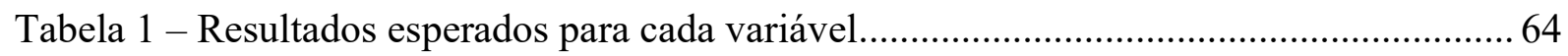

Tabela 2- - Estatística descritiva das principais variáveis utilizadas na pesquisa .................. 73

Tabela 3 - Correlação entre as principais variáveis quantitativas ........................................ 76

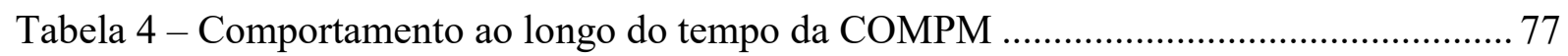

Tabela 5 - Comportamento e diferenças na variável COMPM entre os setores...................... 80

Tabela 6 - Comparabilidade temporal da COMPT ….......................................................... 81

Tabela 7-Comportamento e diferenças na variável COMPT entre os setores........................ 83

Tabela 8 - Comparação das variáveis antes e após a adoção do IFRS ................................... 84

Tabela 9 - Análise de diferença de médias variável ACURÁCIA ......................................... 86

Tabela 10 - Correlação entre as variáveis do modelo de Acurácia ......................................... 89

Tabela 11 - Diferenças na RA ao longo do período investigado ............................................ 90

Tabela 12 - Análise de diferença de media variável RA ........................................................ 90

Tabela 13 - Analise correlação entre as variáveis da informatividade .................................. 92

Tabela 14 - Teste para efeitos aleatórios, fixos e modelo pooled (modelos Acurácia) ........... 95

Tabela 15 -Critérios de informação para os modelos com efeitos fixos e pooled .................... 95

Tabela 16 - Resultado do modelo de COMPM ...................................................................... 95

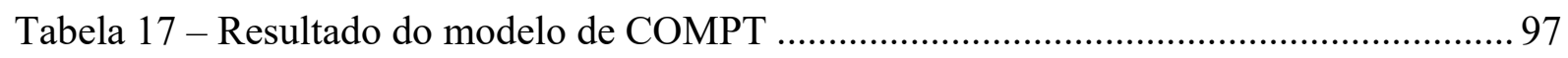

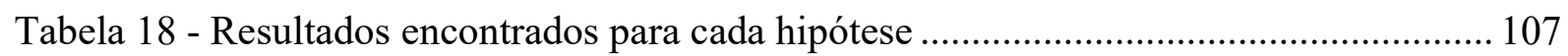




\section{LISTA DE ILUSTRAÇÕES}

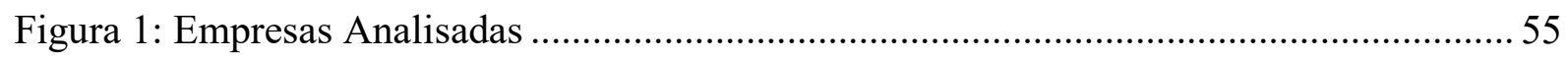

Figura 2 - Distribuição das variáveis COMPM e COMPT ….............................................. 75

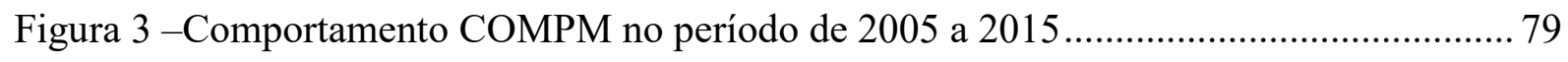

Figura 4 -Comportamento COMPM no período de 2005 a 2015 ......................................... 83

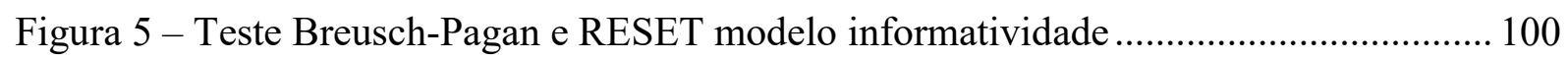

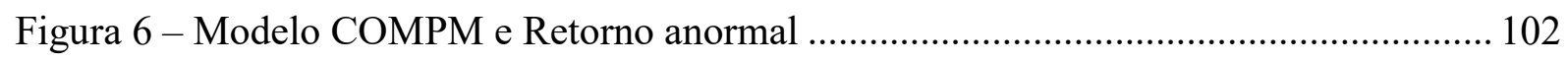

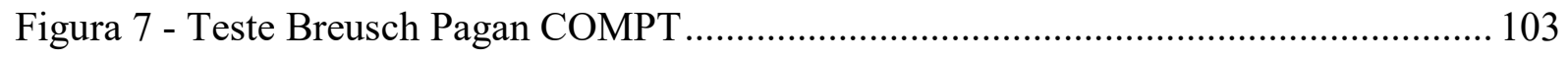

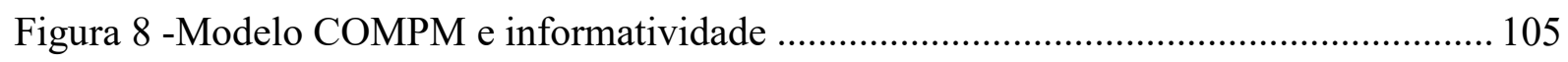




\section{LISTA DE ABREVIATURA E SIGLAS}

FASB

GAAP

IASB

IASC

IFRS

NAICS

SEC

HME
Financial Accounting Standards Board

General Accepted Accounting Principles

International Accounting Standards Board

International Accounting Standards Commitee

International Financial Reporting Standards

North American Classification System

Securities Exchange Commission

Hipótese do Mercado Eficiente 



\section{INTRODUÇÃO}

O mercado financeiro é um dos maiores usuários da informação contábil, tendo em vista a importância da contabilidade como uma fonte de informação sobre a performance empresarial, e também como redutora da assimetria informacional, conflito de agência, custos de transação (De Franco, Kothari, \& Verdi, 2011; Martinez A. L., 2009; Martinez \& Dumer, 2013). Dentre os usuários da informação contábil pode-se destacar os analistas, as corretoras, os investidores, os bancos de investimentos, etc.

Segundo Lopes e Martins (2005), o mercado financeiro é composto por instituições divididas em dois grandes grupos: os intermediários financeiros e os informacionais.Os intermediários informacionais são os agentes responsáveis pelo adequando fluxo de informações do mercado para que os intermediários financeiros possam alocar adequadamente os recursos, e os analistas de mercado de capitais dentre outros são exemplos de intermediários informacionais.

De acordo com Watts \& Zimmerman (1990) para as decisões sobre investimentos no mercado de capitais, cada vez mais a informação contábil tem sido estudada por pesquisadores numa perspectiva entre números contábeis e valor das ações no mercado. Para Kothari (2001), existe uma vasta discussão quanto à importância e relevância das informações contábeis, especialmente, aquelas relacionadas à formação de valor das empresas no mercado e à negociação de suas ações. Para Lopes e Martins (2005, p. 76), a informação contábil possui papel central neste contexto como fonte de informação, pois pode ser utilizada para a avaliação da qualidade dos ativos (análise de balanços), para avaliação da performance de agentes investidos pelos acionistas (remuneração de executivos), e para o controle do comportamento dos agentes após a concessão de créditos.

Nessa perspectiva, merecem atenção os trabalhos iniciais desenvolvidos por Ball e Brown (1968) e Beaver (1968) cuja essência analisava variáveis contábeis e suas influências, também conhecida como uma visão mais positivista dessas informações contábeis. Para Lopes e Iudicibus (2012) essa visão mais positivista está intimamente relacionada com a busca em explicar e predizer fenômenos reais no campo contábil, notadamente pela incorporação de modelos sistemáticos, instrumentos e técnicas matemáticas, estatísticas e contábeis como aliados na busca de respostas para fenômenos reais das empresas 
A teoria positiva da contabilidade surge para incorporar as metodologias empíricas de finanças explicando assim a sua relação entre o mercado de capitais e a contabilidade (Watts \& Zimmerman, 1990; Silva, Sarlo Neto, Reina \& Formentini, 2015). Desta forma, as pesquisas em contabilidade passaram a verificar a utilidade e a influência das demonstrações contábeis sobre as ações de seus usuários (Sarlo Neto, Loss, Nossa \& Teixeira, 2003; Sarlo Neto, Galdi \& Dalmacio, 2009). Segundo Brugni, Fávero, Flores e Beiruth (2016), de modo geral, o que se observa é que a informação contábil vem adquirindo espaço significativo na composição das variáveis dos modelos de avaliação. Ou seja, a contabilidade torna-se imprescindível no processo de realização de previsões e avaliações econômicas das empresas.

De acordo com Silva, Sarlo Neto, Costa Junior e Reina (2016, p. 1):

A formação do valor das ações comercializadas em mercados financeiros reflete as diversas nuances e influências de inúmeras outras variáveis correlacionadas, tais como: a expectativa do mercado, as políticas econômicas, as infraestruturas, confiança e outras peculiaridades do mercado no qual operam as empresas, que combinadas levam os investidores a precificarem o valor das firmas.

Observa-se assim, a importância de se compreender a qualidade das informações divulgadas nos demonstrativos contábeis, pois a qualidade dessas informações é que possibilita a eficiência informacional aos usuários (Soderstrom \& Sun, 2007). Neste contexto, o International Accounting Standard Board (IASB) argumenta que um único conjunto de normas contábeis globais de alta qualidade é elaborado com o objetivo de proporcionar aos participantes do mercado financeiro demonstrações contábeis comparáveis e, assim, ajudá-los no processo de tomada de decisões econômicas (IASC Foundation).

O aumento da comparabilidade entre os países é uma das principais motivações para o apoio permanente à convergência aos padrões globais de contabilidade (SEC, 2010; Hail, Leuz \& Wysocki, 2010). Na medida em que a adoção obrigatória do IFRS é realizada por meio da introdução de normas contábeis de alta qualidade em todos os países, observa-se dois efeitos de primeira ordem: uma melhoria na qualidade dos relatórios financeiros (maior transparência), e também na comparabilidade das informações evidenciadas por meio dos demonstrativos financeiros 6 
Barth (2013) menciona que permitir aos investidores compararem as oportunidades de investimento é uma das principais razões pelas quais se precisa das normas contábeis financeiras, pois sem elas cada empresa poderia escolher a forma de evidenciar seu desempenho econômico e financeiro. Desta forma, é impossível alcançar a comparabilidade sem o uso de normas globais para a elaboração dos relatórios contábeis.

Os estudos realizados sobre a melhoria dos demonstrativos contábeis após a adoção do IFRS têm relatado o aumento da comparabilidade. Barth, Landsman, Lang e Williams (2012) constataram que a relevância dos lucros e do valor patrimonial é mais comparável entre empresas não americanas que publicam seus demonstrativos contábeis na bolsa de valores local após a aplicação do IFRS do que quando utilizam as normas contábeis locais.

A Comparabilidade da Contabilidade também melhorou para uma amostra de países europeus e do Reino Unido, após a adoção do IFRS (Brochet, Jagolinzer \& Riedl, 2013; Yip \& Young 2012).

Já Horton, Serafeim e Serafeim (2013) fornecem evidências de que as precisões nas previsões dos analistas melhoraram após a adoção obrigatória do IFRS para os analistas que cobrem empresas de diversos países. Nessa mesma linha de raciocínio, Tan, Wang e Welker (2011) observaram que o número de analistas está aumentando na medida em que a adoção do IFRS elimina as diferenças entre os padrões contábeis do país onde a empresa está localizada e o país do analista. Adicionalmente, Found, Hu, Hung e Li (2011) encontraram evidências de que a comparabilidade está associada ao aumento das participações de fundos mútuos estrangeiros após a adoção obrigatória do IFRS para as empresas domiciliadas em países com aumento de uniformidade. Já De Franco, Kothari e Verdi (2011) examinaram a comparabilidade em empresas americanas e encontraram que ela está associada ao aumento do número de analistas que cobrem tais empresas e que a comparabilidade diminui também o custo de aquisição de informações e aumenta a quantidade e a qualidade das informações disponíveis aos analistas.

Nesse contexto, constata-se que a comparabilidade possibilita uma melhora na informatividade dos preços das ações permitindo aos investidores realizarem uma avaliação mais eficiente em relação ao desempenho econômico e financeiro das empresas. As informações contábeis são importantes na formação das expectativas do mercado, e, segundo Sarlo Neto, Lopes e Dalmácio (2009) tal importância influencia o valor das empresas e é conhecida como 
informatividade. No contexto brasileiro, as pesquisas sobre informatividade se iniciaram na segunda metade dos anos 1990, com o trabalho de Schiehll (1996). Mais tarde, outros estudos foram desenvolvidos, entre eles os de: Prux Junior(1998), Martinez (2001), Lopes (2001), Bernardo (2001), Lima e Terra (2004). Sarlo Neto, Bassi e Almeida (2011) lembram que nos vários estudos sobre informatividade foi verificada uma reação dos preços das ações em relação à divulgação das informações contábeis, todavia, alguns grupos de ações sofrem reações mais específicas em função das características das empresas.

Destacam-se alguns estudos envolvendo diversas variáveis que refletem atributos específicos das empresas, especialmente, em relação à capacidade informacional da empresa. Atiase (1985) e Freeman (1987) investigaram a informatividade das demonstrações contábeis em diferentes empresas de variados tamanhos, já Collins e Kothari (1989) testaram a informatividade em diferentes contextos de oportunidades de crescimento (market-to-book) e, Sarlo Neto, Rossi e Almeida (2011) testaram, para as empresas latino-americanas, as variáveis tamanho, oportunidades de crescimento (market-to-book) e endividamento em relação à informatividade. Para Silva, Sarlo Neto, Costa Junior e Reina (2016 p.2) no que tange à capacidade informacional dos lucros, a interação entre o lucro e outras informações contábeis pode detectar a possibilidade de melhoria da capacidade informacional.

Diante disso, a questão norteadora desta pesquisa é: Qual a influência da comparabilidade dos demonstrativos financeiros sobre a acurácia na previsão dos analistas de mercado e na informatividade?

O presente estudo tem como objetivo investigar o impacto da comparabilidade dos demonstrativos financeiros sobre a acurácia na previsão de consenso dos analistas de investimento do mercado brasileiro e na informatividade das empresas listadas na BM\&FBovespa no período de 2005 a 2015.

Na busca de resposta ao problema central da pesquisa, foram formulados os seguintes objetivos específicos:

i) calcular o nível de comparabilidade média de cada companhia analisada com base em seus pares do setor;

ii) mensurar a acurácia na previsão dos analistas financeiros;

iii) avaliar a influência da comparabilidade sobre a informatividade; 
iv) examinar a relação entre a comparabilidade e a acurácia na previsão realizada pelos analistas.

Embora já tenham sido realizadas pesquisas sobre a comparabilidade dos demonstrativos contábeis após a adoção das normas internacionais de contabilidade, destaca-se que esses estudos foram realizados com o foco na comparabilidade entre países e em sua maioria países que compõem a união europeia. Entretanto, este estudo se diferencia respaldado nas lacunas levantadas por Horton, Serafeim e Serafeim (2013), que questionam como a transição obrigatória para as normas internacionais de contabilidade podem impactar também os analistas locais, ao produzirem demonstrativos contábeis mais informativos, sugerindo assim uma melhora na precisão e previsão dos analistas.

A adoção das IFRS no Brasil trouxe inovações tanto no processo de elaboração dos demonstrativos contábeis (ambiente contábil), como na definição dos critérios a serem utilizados (regras de natureza contábil praticadas), uma vez que tais normas são baseadas muito mais em princípios do que na mera aplicação de regras (Saiki \& Antunes, 2010; Sousa, Sousa, \& Demonier, 2016). Essa inovação trazida pela adoção das IFRS pode trazer implicações relevantes para a qualidade da informação contábil bem como para os usuários que utilizam essa informação, tais como investidores e analistas do mercado financeiro (Martinez \& Dumer; 2013). Segundo a CVM (2008), o simples fato de adotarmos as normas internacionais de contabilidade não garantirá, uma melhora na avaliação da qualidade da informação contábil, podendo o efeito ser contrário ao esperado, uma vez que as normas internacionais possibilitam um maior grau de subjetividade, e essa subjetividade pode ampliar as possibilidades de gerenciamento das informações e incorrermos na perda de confiabilidade das informações.

Ao investigar o impacto da adoção completa das IFRS no Brasil em relação ao gerenciamento de resultados; ao conservadorismo condicional; à relevância e tempestividade, Silva (2013) encontrou evidências de que a maior divulgação proporcionada pela adoção completa das IFRS pode ser explicada pelo registro de operações anteriormente não contabilizadas, os modelos de relevância e tempestividade. Corroborando com isso, um estudo realizado por Easton (1999) revela um aumento em ambas as dimensões. Tais achados indicam que a informação contábil em IFRS pode ser mais útil para os diversos usuários, tais como os analistas que necessitam de números contábeis mais informativos, com o propósito de avaliar risco e apresentar estimativas mais precisas. Além disso ser útil para os acionistas e investidores que buscam avaliar o 
desempenho econômico e financeiro das empresas, contribuindo para uma alocação de recursos mais eficiente.

Ribeiro (2014) investigou o impacto do movimento de flexibilização regulatória contábil sobre a comparabilidade dos relatórios financeiros. Como resultados constatou-se que o aumento do poder discricionário do gestor por meio da flexibilização regulatória dos padrões contábeis não diminui a comparabilidade dos relatórios financeiros. Assim, a tese defendida por esta pesquisa é de que:

A comparabilidade proporciona melhoria na qualidade das informações contábeis por meio da acurácia nas previsões dos analistas de mercado e do aumento da informatividade.

Em pesquisas relacionadas à capacidade informacional (informatividade) no Brasil, os autores Schiehll (1996), Martinez (2001), Lopes( 2001), Bernardo (2001), Lima e Terra (2004) e Sarlo Neto (2004) identificaram que o preço das ações reage à divulgação das informações contábeis. Desta forma, quanto mais acurada for a previsão dos analistas de mercado, pressupõe-se que haverá reações positivas nos preços das ações em função da divulgação dessas informações contábeis.

O sistema de contabilidade pode ser definido como um mapeamento de eventos econômicos subjacentes às demonstrações contábeis. Assim, duas empresas são consideradas como tendo sistemas contábeis comparáveis se elas produzem demonstrações financeiras semelhantes, dado o mesmo conjunto de eventos econômicos (De Franco, Kothari \& Verdi 2011; Barth, Landsman, Lang \& Williams 2012). Na literatura, observa-se um aumento dos benefícios da comparabilidade das demonstrações financeiras em vários cenários, que incluem a melhoria do ambiente de informacional medido pelo número de analistas (De Franco, Kothari \& Verdi, 2011) e facilita o fornecimento de informações nos mercados de empréstimos privados e da dívida pública nos mercados (Fang, Li, Xin \& Zhang 2012; Kim, Kraft \& Ryan 2013).

A comparabilidade afeta os usuários finais das demonstrações financeiras, porque as empresas pares servem como referência na análise das informações contábeis de uma empresa. Pesquisas sobre análise das demonstrações financeiras, muitas vezes enfatizam a importância de comparar os índices financeiros com empresas pares apropriadas para formular um juízo sobre o desempenho de uma empresa (Foster, 1986; Penman, 2006). Todavia, espera-se que o aumento 
da qualidade e da comparabilidade das demonstrações financeiras, e o consequente aumento da utilidade da informação, tenha um impacto positivo na quantidade e capacidade de previsão dos analistas que seguem as empresas, no mercado de capitais, no mercado de crédito, na remuneração dos executivos e nas decisões econômicas das empresas (Martinez \& Dumer; 2013; Santos et al., 2011). No que tange à informatividade, os preços das ações refletem as expectativas do mercado em relação ao desempenho futuro da empresa. Nesse sentido, a comparabilidade expande as informações disponíveis sobre a empresa melhorando a capacidade de previsão pelos investidores (Haw, Hu, Lee, \& Wu, 2012). A adoção das IFRS conduzirá, assim, a uma melhoria da capacidade de os investidores tomarem decisões financeiras respaldadas à uma melhoria das condições de investimento e/ou financiamento e a uma eficiente alocação de recursos financeiros.

Com base nas informações apresentadas, as hipóteses desta tese são:

H1 : O aumento da comparabilidade dos demonstrativos financeiros está associado ao aumento na acurácia das estimativas de consenso dos analistas de mercado.

H2 : A comparabilidade dos demonstrativos financeiros influencia positivamente a informatividade.

Esta pesquisa contribui para o debate sobre a melhoria na qualidade dos demonstrativos contábeis e seus benefícios para o mercado financeiro, mais especificamente, por fornecer evidências em um ambiente cujos padrões contábeis regulatórios eram baseados em regras e passaram a ser baseados em princípios. Seguir regras é muito mais fácil do que exercer julgamento e tomar decisões com base em princípios, por exigir maior conhecimento dos profissionais. Ao analisarmos os escândalos contábeis mundiais (tais como Enron, Worldcom, Xerox e outros) foram ocasionados por seguir regras e não princípios.

Outras contribuições para a realização desta pesquisa no contexto brasileiro é que: i) oo restringir a análise a um único país, pode-se atenuar variações relacionadas a características institucionais que possam interferir nos resultados que se baseiam em amostras entre países; ii) a adoção das normas internacionais de contabilidade no Brasil provenientes das Leis n. ${ }^{\circ}$. 11.638/2007 e n. ${ }^{\circ} 11.941 / 2009$, que alteraram os dispositivos da Lei n॰. $6.404 / 1976$ passou a ser obrigatória a partir do encerramento do exercício de 2010. Concernente a isso, a partir do 
encerramento do ano de 2008 as empresas poderiam adotar as normas de forma facultativa, tornando possível a investigação do período anterior ao IFRS, o período de transição, e o período pós-adoção. Por fim, destaca-se como contribuição os aspectos observados por Carvalho e Salotti (2013) de que o Brasil é um raro exemplo de país que realizou a adoção completa das normas internacionais de contabilidade na sua totalidade, ou seja, a adoção foi realizada para os demonstrativos financeiros consolidados e individuais. A literatura, tem abordado os efeitos da adoção das normas internacionais em demonstrações contábeis consolidadas, uma vez que a maioria das pesquisas são realizadas em países Europeus e na Europa somente tais demonstrativos são obrigados a adotarem as normas IFRS. Assim, a investigação dos efeitos da adoção das normas IFRS em um país cujos demonstrativos financeiros consolidados e não consolidados devem ser elaborados com base nesse padrão, torna-se um caso interessante, por contribuir com a literatura sobre a capacidade informacional, qualidade das informações contábeis bem como os efeitos da adoção das IFRS.

$\mathrm{Na}$ pesquisa realizada por Silva (2013) no contexto brasileiro foi possível observar uma melhoria na qualidade das informações contábeis (dada pelas dimensões gerenciamento de resultados, conservadorismo condicional, relevância e oportunidade) após a adoção completa das normas internacionais de contabilidade e, consequentemente, uma redução de custo de capital próprio. No entanto, não foi possível observar pesquisas no contexto nacional que investiguem a comparabilidade dos demonstrativos contábeis e sua relação com a acurácia na previsão dos analistas e na capacidade informacional dos demonstrativos contábeis.

O presente estudo está organizado em cinco seções. Após esta primeira seção de caráter introdutório, apresenta-se, na segunda seção, o referencial teórico sobre comparabilidade dos demonstrativos financeiros; previsão dos analistas e informatividade. Na terceira seção, apresentam-se a metodologia da pesquisa, a população e amostra da pesquisa e os procedimentos para coleta e análise dos dados. Na quarta seção, apresentam-se os resultados da pesquisa. Na quinta seção, as considerações finais, e, por fim, elencam-se as referências utilizadas na pesquisa. 


\section{FUNDAMENTAÇÃO TEÓRICA}

\subsection{Conceito de comparabilidade dos demonstrativos contábeis e suas principais formas de mensuração}

A teoria positiva da contabilidade apoia-se em princípios da teoria econômica, busca testar/explicar a aplicação das normas e práticas contábeis que surgem por meio da teoria normativa e das agências reguladoras. O ponto de partida é a ideia de que os indivíduos agem em função de seus interesses pessoais, no contexto empresarial, passa a ser visto como um conjunto de indivíduos que agem estimulados por interesses próprios, embora, racionalmente se organizem de modo a maximizar a sobrevivência e manutenção da empresa ao longo do tempo por perceber que seu destino depende da mesma (Iudícibus \& Lopes, 2004; Lopes, 2012). A abordagem positiva da contabilidade é baseada em dois fundamentos: o conceito de Information Approach e a Hipótese do Mercado Eficiente (HME).

Segundo Iudícibus (2015) o conceito de Information Approach ou Abordagem da informação faz parte da abordagem sistêmica da contabilidade, em que prevalece, a função de fornecer informações, para que os usuários possam tomar suas decisões e realizar seus julgamentos de forma adequada. Sob esse contexto, a contabilidade contribui para equalizar o conteúdo informacional entre os usuários internos e externos da contabilidade, reduzindo assim, a assimetria informacional. Já a Hipótese do Mercado Eficiente (HME) considera que os preços das ações refletem todas as expectativas e as informações disponíveis sobre um ativo financeiro.

Sob o conceito da abordagem da informação para que a contabilidade possa atuar como redutor da assimetria informacional, é necessário que a mesma possua determinadas características que assegurem a credibilidade e a utilidade das informações. Assim, entre as características da informação contábil duas destacam-se sob o ponto de vista dos usuários a relevância e a confiabilidade. Segundo o CPC 00 R1 as informações são relevantes quando podem influencias as decisões econômicas dos usuários, ajudando-os a avaliar o impacto de eventos passados, presentes ou futuros, confirmando ou corrigindo as suas avaliações anteriores. Nesse contexto, pode inferir que relevante é a informação contábil que faz a diferença para o usuário no processo de tomada de decisão, para atender esse quesito a informação tem que estar disponível em momento oportuno. A confiabilidade é a qualidade da informação contábil que assegura 
que a informação é livre de erros, vieses e que representa com fidedignidade o que se propõe a representar, ou seja, é uma característica que abrange a mensuração, o reconhecimento e a divulgação das informações.

A comparabilidade é uma das características qualitativas da informação contábil que aumenta a sua utilidade, possibilitando às empresas atraírem um número maior de investidores de outros países (Financial Accounting Standards Board, 1980; Kang \& Stulz, 1997; De Fond, Hu, Hung \& Li, 2011). Para Hendriksen e Van Breda (2007) as características qualitativas são propriedades da informação necessária para torná-la útil aos usuários. Corroborando, Lopes (2012) menciona que as características qualitativas são indispensáveis para que a informação contábil possua a utilidade desejada pelos usuários e que a ausência dessas características reduz a qualidade da informação contábil e isso pode comprometer o bom funcionamento do mercado de capitais.

Hendriksen e Van Breda (2007) apresentam por meio de uma ilustração como as características qualitativas propostas pelo conselho do FASB estão relacionadas. Por intermédio da Figura 1 é possível observar como as caracteristicas qualitativas estão associadas. 


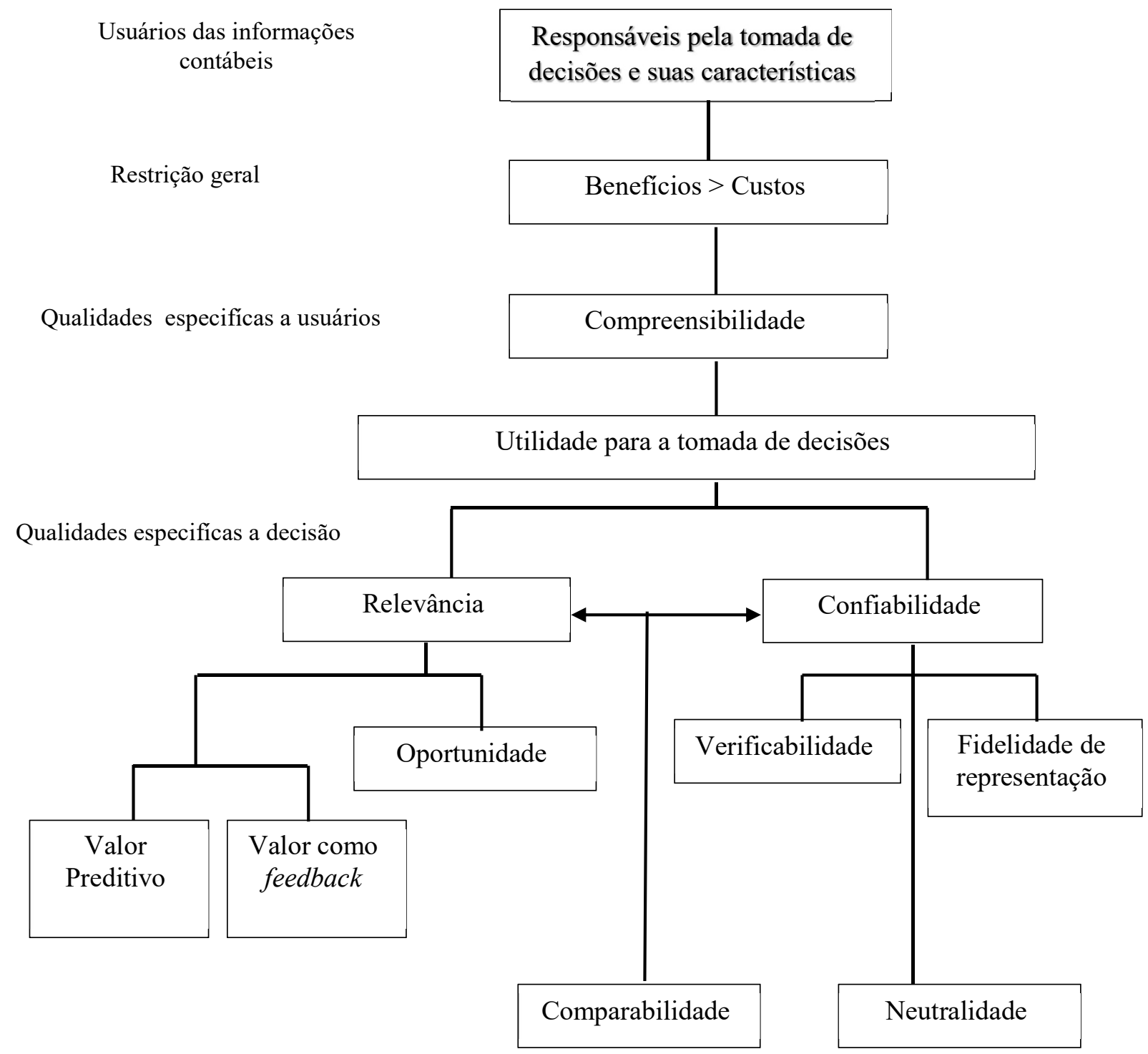

Figura 1 Relação entre as características qualitativas Fonte: adaptado de Hendriksen e Van Breda (2007).

Segundo o Pronunciamento Conceitual Básico (R1) - Estrutura Conceitual para Elaboração e Divulgação de Relatório Contábil-Financeiro elaborado a partir do The Conceptual Framework for Financial Reporting (BV2011), emitido pelo IASB:

Os usuários devem poder comparar as demonstrações contábeis de uma entidade ao longo do tempo, a fim de identificar tendências na sua posição patrimonial e financeira e no seu desempenho. Os usuários devem também ser capazes de comparar as demonstrações contábeis de diferentes entidades a fim de avaliar, em termos relativos, a sua posição patrimonial e financeira, o desempenho e as mutações na posição financeira (Comitê de Pronunciamentos Contábeis, 2011).

A estrutura conceitual do International Accounting Standards Board (IASB, 2010) cita a comparabilidade como uma das características qualitativas que possibilita à informação contábil atingir seu objetivo. Tal objetivo é oferecer aos investidores, financiadores e outros 
credores informações que possam ajudá-los em suas decisões de alocação de capital. Complementando, Barth (2013) menciona que como o capital é um recurso escasso, a comparabilidade é uma característica crucial relatando informação. De acordo com a mesma autora, se os investidores, financiadores e outros credores não podem fazer comparações com oportunidades de investimento alternativo, as suas decisões de alocação de capital serão abaixo do ideal.

No que tange ao conceito de comparabilidade, Barth (2014) define a comparabilidade dos demonstrativos financeiros como a característica qualitativa da informação contábil que possibilita aos usuários das demonstrações contábeis avaliarem semelhanças e diferenças entre os conjuntos de fenômenos econômicos.

Para Iudícibus (2015, p. 66), “a comparabilidade deve poder propiciar ao usuário o discernimento da evolução, no tempo, da entidade observada ou comparações entre entidades distintas, não devendo, entretanto, constituir entrave para a evolução qualitativa da informação".

O conceito de comparabilidade adotado por esta pesquisa é a dos órgãos reguladores da contabilidade o FASB e o IASB:

Comparabilidade é a característica qualitativa que permite aos usuários identificar e compreender as similaridades dos itens e as diferenças entre eles. Diferentemente de outras características qualitativas, a comparabilidade não está relacionada com um único item, a comparabilidade requer no mínimo dois itens (FASB, 2010; IASB, 2010).

De acordo com Choi, Frost e Meek (2001), as informações são comparáveis se elas forem similares o bastante de forma que os usuários das demonstrações contábeis possam comparálas (dentro de determinadas dimensões). Complementando, para De Franco, Kothari e Verdi (2011), a comparabilidade depende do evento econômico e de como as companhias traduzem tais eventos em números contábeis. Segundo os autores para que os usuários possam comparar o desempenho econômico e financeiro de uma empresa com outra ou da mesma empresa ao longo do tempo é necessário que as empresas estejam sujeitas ao mesmo evento econômico e às mesmas condições institucionais. Dessa forma, os resultados econômicos evidenciados por meio dos valores contábeis serão similares (comparáveis). 
Na visão de De Franco, Kothari e Verdi (2011), a comparabilidade reduz o custo de aquisição de informações e aumenta a quantidade total e a qualidade da informação disponível sobre a empresa, o que reduziria o custo de capital da empresa. Nessa perspectiva, o IASB estaria caminhando na direção correta ao criar padrões contábeis internacionalmente aceitos.

Apesar desta pesquisa tratar sobre a Comparabilidade dos demonstrativos financeiros cumpre ressaltar que existe diferença entre a comparabilidade e a uniformidade e muitas vezes se observa uma confusão em relação aos mesmos. Comparabilidade não pode ser confundida com a simples uniformização de procedimentos contábeis, ou seja, todas as empresas devem utilizar as mesmas regras e produzir os mesmos resultados. Barth (2013) menciona que a uniformidade exige tratamento igual para todas coisas, ou seja, estar em conformidade com uma regra onde todas as empresas devem adotar de forma homogênea. Como resultado, pode fazer com que coisas diferentes sejam divulgadas de forma igual, prejudicando assim a comparabilidade. Simmons (1967) destaca que a uniformidade é restritiva e presume uma ausência completa de variação na preparação e apresentação dos relatórios financeiros. Como exemplo, considere uma regra contábil onde todos os edifícios devem ser depreciados de forma linear com a utilização de uma vida útil de 30 anos e valor residual de 10\%. Assim, o método de depreciação para todos os edifícios seria igual, entretanto, e se a vida útil de alguns edifícios for de 20 anos e outros de 100 anos? E se alguns edifícios têm valor residual de $5 \%$ e outros de $20 \%$ ? E se alguns edifícios se deterioram mais rapidamente nos primeiros anos de utilização e outros mais perto do final de sua vida útil? A menos que todos os edifícios possuam vida útil de 30 anos, um valor residual de $10 \%$ e seus benefícios econômicos sejam consumidos em um padrão linear, ao utilizar o mesmo método de depreciação para todos os edifícios atinge-se a uniformidade, mas não a comparabilidade. A uniformidade faz com que todos os edifícios pareçam iguais, quando na verdade eles são diferentes (adaptado de Barth, 2013). Barth cita ainda que a principal razão para que a comparabilidade das informações financeiras seja crucial (assim como todas as características qualitativas) é porque auxilia no entendimento das informações evidenciadas. A estrutura conceitual esclarece que as decisões de compra, venda ou a manutenção de instrumentos de financeiros exigem a alocação de capital, nesse contexto, os demonstrativos financeiros devem ser elaborados para aqueles usuários que não tem a possibilidade de exigir a informação que necessitam ao tomar a decisão de alocação de capital. Assim ao elaborar demonstrativos contábeis que possibilitem aos usuários (investidores, credores e outros) comparar as informações entre duas empresas ou da mesma empresa ao longo 
do tempo é crucial para a melhoria da qualidade da informação, bem como possibilitar que a decisão envolva a liberdade de escolha entre alternativas.

\subsection{Formas de mensuração da comparabilidade}

Como formas de mensuração da comparabilidade, a primeira métrica foi elaborada por Van Der Tas em 1988 com base na similaridade das escolhas contábeis dos gestores para determinados eventos econômicos, sendo que uma derivação deste método são os índices de harmonização (Taplin, 2011). Contudo, com a internacionalização das normas contábeis e a adoção das mesmas por vários países novos modelos foram propostos por De Found, Hu, Hung e Li (2011) e De Franco, Kothari e Verdi (2011) utilizando-se de informações baseada em outputs dos demonstrativos contábeis.

\subsection{1 Índices de harmonização}

A primeira pesquisa sobre este método foi desenvolvida por Van Der Tas em 1988 com base na similaridade das escolhas contábeis. Esse método foi desenvolvido sob a premissa de que harmonização significa a ligação entre dois objetos. Neste contexto, se duas empresas adotarem políticas contábeis similares os resultados obtidos por meio dos demonstrativos contábeis serão comparáveis.

Observa-se que esse método de mensuração leva em consideração as escolhas contábeis, ou seja, as formas como as operações realizadas pela empresa são registradas (método baseado nos inputs).

Nesse método a identificação do nível de comparabilidade pode ser obtida por meio de índices que quantifiquem o grau de similaridade por parte das empresas na adoção das regras contábeis. Para esta pesquisa, o índice utilizado é o T Index desenvolvido a partir das pesquisas realizadas por Taplin (2004). Tal índice reflete a probabilidade de duas ou mais empresas selecionadas aleatoriamente possuírem demonstrações financeiras comparáveis. Para tanto, o índice assume o valor 0 (zero) quando os demonstrativos contábeis de todas as empresas não são comparáveis entre si, e 1 (um) quando todas os demonstrativos são plenamente comparáveis entre si. Este índice pode ser utilizado para análise da comparabilidade entre empresas situadas em um 
mesmo país National Index bem como para comparação de empresas situadas em países diferentes International Index. No contexto desta pesquisa será investigada a comparabilidade entre empresas situadas em um mesmo país. A fórmula geral para o índice $\mathrm{T}$ Index para empresas situadas em um mesmo país é apresentada pela equação a seguir:

$$
\text { T Index }=\sum_{k=1}^{m}(\mathcal{P} k)^{2}
$$

Onde:

$\mathrm{Pk}=$ é a proporção de empresas do país que utilizam o método contábil k;

$\mathrm{M}=$ é a quantidade de métodos contábeis analisados.

Fabiano (2012) menciona que a comparabilidade melhora quando os índices evidenciam que as escolhas das práticas contábeis convergem com um método. Por isso, quanto maior o número de empresas que utilizarem uma prática contábil, maior será a comparabilidade.

A grande limitação deste método de mensuração é que nem sempre a coerência na utilização das políticas contábeis leva a uma melhoria na contabilidade. Segundo Ribeiro (2014) nem sempre a consistência na utilização de políticas contábeis leva a uma maior comparabilidade. Para que a mesma se traduza em comparabilidade é necessário que os eventos econômicos subjacentes às companhias que utilizam as mesmas políticas contábeis sejam os mesmos, caso contrário, a consistência na aplicação das políticas contábeis irá diminuir a comparabilidade e não aumentá-la.

\subsubsection{Modelo de exposição ao mesmo padrão contábil}

Essa medida de comparabilidade foi desenvolvida por De Found, Hu, Hung e Li (2011) tomando como base os conceitos da uniformidade e comparabilidade. A uniformidade significa que as empresas aplicam o mesmo conjunto de normas contábeis, enquanto, a comparabilidade é uma caracteristica de relação entre dois ou mais elementos de informação.

O aumento da uniformidade a partir da adoção de um padrão contábil único entre as empresas de diferentes países, leva a uma melhor comparabilidade. Para os autores supracitados, os benefícios de uma melhor comparabilidade são estabelecidos no pressuposto de que as informações sobre uma empresa é mais útil quando as empresas pares do setor utilizam os mesmos padrões contábeis. 
A mensuração da uniformidade foi realizada por meio de um indicador representativo da proporção de empresas pertencentes ao mesmo setor de atividade econômica e sujeitas ao mesmo padrão contábil. Para ilustrar como esta medida de uniformidade se transforma em comparabilidade os autores apresentam um exemplo: anteriormente à adoção das normas internacionais de contabilidade existiam duas empresas do setor de petróleo na Finlândia as quais aplicavam o mesmo conjunto de padrões contábeis. Após a adoção das normas internacionais na Europa 82 empresas pares do mesmo setor passaram a utilizar o mesmo padrão contábil. Devido ao aumento do número de empresas pares no setor. passando de 2 para 82, a variação da uniformidade é mensurada para as companhias de petróleo na Finlância como 41, ou seja, o resultado de 82/2. Já na Inglaterra havia 19 empresas do setor petrolífero, após a adoção das normas internacionais o ganho de uniformidade entre as empresas de petróleo inglesas é de 4,32 (82/19). Com base nessa mensuração o aumento da uniformidade é menor na Inglaterra se comparada com a Finlândia após a adoção das normas internacionais, isto é, as empresas do setor petrolífero inglesas se beneficiaram menos da uniformidade.

Esse método apresenta como limitações que o pressuposto implícito na análise considera que os padrões contábeis anteriores não eram comparáveis entre os países e como foi utilizada por uma quantidade de companhias anteriores como denominador no indicador de uniformidade, pode levar a discrepância de valores maior do que a esperada (De Found, Hu, Hung \& Li, 2011; Ribeiro, 2014).

\subsubsection{Modelo de similaridade da função contábil}

O modelo para mensuração da comparabilidade com base na similaridade da função contábil foi elaborado por De Fanco, Kothari e Verdi (2011). Os autores construíram seu modelo de mensuração a partir da premissa de que os resultados apresentados pela contabilidade são um mapeamento dos eventos econômicos a que uma empresa está sujeita, ou seja, as transações econômicas das empresas são traduzidas em dados contábeis. Para tanto, os valores das demonstrações financeiras de uma empresa são uma função dos eventos econômicos, representados da seguinte forma: 
Onde $f_{i}(\quad$ ) representa o sistema contábil de uma empresa i .

Duas empresas possuem sistemas contábeis comparáveis se, para um mesmo evento econômico elas produzem outputs contábeis similares. Desta maneira, a comparabilidade é maior para empresas que atuam no mesmo setor e que utilizam método de capitalização de mercado semelhantes. Alford (1992) e De Fond, Hu, Hunge Li (2011) mencionam que empresas do mesmo setor são consideradas mais comparáveis, uma vez, que possuem características de funcionamento semelhantes e compartilham de práticas contábeis específicas do setor.

Para os autores supracitados, as demonstrações contábeis (método baseado em outputs) são comparáveis se para um mesmo evento econômico (por exemplo: o preço das ações) as empresas apresentem resultados contábeis similares. Por ser um método baseado nos valores contábeis o mesmo também captura as políticas contábeis adotadas pelas empresas.

Para operacionalizar o modelo são utilizadas duas proxys o lucro e o retorno de mercado das ações da empresa. O lucro ${ }^{1}$ é utilizado como uma proxy que representa o produto final do sistema contábil, e o retorno de mercado das ações é utilizado como uma proxy para representar o evento econômico.

Para obter a medida de comparabilidade, primeiro calcula-se as funções contábeis para cada empresa individualmente e, na sequência, trava-se o evento econômico de uma empresa e aproveitam-se as funções das outras empresas do mesmo setor. A proximidade das funções entre duas empresas representa a comparabilidade.

Este método apresenta como vantagem o fato de utilizar como fonte de dados as informações disponíveis por meio dos demonstrativos contábeis bem como o retorno da empresa, diferenciando-se dos demais métodos que se utilizam de informações qualitativas, tais como as escolhas contábeis.

Ribeiro (2014) menciona que uma possível limitação deste método é a utilização do lucro como proxy, uma vez que o lucro evidencia apenas uma parcela dos eventos econômicos e da aplicação das políticas contábeis, pois parte do resultado transita no balanço patrimonial por

\footnotetext{
${ }^{1}$ O lucro é derivado do termo em inglês earnings, cujo significado é o de resultado contábil, podendo desta forma ser positivo ou negativo.
} 
meio dos resultados abrangentes, não sendo, portanto, possível ao modelo de similaridade da função contábil capturar esse valor.

Assim, essa foi a medida utilizada neste estudo por possibilitar a mensuração da comparabilidade entre empresas do mesmo país, atendendo melhor aos objetivos propostos por esta pesquisa.

\subsubsection{Evidências Empíricas}

A importância da informação financeira comparável na economia global levou a um maior interesse no desenvolvimento de pesquisa sobre o tema.

Em 2001 Parker e Morris investigaram a escolha das políticas contábeis de 80 empresas situadas no Reino Unido e Austrália no ano de 1993, como resultados eles obtiveram um índice de comparabilidade nacional considerável (T Index $=1,00)$ em ambos os países.

Em 2008, Barth, Landsman, e Lang, em seu estudo que envolveu as empresas nãoestadunidenses, concluíram que o processo de convergência melhora a comparabilidade, mas não a ponto de concluir que este processo alcançará um nível ímpar de convergência; ou seja, ainda necessitará de algum tempo para que a harmonização material (das práticas contábeis) seja finalizada, se é que será finalizada em algum momento. Ainda neste estudo, verificou-se que as empresas que apresentam suas informações financeiras elaboradas a partir das normas internacionais apresentam melhor qualidade das informações contábeis do que quando elaboradas a partir de normas locais.

Bradshaw e Miller (2008) examinaram a associação entre a variabilidade do método contábil (como uma proxy para comparabilidade da informação) e a previsão dos analistas, para tanto utilizaram uma amostra de empresas americanas. Os resultados evidenciaram que a redução no nível de comparabilidade da informação está associada a um maior erro de previsão e dispersão.

Em 2011 Cairns, Massoudi, Taplin e Tarca investigaram o uso da mensuração a valor justo em 228 empresas do Reino Unido e Austrália, por meio do $T$ Index. Como resultados observaram um crescimento na utilização do valor justo em relação à mensuração dos instrumentos 
financeiros e pagamentos baseados em ações nas empresas de ambos os países. Quanto à comparabilidade Nacional (índice National Index), em relação às IFRS, o Reino Unido alcançou 0,917 e a Austrália 0,881.

Ainda em 2011 De Franco, Kothari e Verdi criaram uma nova medida para mensurar o nível de comparabilidade dos relatórios financeiros e testaram em uma amostra de empresas americanas. $\mathrm{O}$ estudo concluiu que a comparabilidade está positivamente associada à precisão das previsões, e, negativamente, com previsão de otimismo.

De Found, Hu, Hung e Li, (2011) examinaram os benefícios do aumento da uniformidade da contabilidade como uma proxy para a comparabilidade, usando dados de 14 países europeus. Como resultados constatou-se que o aumento na propriedade de fundos mútuos estrangeiros entre os países que adotaram de forma obrigatória as normas internacionais e em países com forte credibilidade na implementação.

Em 2013 Brochet, Jagolinzer, e Riedl investigaram se a adoção obrigatória das Normas Internacionais melhorou a comparabilidade das demonstrações financeiras das empresas do Reino Unido no período de 2003 a 2006. Os autores confirmaram a premissa de que após a adoção das normas internacionais ocorreram melhorias na comparabilidade das demonstrações financeiras.

No contexto nacional no ano de 2012, Fabiano investigou os níveis de comparabilidade nacional e internacional dos relatórios financeiros das empresas pertencentes aos países que fazem parte do BRIC no período de 2006 a 2010, sob a ótica das escolhas contábeis (para o reconhecimento dos estoques, imobilizado, ativos intangíveis, instrumentos financeiros e exploração e avaliação de recursos minerais) das empresas pertencentes ao setor de Petróleo e Gás, Siderurgia, Mineração e Energia, por meio do T Index. O estudo identificou uma queda do índice de comparabilidade internacional consolidado dos países do BRIC. Em relação ao índice nacional a China obteve grau de comparabilidade máximo em todos os itens avaliados, a Índia apresentou crescimento e o Brasil e a Rússia evidenciaram comportamento de queda no indicador.

Em 2013, Freri e Salotti analisaram a comparabilidade de empresas administradoras de Shoppings Centers do mercado brasileiro que possuíam propriedades para investimento no 
período de 2010 e 2011. Como resultados constatou-se que nenhuma das empresas atendem completamente aos requisitos de divulgação e que diversas informações são expressas em formatos diferentes, prejudicando a comparabilidade entre as mesmas.

Já em 2014, Reina, Reina, e Silva investigaram os níveis de comparabilidade dos relatórios financeiros das empresas que compõem o Índice Brasil IBRX 50 no período de 2010 a 2012 por meio do índice T Index. Como resultados observou-se índices médios para as políticas contábeis de registro de estoques, imobilizado, intangíveis e instrumentos financeiros.

No entanto, uma das grandes limitações das pesquisas realizadas por Fabiano (2012) e Reina, Reina e Silva (2014) encontra-se no raciocínio subjacente de que quanto maior a similaridade das escolhas contábeis entre duas empresas, maior será o nível de comparabilidade. Ao mensurar a comparabilidade apenas sob o aspecto da similaridade das escolhas contábeis não é possível inferir sobre o produto final da comparabilidade que são os demonstrativos contábeis, tendo em vista que não foi considerado o evento econômico no momento de avaliar a política contábil. Com isso, não é possível afirmar se a escolha contábil adotada foi ou não adequada. Para Ribeiro (2014), nem sempre a consistência na utilização de políticas contábeis leva a uma maior comparabilidade, para que a mesma se traduza em comparabilidade é necessário que os eventos econômicos subjacentes às companhias que utilizam as mesmas políticas contábeis sejam os mesmos, caso contrário, a consistência na aplicação das políticas contábeis irá diminuir a comparabilidade e não aumentá-la.

Em 2015, Petainbalue, Walker e Lee, investigaram os benefícios do aumento da comparabilidade transfronteiriça para a precisão na previsão dos lucros projetados pelos analistas após a recém adoção do IFRS na União Europeia. Para tanto, os autores construíram um indicador de pontuação dos benefícios esperados da comparabilidade, cujo objetivo é capturar o aumento do número de novos pares de empresas comparáveis entre os países da União Europeia. Os autores identificaram que as melhorias na precisão das previsões dos analistas estão positiva e significativamente relacionadas com o aumento na pontuação dos benefícios esperados da comparabilidade. Observou-se também que os benefícios da comparabilidade refletidos na precisão das previsões diferem de acordo com os princípios contábeis da empresa e de seus novos pares no período pré-adoção do IFRS. 


\subsection{Previsão dos analistas e a comparabilidade}

O Brasil passou a adotar as Normas Internacionais de Contabilidade, mais comumente conhecidas como International Financial Reporting Standards (IFRS), de forma parcial a partir de 2008, com a promulgação da Lei n. ${ }^{\text {o }} 11.638$, de 28 de dezembro de 2007 e integral a partir de 2010. A principal inovação trazida por esse processo de convergência às normas internacionais é que a prática contábil brasileira passa a estar muito mais amparada na interpretação dos pronunciamentos do Comitê de Pronunciamentos Contábeis (CPC) do que na mera aplicação de regras. Presume-se que isso traga implicações relevantes para a qualidade da informação contábil e para os profissionais que utilizam essa informação, tais como investidores e analistas do mercado financeiro (Antunes \& Mendonça, 2008; Martinez \& Dumer; 2013).

Os analistas se caracterizam como usuários externos das informações contábeis disponíveis, com o objetivo de calcular, analisar e projetar suas previsões de resultados futuros das empresas. Como resultado os analistas emitem suas recomendações de compra e venda dessas ações; fornecem outras informações para corretoras, gestores de fundos e investidores em geral. Essas informações posteriormente serão utilizadas por agentes do mercado para auxiliá-los no processo de tomada de decisão de investimento (Martinez, 2007; Pessotti \& Costa, 2013; Amato, Lima, Gatsio \& Assaf Neto; 2016).

De acordo com Iudícibus e Lopes (2008), esses profissionais possuem a atribuição de recomendar compra, venda e manutenção dos ativos baseados nas projeções realizadas para o desempenho futuro da empresa.

Para Martinez (2007), a postura dos analistas se resume em harmonizar o fluxo de informações disponíveis entre os agentes melhor informados e os investidores que possuem menor nível de informação. Essa harmonização consolida a expectativa do mercado com relação ao desempenho da companhia no futuro.

Ao examinar as projeções de resultados contábeis dos analistas, individualmente ou como parte de um consenso, várias abordagens podem ser utilizadas. Uma alternativa é identificar as propriedades estatísticas das projeções dos analistas, a acurácia (accuracy), o viés (bias) e a precisão (ou 'confiabilidade') das projeções são exemplos de pontos avaliados e testados para 
observar se os analistas estão desenvolvendo um bom e/ou eficiente trabalho. A precisão ou 'confiabilidade' de um estimador está inversamente relacionada com a variância (ou desviopadrão) - quanto menor a variância, maior será a precisão. O viés é um erro no estimador que faz com que o valor médio estimado de um parâmetro seja sistematicamente diferente do verdadeiro valor. O nível de acurácia é definido pela combinação da precisão e do viés. Em termos simples, pode-se afirmar que um estimador será mais acurado quanto menor for o seu viés e maior a sua precisão. A precisão perfeita (variância nula) não é condição suficiente de alta acurácia (Martinez, 2007; Dalmácio, 2009; Martinez \& Dumer, 2013).

As pesquisas sobre os analistas do mercado de capitais dividem-se em duas categorias: previsões e/ou recomendações individuais e consenso dos analistas. Na categoria de previsões de consenso dos analistas, estão inclusos trabalhos que buscam identificar as variáveis que influenciam na média ou mediana das previsões de lucros ou recomendações dos analistas (Martinez, 2004; Pessotti \& Costa, 2013). A Tabela 1 apresenta uma síntese das evidencias encontradas sobre as variáveis que afetam a acurácia nas previsões de consenso. 
Tabela 1 - Variáveis que afetam a acurácia das previsões de consenso dos analistas

\begin{tabular}{|c|c|}
\hline Variáveis & Evidências \\
\hline Idade da previsão & $\begin{array}{l}\text { Quanto maior a distância entre o número de dias da data da previsão pelo analista } \\
\text { e a data do resultado real, menor a acurácia }\end{array}$ \\
\hline $\begin{array}{l}\text { Comportamento enviesado } \\
\text { e otimista }\end{array}$ & A acurácia é maior quando o comportamento é otimista. \\
\hline $\begin{array}{lll}\begin{array}{l}\text { Resultado } \\
\text { prejuízo) }\end{array} & \text { (lucro ou }\end{array}$ & ácia é menor quando a empresa obtém prejuízo. \\
\hline Volatilidade dos resultados & $\begin{array}{l}\text { Quanto maior o desvio padrão dos resultados atuais (5 anos anteriores) } \\
\text { escalonado pelo preço da ação no início do ano fiscal, menor a acurácia. }\end{array}$ \\
\hline Cobertura dos analistas & $\begin{array}{l}\text { Quanto maior o número de analistas que acompanham uma empresa, maior a } \\
\text { acurácia. }\end{array}$ \\
\hline Dispersão das estimativas & $\begin{array}{l}\text { Quanto maior o desvio padrão das estimativas escalonado pelo preço da ação do } \\
\text { início do ano fiscal (medida de risco), menor a acurácia. }\end{array}$ \\
\hline $\begin{array}{l}\text { Tamanho da empresa } \\
\text { analisada }\end{array}$ & $\begin{array}{l}\text { Quanto maior o valor de mercado da empresa, medido numa unidade monetária } \\
\text { constante (log do valor de mercado), maior a acurácia. } \\
\text { Outra proxy para tamanho é o logaritmo natural do ativo total da empresa } \\
\text { calculado no período t, não existe um consenso em relação à sua influência sobre } \\
\text { a acurácia. }\end{array}$ \\
\hline $\begin{array}{l}\text { Valor de mercado/ valor } \\
\text { patrimonial }\end{array}$ & $\begin{array}{l}\text { Quanto maior a relação entre o valor de mercado e o valor patrimonial (price-to- } \\
\text { book), maior a acurácia. }\end{array}$ \\
\hline Particularidade de cada ano & $\begin{array}{l}\text { Circunstâncias econômicas e fatores políticos ocorridos em cada ano influenciam } \\
\text { as previsões dos analistas e, com isso, sua acurácia. }\end{array}$ \\
\hline Setor de atividade & Os analistas são mais acurados em alguns setores de atividades do que em outros. \\
\hline Governança corporativa & $\begin{array}{l}\text { A acurácia dos analistas é maior para empresas que adotam práticas diferenciadas } \\
\text { de governança corporativa. }\end{array}$ \\
\hline Qualidade do auditor & $\begin{array}{l}\text { A acurácia aumenta nas empresas auditadas pelas maiores empresas de auditoria } \\
\text { do mundo. }\end{array}$ \\
\hline Alavancagem & $\begin{array}{l}\text { Quanto maior a alavancagem da empresa, medida pela divisão entre o total de } \\
\text { dívidas e o total de ativos, menor a acurácia. }\end{array}$ \\
\hline
\end{tabular}

O consenso é a média ou mediana das previsões dos lucros para uma empresa num determinado período (trimestral, anual ou a longo prazo), conhecido como o street consensus. A análise de consenso fundamenta-se na ideia de que a representação das expectativas do mercado pode ser obtida por uma medida de tendência central da distribuição das projeções dos analistas (Martinez, 2009).

Os analistas de mercado utilizam as informações contábeis como ferramenta para elaborar as suas estimativas e justificar as suas opiniões, assim é esperado que a adoção do padrão International Financial Reporting Standards (IFRS) aumente a acurácia das suas previsões, uma vez que de acordo com (Barth, et al., 2008) a adoção do padrão internacional de contabilidade aumenta a qualidade do conteúdo informacional divulgado e a comparabilidade.

Assim, os analistas são particularmente sensíveis à comparabilidade das demonstrações financeiras por causa de sua dependência das informações contábeis para a realização de suas 
previsões, sendo, portanto, crucial para a avaliação do desempenho econômico e financeiro da empresa, bem como para os eventos econômicos subjacentes e para a previsão de ganhos futuros (Horton, Serafeim, \& Serafeim, 2013; Petaibanlue, Walker, \& Lee, 2015). Pesquisas empíricas evidenciam que os analistas utilizam consistentemente para sua avaliação dados que possam ser comparáveis do que uma avaliação realizada com base em fluxos de caixa descontado (Petaibanlue, Walker, \& Lee, 2015; Demirakos, Strong, \& Walker, 2004). A comparabilidade representa uma vantagem para os analistas financeiros, uma vez que aumenta a sua capacidade de prever os resultados das empresas, reduzindo o erro na previsão e dispersão dos lucros futuros (De Franco, Kothari, \& Verdi, 2011).

$\mathrm{Na}$ literatura internacional, existem diversos trabalhos que relacionam as normas contábeis com a acurácia dos analistas. Alguns deles, como o de Acker, Horton e Tonks (2002), fizeram uma comparação da acurácia antes e após a adoção de determinadas normas; enquanto outros, como o de Ashbaugh e Pincus (2001) e de Bae, Tan e Welker (2008), utilizaram métricas que quantificaram as diferenças entre o GAAP de cada país para estabelecer uma relação entre elas e a acurácia dos analistas. Estes trabalhos mostraram que há relação entre as normas contábeis e acurácia, sendo ela maior quando da adoção das IFRS.

A relação entre a acurácia dos analistas e as normas contábeis ocorre porque, segundo Ashbaugh e Pincus (2001) e Bae, Tan e Welker (2008), as demonstrações financeiras em IFRS tendem a ser mais informativas do que as publicadas em outros padrões contábeis, contribuindo para que os analistas sejam mais acurados na elaboração de suas projeções.

Dentre os trabalhos que tratam da relação entre os padrões de contabilidade e a acurácia dos analistas, Ashbaugh e Pincus (2001) investigaram se as diferenças entre os padrões de contabilidade adotados em cada país e os padrões internacionais de contabilidade causam impacto na acurácia dos analistas de empresas não americanas e se a acurácia dos analistas aumenta após a adoção das IFRS. Os autores observaram que os padrões de contabilidade de cada país estão positivamente correlacionados com o valor absoluto dos erros de previsão dos analistas, e que a acurácia aumenta após a adoção das IFRS pelas empresas.

Acker, Horton e Tonks (2002) avaliaram o impacto da norma FRS3, do Reino Unido, sobre a acurácia das previsões do LPA pelos analistas. A norma exige que as companhias publiquem um conjunto mais amplo de informações financeiras para auxiliar os usuários a avaliarem o 
desempenho atual e formarem uma opinião sobre o desempenho futuro das companhias. Concluíram que houve aumento no erro de previsão dos analistas no primeiro ano de adoção da norma, mas o erro inicial diminuiu depois de dois anos da adoção.

Black e Carnes (2006) examinaram a relação entre o viés e a acurácia das previsões dos analistas com fatores que refletiam a competitividade econômica e os sistemas contábeis de 13 países asiáticos. Dentre suas conclusões, observaram: (i) as previsões dos analistas apresentaram viés pessimista para a maioria das nações pesquisadas, e este pessimismo vinha aumentando; e (ii) as previsões dos analistas para as nações que possuíam sistemas contábeis mais reservados apresentavam viés pessimista significativamente maior do que nas de outros países.

Bae, Tan e Welker (2008) investigaram a relação entre os GAAPs de 49 países e a cobertura e acurácia dos analistas, para testar a hipótese de que os diferentes padrões de contabilidade de cada país geram custos para analistas estrangeiros, dissuadindo-os a não cobrir empresas que divulgam suas informações em um padrão diferente daquele adotado pelo país em que residem. Os autores identificaram que: (i) uma relação negativa entre as pontuações do GAAP de cada país e a acurácia dos analistas e; (ii) uma relação negativa ainda maior em relação à cobertura dos analistas estrangeiros. Tais resultados evidenciam que uma maior diferença entre os padrões de contabilidade de diferentes países levou a uma queda na cobertura e na acurácia dos analistas estrangeiros.

Ernstbergerger e Krotter (2008), analisaram o impacto da adoção de diferentes padrões contábeis na Alemanha sobre a acurácia dos analistas. Como resultados observou-se que a acurácia dos analistas é maior quando eles fazem suas estimativas a partir de relatórios em USGAAP ou IFRS do que a partir de relatórios no padrão contábil Alemão. Observaram ainda, que a acurácia é menor no ano de adoção do US-GAAP do que nos anos seguintes.

Tendo em vista que algumas pesquisas apresentam evidencias empiricas de que as IFRS proporcionam melhorias na precisão das previsões, Horton, Serafeim, \& Serafeim (2013), investigaram se o aumento na precisão das previsões pode ser atribuído à melhoria das informações e/ou maior comparabilidade, ou simplesmente com as IFRS os gerentes tem maiores oportunidades para manipulação das informação, atendendo assim às previsões dos analistas.Como resultados encontram evidências consistentes de que a melhoria no ambiente de informação pode ser atribuída tanto à informação de qualidade superior quanto a uma melhor 
comparabilidade das informações contábeis. A precisão nas previsões melhora mais para os analistas que realizam previsões de empresas que se beneficiam dos benefícios da comparabilidade, além disso não encontram evidências de aumento na precisão das previsões impulsionado por manipulação nos resultados contábeis.

Jiao, Koning, Meterns, \& Roosenboom (2012) investigaram o impacto da adoção do IFRS sobre a qualidade dos lucros que se reflete nas características de previsões dos analistas. Constataram que as previsões dos analistas se tornaram mais precisas e menos dispersas após a adoção das IFRS, estes efeitos persistem após o controle de fatores como o tamanho da empresa, número de analistas, a volatilidade do desempenho, país e setor. Os autores mencionam que embora os efeitos adoção do IFRS foi investigada de forma indireta, é razoável atribuir a melhoria da qualidade de previsões dos analistas para a melhoria na qualidade das informações contábeis após a adoção obrigatória de IFRS em países europeus, por ser a única diferença sistemática entre os dois períodos de tempo em nosso estudo.

No contexto nacional Pessotti e Costa (2013) investigou o impacto da convergência às normas internacionais de contabilidade sobre a acurácia dos analistas do mercado de capitais brasileiro, controlando as empresas que, antes da adoção às normas, publicavam suas demonstrações financeiras exclusivamente no padrão BR-GAAP e aquelas que eram incentidas a divulgar suas informações contábeis em US-GAAP. Constatando indicios de relação entre a acurácia das previsões dos analistas de mercado e a adoção das normas internacionais, observou-se também que não houve mudanças estatisticamente significante na acurácia quando as empresas que publicavam suas demonstrações financeiras no padrão US-GAAP também adotaram as IFRS, possibilitando inferir que os dois padrões contábeis são informativos.

Já Martinez e Dumer (2013) realizou uma pesquisa com o objetivo de identificar as características gerais das projeções de lucros dos analistas de empresas brasileiras, apreciando dois pontos especificos: i) o viés; e ii) a acurácia. Os resultados apresentam indicam que a acurácia dos analistas melhora com um aumento na cobertura e nas empresas lucrativas, e que a adoção das IFRS não podeser vista panaceia para os males da contabilidade e ineficiências do mercado de capitais. A complexidade dos ajustes às novas normas contábeis e o lento processo de consolidação de conversão das demonstrações contábeis podem explicar parcialmente os resultados. 
Gatsios (2013) analisou o impacto da convergência às normas IFRS sobre a qualidade preditiva da informação contábil no Brasil. Como resultados constatou-se que a adoção às IFRS ainda não contribuiu para a melhora da qualidade preditiva da informação contábil, embora o viés de previsão tenha diminuido. A acurácia dos analistas diminuiu no período de adoção parcial e no período de adoção obrigatória, não permitindo assim concluir que houve uma melhora na acurácia dos analistas. A dispersão das estimativas aumentou no período de adoção parcial, e no período de adoção obrigatória não houve auteração no nível da mesma. $\mathrm{O}$ autor menciona que a explicação para tais resultados podem ser: (i) ao método de adoção do IFRS no Brasil que incluiu um período de adoção parcial - diferentemente de outros países; e (ii) à necessidade de um tempo de aprendizado para as empresas e analistas de mercado, haja vista as alterações ainda serem recentes.

Em 2016 Amato, Lima, Gatsios e Assaf Neto (2016), verificaram o impacto da adoção do padrão IFRS sobre a acurácia das estimativas de lucro projetadas pelos analista de mercado para as empresas financeiras brasileiras. Os resultados do trabalho indicam que a adoção do padrão IFRS no Brasil ainda não contribuiu para melhora da qualidade preditiva da informação contábil. A acurácia dos analistas de mercado diminuiu no período de adoção parcial do IFRS no Brasil e, no período de adoção obrigatória, as evidências encontradas não permitem concluir sobre a melhora da acurácia dos analistas. As explicações para os resultados obtidos podem estar relacionadas (i) ao método de adoção do IFRS no Brasil - que incluiu um período de adoção parcial - diferentemente de outros países; e (ii) à necessidade de um tempo de aprendizado para as empresas e analistas de mercado, haja vista as alterações ainda serem recentes.

As evidencias encontradas a partir das pesquisas sobre o impacto do IFRS na comparabilidade dos relatórios contábeis variam em termos de ambiente de pesquisa bem como em metodologias utilizadas. Grande parte das pesquisas realizadas no contexto internacional utilizam como amostras países que compõem a União Europeia por serem os primeiros países a adotar as normas IFRS a partir de 31/12/2005. Em geral tanto as pesquisas realizadas no contexto internacional quanto no nacional são conflitantes sobre a efetiva melhoria da adoção das normas IFRS sobre a acurácia na avaliação dos analistas de mercado, necessitando, portanto, de continuidade nessas investigações para que se possa chegar a um consenso convincente sobre melhoria da adoção aos padrões IFRS sobre a comparabilidade das demonstrações financeiras. 
Assim, espera-se com esta pesquisa contribuir para a literatura sobre a avaliação da melhoria da comparabilidade no Brasil após a adoção das normas IFRS, por avaliar se adoção às IFRS trouxe benefícios e se estes benefícios representam vantagens informacional para os usuários da informação contábil bem como redutor da assimetria informacional.

\subsection{Informatividade}

As demonstrações financeiras de uma empresa são consideradas condutoras de conteúdo informacional se acarretar mudanças em relação à expectativa do investidor ao avaliar os retornos futuros e consequentemente, variação no preço das ações. $\mathrm{O}$ tema relevância da informação contábil vem sendo estudado ao longo dos anos por intermédio de um vasto conjunto de evidências. Segundo Barth, Beaver e Landsman (2001) a primeira pesquisa a utilizar o termo relevância da informação contábil ao investigar a associação entre as reações do mercado frente às informações contábeis é de Amir, Harris e Venuti (1992). Entretanto, o tema é mais antigo e as pesquisas seminais que buscam analisar a relação entre as variáveis contábeis e de mercado foram realizadas por Ball e Brow (1968) e Beaver (1968), por meio da aplicação do método de estudo de eventos. O método de estudo de eventos compreende a análise do efeito de um conjunto de informações sobre uma empresa específica ou um conjunto de empresas e sua influência sobre os preços das ações, essas pesquisas deram origem à teoria positiva da contabilidade. Segundo Lopes e Iudicibus (2012), a teoria positiva busca explicar e predizer determinados fenômenos com base no que acontece na realidade. Essas pesquisas foram realizadas sob o enfoque da Hipótese de Mercado Eficiente (EMH). Segundo Lopes e Iudicibus (2012, p. 74),

A Hipótese de Mercado Eficiente (EMH) é utilizada em pesquisas empíricas com o objetivo de identificar e medir o impacto da informação contábil na formação do preço dos ativos financeiros no mercado, pois auxilia na explicação dos efeitos das informações relevantes sobre os preços dos títulos. Ressalta-se que as informações relevantes são todas aquelas que possam ter algum impacto nos preços dos títulos, dentre elas as informações contábeis.

Nas pesquisas sobre o conteúdo informativo das informações contábeis, a Hipótese do Mercado

Eficiente é um dos conceitos mais importantes. De uma forma simplificada, a EMH sugere preços de mercado em equilíbrio como se todos os agentes do mercado tivessem as mesmas informações, a mesma aversão ao risco e capacidade de interpretação e precificação da informação (Lopes \& Iudicibus, 2012, p. 75). 
Dentre os graus de eficiência de mercado, a hipótese do mercado eficiente na forma semiforte é significativa pois as informações geradas pela contabilidade devem estar refletidas nos preços das ações (Sarlo Neto, 2009; Lopes, 2012). Assim, pressupondo que o mercado é eficiente na forma semiforte, as informações contábeis publicamente disponíveis refletiriam nos preços das ações (Fama, 1970). Nesse contexto, uma forte relação entre a Contabilidade e o mercado, sugere que a alteração em uma variável contábil produzirá variação nos preços das ações (Sarlo Neto, 2009; Lopes, 2012; Silva, Sarlo Neto, Reina, \& Formentini, 2015). Nesta perspectiva, este trabalho considera o pressuposto da hipótese do mercado eficiente na forma semiforte.

Os estudos realizados por Ball e Brow (1968) e Beaver (1968), partem da hipótese de que, se os números contábeis divulgados abrangessem informações ainda não conhecidas pelo mercado, os preços das ações poderiam se ajustar devido às alterações nas expectativas futuras no fluxo de caixa das empresas geradas por meio da divulgação de novas informações.

A partir dessa perspectiva, diversas pesquisas foram desenvolvidas buscando identificar a influência/relevância das informações contábeis como parâmetro para as decisões de seus usuários, desse modo, a contabilidade passou a ter uma perspectiva informacional (Watts \& Zimmerman, 1990; Sarlo Neto, Losss, Nossa \& Teixeira, 2003; Silva, Sarlo Neto, Reina \& Formentini, 2015).Assim constata-se que tais pesquisas buscam identificar de que forma e em qual dimensão as informações contábeis são uteis para a tomada de decisão dos investidores (Dantas, Medeiros, \& Lustosa, 2006).

Segundo Dantas, Medeiros e Lustosa (2006, p.73):

A premissa é que, nas decisões tomadas com o objetivo de maximizar a riqueza, os investidores consideram o impacto de variáveis macroeconômicas e de variáveis específicas na empresa. Como a contabilidade tem por missão identificar e mensurar essas variáveis específicas, espera-se que as informações contábeis divulgadas sejam consideradas pelo investidor.

Segundo Sarlo Neto (2009) na prática o termo conteúdo informativo ou capacidade informacional amplamente utilizados nas pesquisas que analisam a relação entre as variáveis contábeis e de mercado é substituído pelo termo informatividade. Nesse contexto, a informatividade é identificada como a relação entre a informação contábil e os preços das ações, sendo, usualmente, representada pela associação entre o retorno dos preços das ações e o lucro contábil. Assim, quanto maior a relação entre o retorno das ações e o lucro contábil, maior será a informatividade do lucro divulgado pela contabilidade. 
A maioria das pesquisas realizadas sobre informatividade tem o lucro, como a variável contábil examinada. Isso ocorre, porque o lucro líquido é uma informação contábil relevante para os investidores utilizarem no processo de tomada de decisão de investimento no mercado de capitais. Com isso, diversas informações apresentadas nos demonstrativos contábeis podem ser utilizadas e influenciar a decisão dos investidores (Ball \& Brown, 1968).

A partir do modelo consagrado por Easton e Harris (1991), aplicado por pesquisadores tais como: Francis e Schipper (1999), Bushman et al. (2004), Sarlo Neto (2009), e Silva, Sarlo Neto, Costa Junior e Reina (2016). A relação entre o lucro contábil e o retorno das ações é representada por uma equação em que o retorno das ações (variação dos preços em um determinado período) é definido como uma variável explicada/dependente do lucro contábil, assim é possível identificar o poder de explicação da informação contábil sobre a variação dos preços das ações. A partir desta definição, os autores mencionam que a relação entre o retorno das ações e o lucro contábil assume a seguinte especificação:

$$
R_{i t}=\alpha_{0}+\alpha_{1} \cdot L C_{i t}+\varepsilon
$$

onde:

$\mathrm{R}_{\mathrm{it}}=$ Retorno da ação da empresa i no período t;

$\mathrm{LC}_{\mathrm{it}}=$ Lucro contábil da empresa i no período t;

$\alpha_{0}=$ Intercepto;

$\alpha_{1}=$ Coeficiente angular entre o lucro contábil e o retorno; $\varepsilon=$ Erro.

Interpretando a equação 2, o intercepto compreende todas as outras informações que não são contempladas pelo lucro contábil, o coeficiente de variação entre o retorno e o lucro representa a parcela do lucro contábil que explica o retorno das ações, e a informatividade é a intensidade da relação entre o lucro contábil e o retorno das ações mensuradas pelo coeficiente angular da reta estimada entre essas duas variáveis (Sarlo Neto, 2009).

No Brasil, estudos seminais sobre capacidade informacional (informatividade) evidenciaram que o preço das ações reage à divulgação das informações contábeis.

Schiehll (1996) verificou o efeito da divulgação das demonstrações contábeis no mercado de capitais brasileiro, com ênfase na variação nos preços das ações. Como resultados, a divulgação 
das informações contábeis produz efeitos significativos sobre o comportamento dos preços das ações e o mercado de capitais brasileiro reage de forma semiforte.

Em 2001, Bernardo investigou a maneira pela qual os investidores que atuam o mercado de capitais brasileiro reagem às divulgações trimestrais de resultado através da observação do comportamento dos retornos das ações em torno das datas de publicação. Contatou-se que o investidor que atua no mercado brasileiro de capitais considera o resultado negativo (prejuízo) como informação de caráter desfavorável, independente da série histórica anterior. Também foi constatado que o ajuste de preços das ações ao redor da data da divulgação dos resultados contábeis trimestrais é consistente com a forma semiforte de eficiência de mercado em relação a tal informação.

Similarmente, Lima e Terra (2004), investiga por meio de um estudo de eventos, se o conteúdo informacional das demonstrações financeiras, trimestrais e anuais, é capaz de influenciar o processo de precificação das ações. Os resultados indicam que os retornos anormais das ações no dia da divulgação dos seus demonstrativos financeiros são estatisticamente insignificantes para a amostra total. Desta forma, estes resultados corroboram a hipótese de eficiência do mercado brasileiro de capitais na forma semiforte. Foi possível perceber que os retornos anormais significativos referentes ao resultado do exercício, indicando que a natureza da informação divulgada é relevante para o mercado confirmar ou não as suas expectativas.

Martinez (2001) busca demonstrar empiricamente que as companhias abertas brasileiras gerenciam seus resultados contábeis como resposta a estímulos do mercado de capitais. Os resultados demonstram que as empresas com resultados muito ruins os manejam de maneira a piorá-los ainda mais, visando melhores resultados no futuro. Constatou-se que empresas que manejam "artificialmente" os resultados conseguem no curto prazo seduzir os investidores, no entanto, no longo prazo, o mercado identifica os procedimentos e essas ações são penalizadas com os piores desempenhos acumulados.

Com base nas peculiaridades do mercado acionário brasileiro que possui características que o distingue dos países mais desenvolvidos, dentre essas: a volatilidade do mercado, a presença marcante do Estado, a excessiva regulamentação da Contabilidade, o mercado acionário concentrado e a fraca proteção aos acionistas (Lopes, 2001). 
Novas pesquisas são desenvolvidas como: Sarlo Neto (2004) que investigou o impacto da divulgação dos resultados contábeis sobre os preços das ações, com abordagem nas classes de ações, na regulamentação específica e no tipo de controlador, com base na metodologia proposta por Ball e Brown (1968). Os resultados confirmaram a relevância da divulgação dos resultados contábeis como fonte de informação para os investidores no mercado de capitais brasileiro.

Aprofundando a pesquisa anterior em 2009 Sarlo Neto averiguou a influência da estrutura de propriedade (a concentração dos votos e a divergência entre os direitos das ações) sobre a informatividade dos lucros contábeis divulgados pelas empresas negociadas no mercado de capitais brasileiro. Os resultados, indicaram que a concentração de votos tem influência positiva e a divergência de direitos das ações uma influência negativa sobre a informatividade dos lucros contábeis. Adicionalmente constatou que o lucro contábil é mais relevante do que o dividendo para explicar os retornos das ações.

Sarlo Neto, Galdi e Dalmácio (2009) afirmam que vários estudos constataram que a divulgação dos lucros contábeis afeta os preços das ações, no entanto os achados não seguem uma correlação perfeita. Deste modo, tornam-se necessárias novas pesquisas que explorem a referida relação. Para Brugni, Sarlo Neto, Bastianello e Paris (2012) a interação entre o lucro e outras informações contábeis podem melhorar a capacidade informacional.

Com base nas pesquisas realizadas sobre a informatividade dos lucros, a Tabela 2 apresenta uma síntese das evidencias encontradas sobre as variáveis que afetam a informatividade. 
Tabela 2 - Variáveis que afetam a informatividade

\begin{tabular}{|c|c|}
\hline Variáveis & Evidências \\
\hline $\begin{array}{l}\begin{array}{l}\text { Resultado } \\
\text { prejuízo) }\end{array} \quad \text { lucro ou } \\
\end{array}$ & $\begin{array}{l}\text { Prejuízos possuem menos conteúdo informativo (Almeida, Sarlo Neto, Gomes, } \\
\& \text { Novaes, 2014). }\end{array}$ \\
\hline $\begin{array}{lll}\text { Tamanho } & \text { da } & \text { empresa } \\
\text { analisada } & & \\
\end{array}$ & $\begin{array}{l}\text {. tamanho da empresa está diretamente associado à informatividade dos lucros } \\
\text { contábeis (Atiase, 1985; Freeman, 1987; Collins \& Kothari, 1989). Na América } \\
\text { Latina, Sarlo Neto, Bassi e Almeida (2011) identificaram apenas a relação } \\
\text { negativa em relação ao tamanho da empresa. }\end{array}$ \\
\hline Market-to-Book & $\begin{array}{l}\text { Proxy para avaliação de oportunidade de investimentos, que constitui um relação } \\
\text { positiva com a informatividade, sendo que quanto maior o Market-to-book, maior } \\
\text { a informatividade dos lucros contábeis (Collins; \& Kothari, 1989; Sarlo Neto, } \\
\text { Bassi, \& Almeida, 2011). Na América Latina, Sarlo Neto, Bassi e Almeida (2011) } \\
\text { identificaram relação positiva do índice de Market-to-book }\end{array}$ \\
\hline Setor de atividade & $\begin{array}{l}\text { Tem por finalidade eliminar qualquer evento macroeconômico que possa } \\
\text { influênciar a relação entre o retorno das ações e as informações contábeis que } \\
\text { compõem a amostra (Sarlo Neto, 2009). }\end{array}$ \\
\hline END & $\begin{array}{l}\text { considerando que o endividamento é uma proxy do risco de inadimplência, então } \\
\text { as empresas altamente alavancadas estão associadas à alto risco. As empresas } \\
\text { mais alavancadas (mais endividadas) apresentaram uma menor intensidade na } \\
\text { relação entre lucro contábil e retorno do que as empresas menos alavancadas Na } \\
\text { América Latina, Sarlo Neto, Bassi e Almeida (2011) em relação ao } \\
\text { endividamento não foi observada associação. }\end{array}$ \\
\hline
\end{tabular}

Fonte: Atiase, 1985; Freeman, 1987; Collins; e Kothari (1989); Sarlo Neto (2009); Sarlo Neto, Bassi e Almeida (2011); Almeida, Sarlo Neto, Gomes e Novaes (2014).

Apesar de a maioria dos estudos que relacionam a informação contábil e o preço das ações utilizarem o lucro como proxy para analisar essa relação. Outras variáveis contábeis também podem contribuir para explicar os preços das ações (Lopes, 2012). Nesse contexto encontra-se a pesquisa realizada por Dantas, Lustosa e Medeiros (2005) cujo estudo segue a mesma lógica das pesquisas lucro-retorno, no entanto, a medida de resultado contábil foi substituída pela de alavancagem operacional. Como resultado observou que a variável alavancagem operacional é estatisticamente relevante para explicar o comportamento do retorno das ações e que essa relação é positiva.

No que tange à comparabilidade, Durnev, Morck, Yeung, e Zarowin (2003) concluíram que a comparabilidade ajuda os investidores a compreenderem informações específica da empresa e sugerem que a comparabilidade é útil aos investidores quando eles avaliam investimentos alternativos. Além disso, eles também destacam o papel da comparabilidade em melhorar a eficiência da alocação de capital em função de que quanto mais informados são os preços, estes devem levar a uma alocação mais eficiente de riqueza.

Haw, Hu, Lee, e Wu (2012) mencionam que a comparabilidade pode influenciar na informatividade do preço das ações por expandir as informações disponíveis aos investidores.A partir de informações comparáveis, os investidores podem identificar as semelhanças e 
diferenças entre as empresas de um mesmo setor e, assim, fazer comparações mais significativas, ao possibilitar aos investidores extrair informações específicas de cada empresa. Como resultado, os preços das ações devem refletir mais informações para as empresas com maior comparabilidade, assim, a comparabilidade melhora a informatividade dos preços das ações e permite aos investidores antecipar melhor o desempenho futuro da empresa. Tais pressupostos partem da ideia de que os preços atuais das ações refletem as expectativas do mercado sobre o desempenho futuro da empresa e os preços das ações são mais informativos quando melhor for a capacidade de antecipar os lucros futuros, ou seja, a capacidade de retorno do período atual reflete os ganhos futuros (Collins \& Kothari, 1989; Haw, Hu, Lee, \& Wu, 2012). Pesquisas que investigam, a informatividade dos preços das ações sobre os retornos futuros revela até que ponto as informações de valor relevante (sobre as perspectivas de uma empresa) estão disponíveis para os investidores e está incorporada nos preços das ações. Sob este enfoque, esta pesquisa busca contribuir para a literatura sobre capacidade informacional, relevância e qualidade das informações contábeis ao investigara relação entre a comparabilidade (utilizando a medida de De Franco et al., 2011) e a informatividade do preço das ações, até então pouco explorada pelas pesquisas já realizadas. 


\section{METODOLOGIA}

\subsection{Enquadramento Metodológico}

Define-se esta pesquisa como sendo de natureza descritiva por investigar a influência da comparabilidade dos demonstrativos financeiros sobre a acurácia e previsão dos analistas de investimento do mercado brasileiro (Gil, 2010).

Em relação à coleta dos dados, esta pesquisa utiliza-se de dados secundários (Richardson, 2008). Os dados secundários foram coletados a partir do Banco de Dados do Sistema Thomson Reuters Eikon ${ }^{\circledR}$, Economática ${ }^{\circledR}, \mathrm{e}$, Comdinheiro ${ }^{\circledR}$.

No que tange à abordagem do problema, a presente pesquisa caracteriza-se como quantitativa (Richardson, 2008) e, para mensurar a comparabilidade, será utilizada como métrica o modelo desenvolvido por De Franco, Kothari e Verdi (2011). Para tanto serão utilizadas informações sobre o lucro e o retorno de mercado das ações da empresa, projetados e realizados. Para calcular o retorno foram utilizadas, preferencialmente, as ações ordinárias das empresas e na falta destas as ações preferenciais. O código das ações utilizadas em cada empresa encontra-se na Figura 2. Por fim, para testar o comportamento das variáveis será utilizada a abordagem estatística de dados em painel.

\subsection{Empresas analisadas e Coleta dos Dados}

A população desta pesquisa é composta por empresas brasileiras com ações listadas na Bolsa de Valores de São Paulo (BM\&FBOVESPA). A amostra do estudo foi selecionada de forma intencional (Martins \& Theóphilo, 2009), e as empresas foram classificadas por seus respectivos setores de atividades econômicas. Tal classificação por setor foi realizada utilizando-se a classificação do North American Classification System - NAICS nível 2. O NAICS consiste em uma classificação de padrão internacional de todas as atividades econômicas, publicadas pelas nações unidas e, utilizada para facilitar a mensuração das atividades econômicas globais. 
$\mathrm{Na}$ literatura, observa-se que esta metodologia também foi utilizada em pesquisas que analisaram a comparabilidade entre os setores econômicos (De Franco, Kothari \& Verdi, 2011; Ribeiro, 2014; Yip \& Young, 2012). Foram selecionados para esta pesquisa os setores econômicos que apresentaram os dados trimestrais disponíveis no período de 2005 a 2015 para mais de duas empresas (conforme apresentado na Figura 2), exceto as empresas do setor financeiro que foram excluidas da amostra, por não arquivarem seus demonstrativos em conformidade com o padrão IFRS. tendo em vista que para analisar a comparabilidade foi necessário realizar a comparação par a par (Marconi \& Lakatos, 2015). . Ao todo foram objeto de análise 37 empresas classificadas em dez setores: eletricidade, gás e água; siderurgia e industria básica de outros metais; industria de produtos de metal; telecomunicações; industria de equipamentos de transporte; industria quimica; papel e celulose; calçados; tecidos e vestuários; e, lojas de mercadorias em geral.

A adoção das normas internacionais de contabilidade no Brasil provenientes das Leis n. ${ }^{\circ}$ 11.638/2007 e n. ${ }^{\circ} 11.941 / 2009$, que alteraram os dispositivos da Lei n. ${ }^{o}$ 6.404/1976, as empresas brasileiras passaram a adotar as normas internacionais de forma obrigatória a partir do encerramento do exercício de 2010. No entanto, a partir do encerramento do ano de 2008 as empresas poderiam adotar as normas de forma facultativa. Nesse contexto, o período investigado nesta pesquisa compreende os anos de 2005 a 2015 possibilitando, assim a analise de informações anteriores a adoção dos IFRS (dados de 2005 a 2007); durante o período de transição (2008 e 2009); e no período de adoção obrigatória (2010 a 2015). 


\begin{tabular}{|c|c|c|c|}
\hline Nr. & Setor & Ação & Nome da Empresa \\
\hline 1 & Eletricidade, gás e água & CESP3 & CESP Companhia Energética de São Paulo \\
\hline 2 & Eletricidade, gás e água & ELET3 & Centrais Elétricas Brasileiras SA - Eletrobrás \\
\hline 3 & Eletricidade, gás e água & CLSC4 & Centrais Elétricas de Santa Catarina SA Celesc \\
\hline 4 & Eletricidade, gás e água & CMIG3 & Companhia Energética de Minas Gerais Cemig \\
\hline 5 & Eletricidade, gás e água & COCE5 & Companhia Energética do Ceará - COELCE \\
\hline 6 & Eletricidade, gás e água & CPLE3 & Companhia Paranaense de Energia - COPEL \\
\hline 7 & Eletricidade, gás e água & CPFE3 & CPFL Energia as \\
\hline 8 & Eletricidade, gás e água & TRPL4 & $\begin{array}{l}\text { CTEEP Companhia de Transm. de Energia Elétrica Paulista } \\
\text { - TRANSPAULIST }\end{array}$ \\
\hline 9 & Eletricidade, gás e água & ELPL4 & Eletropaulo Metropolitana Eletricidade de São Paulo as \\
\hline 10 & Eletricidade, gás e água & EGIE3 & Engie Brasil Energia SA - Tractebel (EGIE3) \\
\hline 11 & Eletricidade, gás e água & LIGT3 & Light as \\
\hline 12 & Eletricidade, gás e água & SBSP3 & $\begin{array}{l}\text { Companhia de Sanea. Básico do Estado de São Paulo - } \\
\text { SABESP }\end{array}$ \\
\hline 13 & Eletricidade, gás e água & SAPR4 & Companhia de Saneamento do Paraná Sanepar \\
\hline 14 & Eletricidade, gás e água & CGAS5 & Companhia de Gás de São Paulo Comgas \\
\hline 15 & $\begin{array}{l}\text { Siderurgia e indústria básica de outros } \\
\text { metais }\end{array}$ & FESA4 & Companhia de Ferro Ligas da Bahia FERBASA \\
\hline 16 & $\begin{array}{l}\text { Siderurgia e indústria básica de outros } \\
\text { metais }\end{array}$ & GGBR4 & Gerdau as \\
\hline 17 & $\begin{array}{l}\text { Siderurgia e indústria básica de outros } \\
\text { metais }\end{array}$ & CSNA3 & Companhia Siderúrgica Nacional \\
\hline 18 & $\begin{array}{l}\text { Siderurgia e indústria básica de outros } \\
\text { metais }\end{array}$ & GOAU4 & Metalúrgica Gerdau as \\
\hline 19 & $\begin{array}{l}\text { Siderurgia e indústria básica de outros } \\
\text { metais }\end{array}$ & USIM5 & Usinas Siderúrgicas de Minas Gerais SA Usiminas \\
\hline 20 & $\begin{array}{l}\text { Siderurgia e indústria básica de outros } \\
\text { metais }\end{array}$ & VALE5 & Vale as \\
\hline 21 & Indústria de produtos de metal & MGEL4 & Mangels Industrial as \\
\hline 22 & Indústria de produtos de metal & FJTA4 & Forjas Taurus as \\
\hline 23 & Telecomunicações & OIBR3 & Oi as \\
\hline 24 & Telecomunicações & VIVT3 & Telefônica Brasil as \\
\hline 25 & Telecomunicações & TIMP3 & Tim Participações as \\
\hline 26 & Indústria de Equipamentos de transp. & POMO4 & Marcopolo as \\
\hline 27 & Indústria de Equipamentos de transp. & RAPT4 & Randon SA Implementos e Participações \\
\hline 28 & Indústria química & BRKM5 & Braskem as \\
\hline 29 & Indústria química & UNIP6 & Unipar Carbocloro as \\
\hline 30 & Papel e celulose & KLBN4 & Klabin as \\
\hline 31 & Papel e celulose & SUZB5 & Suzano Papel e Celulose as \\
\hline 32 & Calçados & ALPA4 & Alpargatas as \\
\hline 33 & Calçados & GRND3 & Grendene as \\
\hline 34 & Tecidos e vestuários & CTNM4 & Companhia de Tecidos Norte de Minas Coteminas \\
\hline 35 & Tecidos e vestuários & LREN3 & Lojas Renner as \\
\hline 36 & Lojas de mercadorias em geral & LAME4 & Lojas Americanas \\
\hline 37 & Lojas de mercadorias em geral & PCAR4 & Companhia Brasileira de Distribuição - Açúcar \\
\hline
\end{tabular}
Figura 2: Empresas Analisadas 


\subsection{Modelos Econométricos}

Para a realização desta pesquisa foram utilizados diversos modelos, nesta seção será apresentado os modelos e também as variáveis utilizas nesta pesquisa.

\subsubsection{Comparabilidade}

Para mensurar a comparabilidade em relação à similaridade da função contábil utilizou-se o modelo proposto por De Franco, Kothari e Verdi (2011), e atualizado ao contexto brasileiro por Ribeiro (2014). Ribeiro (2014) efetuou três adaptações às variáveis utilizadas por De Franco, Kothari e Verdi (2011). A primeira adaptação é em relação à mensuração do retorno sobre o lucro e a variáveis utilizada foi o lucro líquido, tal adaptação foi necessária porque no Brasil a norma internacional acabou com o lucro operacional e criou a figura dos resultados líquidos de operações continuadas; segunda, a função contábil individual foi estimada com base nos dados dos doze últimos trimestres e não com base nos 16 últimos trimestres como na pesquisa original. Este recorte permite separar de forma mais confiável os períodos de transição regulatória ocorridos na contabilidade brasileira, além disso, outros estudos (Yip \& Young, 2012; Cascino \& Gassen, 2012; Brochet et al., 2013; Lang et al., 2010); terceira, como deflator do lucro líquido empregou-se o ativo total final ao invés do valor de mercado da companhia. O único objetivo para deflacionar o lucro é para retirar qualquer efeito tamanho do modelo. Como a comparabilidade é uma medida relativa, o importante não é qual medida foi utilizada no denominador, mas sim, utilizar a mesma medida para todas as empresas. Assim, devido a facilidade de acesso optou-se por utilizar o retorno sobre o ativo total final, outras pesquisas utilizaram essa variação e não documentaram viés (Yip \& Young, 2012; Lang et al., 2010). De acordo com estes autores, os valores das demonstrações financeiras de uma empresa são uma função dos eventos econômicos, representada da seguinte forma:

\section{Financial Statements $s_{i}=f_{i}\left(\right.$ Economic Event $\left._{i}\right)$}

Onde $f_{i}(\quad)$ representa o sistema contábil de uma empresa i.

Duas empresas possuem sistemas contábeis comparáveis se, para um mesmo evento econômico, elas produzem outputs contábeis similares. Para operacionalizar o modelo, são 
utilizadas duas proxys o lucro e o retorno de mercado das ações da empresa. O lucro ${ }^{2}$ é utilizado como uma proxy que representa o produto final do sistema contábil, e o retorno de mercado das ações é utilizado como uma proxy para representar o evento econômico.

\subsubsection{Medida de comparabilidade individual média (COMPM)}

Como primeiro passo para mensurar a medida de comparabilidade utilizada nesta pesquisa, estimou-se a função contábil individual de cada companhia com base nos últimos 12 últimos trimestres (para calcular os dados de 2005 foi necessário a obtenção dos dados do ano de 2002) usando a seguinte equação:

Onde:

$$
R O A_{i t}=\alpha_{i}+\beta \text { Retorno }_{i t}+\varepsilon_{i t}
$$

$\mathrm{ROA}_{\mathrm{it}}=$ Lucro líquido trimestral sobre o ativo total final da empresa i no período $\mathrm{t}$ não consolidado.

Retorno $_{\text {it }}=$ Retorno médio trimestral da empresa i no período $t$, calculado com base no preço de fechamento ajustado para dividendos e desdobramentos.

Depois de estimar os parâmetros das funções individuais, foi preciso projetar o ROA esperado [E(ROA)] de cada empresa com base nas regressões obtidas. Primeiro, estimou-se o ROA específico da companhia no período de acordo com a seguinte função:

$$
E(R O A)_{i i t}=\widehat{\alpha}_{i}+\widehat{\beta}_{l} \text { Retorno }_{i t}
$$

Posteriormente foi calculado o E(ROA) da mesma empresa com os estimadores das outras companhias do mesmo setor, conforme a seguinte equação:

$$
E(R O A)_{i j t}=\hat{\alpha}_{j}+\widehat{\beta}_{J} \text { Retorno }_{i t}
$$

A ideia é manter o evento econômico constante, usando os estimadores de uma companhia no evento econômico da outra, assim a medida de comparabilidade é a média da distância entre estas duas funções para cada trimestre $\left[\mathrm{E}\left(\mathrm{ROA}_{\mathrm{iit}}\right)-\mathrm{E}\left(\mathrm{ROA}_{\mathrm{ijt}}\right)\right]$. Segundo, De Franco, Kothari, e Verdi (2011), quanto mais próximas forem as duas funções, maior será comparabilidade entre as empresas.

\footnotetext{
${ }^{2} \mathrm{O}$ lucro é derivado do termo em inglês earnings, cujo significado é o de resultado contábil, podendo desta forma ser positivo ou negativo.
} 
Nesse contexto, a medida de comparabilidade final é a distância entre estas duas funções, onde a proximidade das funções representa a comparabilidade entre as empresas. A métrica utilizada para calcular a média de proximidade de cada função contábil por período (trimestre) será realizada por meio da seguinte fórmula:

$$
\operatorname{Compb}_{i j t}=-\frac{1}{12} \mathrm{x}+\sum_{t-11}^{t}\left|E\left(R O A_{i i t}\right)-E(R O A)_{i j t}\right|
$$

Onde:

$\mathrm{Compb}_{\mathrm{ijt}}=$ Medida de comparabilidade individual relativa da empresa $\mathrm{i}$ baseada na empresa $\mathrm{j}$. $\mathrm{E}\left(\mathrm{ROA}_{\mathrm{iit}}\right)=$ Retorno sobre $\mathrm{o}$ ativo previsto da empresa i com base nos estimadores da empresa i e o retorno da empresa i no período $t$.

$\mathrm{E}\left(\mathrm{ROA}_{\mathrm{ijt}}\right)=$ Retorno sobre o ativo previsto da empresa $\mathrm{i}$ com base nos estimadores da empresa $\mathrm{j}$ e o retorno da empresa i no período t.

De acordo com esta medida, quanto maior o valor obtido em Compb $\mathrm{ijt}_{\mathrm{jt}}$, maior é a comparabilidade entre as empresas, já que a medida de comparabilidade da equação 5 apresenta a distância média entre as funções de duas empresas isoladas.

Para se obter uma medida de comparabilidade individual geral comparando com os pares do setor, é necessário calcular a média destas distâncias entre as companhias de referência, conforme a seguinte equação:

$$
\operatorname{COMPM}_{i t}=\frac{\operatorname{Compb}_{i j t}}{n}
$$

Onde:

$\mathrm{COMPM}_{\mathrm{it}}=$ Medida de comparabilidade individual de cada companhia em relação aos seus pares do setor.

$\mathrm{Compb}_{\mathrm{ijt}}=$ Medida de comparabilidade individual relativa de cada par de empresa $\mathrm{N}=$ número de companhias no setor (ou sendo comparadas).

Para esta medida quanto mais próximo de zero, maior é o nível de comparabilidade.

\subsubsection{Medida de comparabilidade intertemporal (COMPT)}

Para atingir a comparabilidade é necessário que os usuários possam identificar similaridades e diferenças entre a mesma empresa ao longo do tempo. Assim, para capturar esse aspecto da comparabilidade Ribeiro (2014) fez uma adaptação à medida de comparabilidade proposta por De Franco, Kothari e Verdi (2011). Para mensurar a comparabilidade intertemporal, ao invés 
de utilizar o retorno esperado da outra empresa para medir a distância entre as funções (conforme proposto por De Franco, Kothari e Verdi (2011), para a medida de COMPM), a comparabilidade é obtida com base no retorno defasado em um período. Desta forma, a medida de comparabilidade obtida será a distância entre o lucro estimado pela função contábil de uma empresa no trimestre $\mathrm{t}$ utilizando como referência o lucro estimado da mesma empresa com base no retorno defasado em um trimestre (t-1) (Ribeiro, 2014). A comparabilidade intertemporal foi medida conforme a seguinte equação:

$$
\operatorname{COMPT}_{i i t}=-\frac{1}{12} \mathrm{x}+\sum_{t-11}^{t}\left|E\left(R O A_{i i t}\right)-E\left(R O A_{i i t-1}\right)\right|
$$

Onde:

$\mathrm{COMPT}_{\mathrm{iit}}=$ Medida de comparabilidade relativa da empresa i com base no retorno defasado em um período (t-1) da empresa i.

$\mathrm{E}\left(\mathrm{ROA}_{\mathrm{iit}}\right)=$ Retorno sobre o ativo previsto da empresa i com base nos estimadores da empresa i e o retorno da empresa i no período $t$.

$\mathrm{E}\left(\mathrm{ROA}_{\mathrm{iit}-1}\right)=$ Retorno sobre o ativo previsto da empresa $\mathrm{i}$ com base nos estimadores da empresa i e o retorno da empresa i no período t-1.

Diferente do cálculo da comparabilidade média, a mensuração da medida de comparabilidade temporal é calculada com base individual, pois utiliza como base a mesma empresa ao longo do tempo.

\subsubsection{Acurácia das previsões dos analistas}

O modelo utilizado para mensurar a acurácia da previsão de consenso dos analistas é derivado de estudos anteriores realizados no Brasil por (Martinez., 2004;Martinez \& Salim, 2004; Martinez A. L., 2007; Dalmácio, 2009). Para esses autores a acurácia é a medida de quão próximo o valor obtido está do valor verdadeiro, ou seja, é a medida de quão correto é o resultado. Neste contexto o primeiro passo para a mensuração da acurácia é identificar o desempenho dos analistas em suas projeções, para tanto, é calculado o erro de previsão (ErrPrev), que resulta da diferença entre o resultado do lucro por ação efetivamente obtido pelas empresas e o lucro por ação médio projetado a partir do consenso dos analistas de mercado, conforme demonstrado abaixo:

$$
\text { ErrPrev }=L P A_{\text {real }}-L P A_{\text {prev }} /\left|L P A_{\text {real }}\right|
$$


Onde:

$L_{P A}$ real $=$ lucro por ação efetivamente obtido pela empresa i no ano t;

$\mathrm{LPA}_{\text {prev }}=$ lucro por ação médio dos últimos ganhos anuais projetado pelos analistas para a empresa $\mathrm{i}$ antes da data do anuncio dos rendimentos anuais no ano t; e, $\mid$ LPA $_{\text {real }} \mid=$ valor absoluto do lucro por ação real ${ }^{3}$.

Foram utilizados os dados da previsão anual da variável LPA das empresas realizadas pelos analistas no mês de dezembro de cada ano, justifica-se a utilização deste período por possibilitar coletar as previsões com a maior quantidade de informações disponíveis, bem como por serem projeções menos viesadas (Martinez, 2004).

Os erros de previsão dos analistas foram analisados em termos médios. A média dos erros de previsão (MEP) resulta da divisão da soma do total dos erros de previsão pelo número de erros de previsão (n):

$$
\operatorname{MEP}=\left(\frac{1}{n}\right) \times \sum_{i=1}^{n} \mid \text { ErrPrev } \mid
$$

A MEP foi utilizada para apurar o viés das previsões dos analistas. Quando MEP é negativa, significa que, em média, os resultados realizados foram maiores do que os projetados pelos analistas, configurando um viés otimista, ou seja, os analistas foram otimistas em suas previsões. Quando a MEP é positiva, há um viés de previsão pessimista.

Como é possível encontrar erros de previsão negativos e positivos, que somados poderiam se aproximar de zero, a acurácia dos analistas foi definida pela média absoluta dos erros de previsão (MEPA), e não pela MEP. A MEPA resulta da divisão entre a soma dos valores absolutos (módulo) dos erros de previsão e o número de observações. Em sua análise, quanto mais distante de zero for o valor dessa variável, maior será o montante de erros de previsão. Como a amostra do trabalho é constituída por observações anuais, o número de observações (n) se referiu à quantidade de meses para os quais havia dados disponíveis em cada ano. Com o intuito de facilitar a interpretação dos resultados das regressões, foi calculada a variável ACUR, como resultado da multiplicação da variável MEPA por (-1):

\footnotetext{
${ }^{3}$ Utiliza-se no denominador o valor absoluto (módulo) para capturar com exatidão o sentido do erro de previsão. Ao ser o numerador dividido pelo valor absoluto do lucro efetivo, permite-se a comparabilidade em termos percentuais. Entende-se que os preços trariam, na análise, distorções, pois os erros de previsão passariam a ser mensurados em termos de um fator sobre os quais os analistas não possuem controle. Flutuações nos preços gerais das ações repercutiriam sobre a magnitude da métrica dos erros de previsão (Martinez, 2004
} 


$$
\operatorname{ACUR}=(-1) \times \text { MEPA }
$$

Ao multiplicar o valor da variável MEPA por (-1), obtém-se uma medida que aumenta quando a acurácia da previsão é maior, assim, quanto maior ou mais próximo de zero for o resultado da variável ACUR, menor a divergência entre a média dos erros de previsão dos analistas (DALMÁCIO, 2009).

Para examinar a relação entre a comparabilidade e a acurácia na previsão de consenso dos analistas a fórmula utilizada será:

$$
\begin{aligned}
\text { Acurácia }_{i, t}= & \alpha_{i}+\beta_{1} \text { Comparabilidade }_{i t}+\beta_{2} \text { DSETOR }_{i t}+ \\
& \beta_{3} \text { IFRS }_{i t}+\Upsilon \text { Controle }_{i t}+\varepsilon_{i t+1}
\end{aligned}
$$

Onde, Comparabilidade pode assumir COMPM ou COMPT e Controle pode assumir as seguintes variáveis: QANALIST, LNATIVO, PTB, PERDA, VP, DVESTIMAT, DPROE e LNRISCO.

As variáveis independentes são apresentadas para capturar os efeitos da comparabilidade, do setor de atividade das empresas e dos períodos: anterior à adoção, adoção parcial, adoção obrigatória do IFRS.

Comparabilidade $=$ Medida de comparabilidade individual de cada companhia em relação às suas empresas pares do setor (COMPMit $)$.

Setor de atividade (DSETOR): representado por um conjunto de variáveis binárias (dummies), que assumem valor igual a 1 para as empresas que participam de determinado setor e igual a 0 para as empresas de outros setores. Com esta variável busca-se controlar fatores não observáveis associados às características do setor de atividade das empresas. De acordo com a literatura as previsões são mais imprecisas e viesadas para setores intensivos em tecnologia (Silva, 1998; Martinez, 2004, Bhat, Hope, \& Kang, 2006, Byard, Li , \& Weintrop, 2006).

IFRSANT: variável dummy utilizada para analisar a acurácia no período anterior à adoção obrigatória do IFRS (2005 a 2007). Assumindo valor 1 para períodos anteriores à convergência ao IFRS e zero para os demais períodos. 
IFRSTRANS: variável dummy utilizada para analisar a acurácia no período de transição (2008 e 2009). Assumindo valor 1 para períodos anteriores à transição ao IFRS e zero para os demais períodos.

IFRSPOS: variável dummy utilizada para analisar a acurácia no período de adoção obrigatória (2010 a 2015). Assumindo valor 1 para períodos os períodos de adoção obrigatória ao IFRS e zero para os demais períodos.

As variáveis de controle da acurácia na previsão dos analistas foram adicionadas ao modelo com o intuito de isolar seus efeitos sobre a variável dependente. Abaixo apresentam-se as variáveis de controle utilizadas e que, foram identificadas com base na literatura nacional e internacional. A respeito dos determinantes da acurácia da previsão de consenso dos analistas de mercado.

Cobertura dos analistas (QANALIST): consiste na quantidade de analistas que acompanham a empresa i no período t. Há evidências na literatura de que quanto maior for o número de analistas que acompanham uma determinada empresa, maior será a acurácia (Conroy \& Harris, 1987; Brown, 1997; Martinez \& Salim, 2004; Martinez, 2004, DALMÁCIO, 2009).

Os resultados evidenciaram que efetivamente no contexto do Brasil, as empresas que são cobertas por um número maior de analistas são menos propensas ao gerenciamento de resultados. Outro ponto constatado é que as previsões de consenso são mais acuradas, quanto maior for o número de analistas que participam na apuração do consenso (Martinez, 2004)

LNATIVO: Representa o logaritmo natural do ativo total da empresa calculado no período t. Essa variável representa uma proxy para o tamanho da empresa. Pesquisas anteriores que utilizaram esta variável de controle, não encontraram um consenso em relação à sua influência sobre a acurácia dos analistas de mercado. Alguns pesquisadores evidenciaram que os analistas possuem maior acurácia e menor dispersão ao analisar empresas maiores pois as mesmas divulgam um número maior de informações (Lang \& Lundholm, 1996; Ashbaugh \& Pincus, 2001. Entretanto, Lang, Lins e Miller (2003) mencionam que o tamanho da empresa pode aumentar o desvio das previsões e aumentar o erro em relação ao lucro previsto, tal fato pode ser observado pois as empresas maiores possuem maior complexidade ao realizar a análise, podendo levar os analistas a incorrerem em maiores erros, reduzindo a acurácia e aumentando 
a dispersão das estimativas. Nesse contexto, espera-se encontrar uma relação entre o tamanho da empresa e a acurácia da previsão dos analistas, mas a direção não apresenta consenso na literatura.

Price-to-book (PTB): relação entre o valor de mercado e o valor patrimonial da empresa i no tempo t. Conforme a literatura, há evidências de que quanto maior o price-to-book, maior a acurácia (Martinez, 2004).

PERDA: variável dummy que assume valor igual a 1 em caso de prejuízo e 0 em caso de lucro no exercício divulgado para a empresa. Empresas com resultado negativo tendem a ter previsões menos acuradas e mais dispersas do que empresas que divulgam lucro. Assim, em períodos de lucro espera-se que o erro e a dispersão das previsões sejam menores se comparados a períodos de prejuízo (Martinez, 2004; Dalmácio, 2009; Gatsio, 2013).

Viés da previsão (VP): variável binária (dummy) que captura o viés da previsão. Essa variável assume valor igual a 1 quando a previsão é otimista e 0 quando é pessimista (Silva, 1998; Martinez \& Salim, 2004; Martinez, 2004).

Dispersão das estimativas (DVPESTIMAT): medida de risco, calculada como desvio padrão das estimativas (previsões) para a empresa i no período t, escalonado pelo preço da ação da empresa i no período t. De acordo com a literatura, há evidências de que quanto maior a dispersão das estimativas, menor a acurácia (Conroy \& Harris, 1987; Martinez \& Salim, 2004; Martinez, 2004; Byard; Li \& Weintrop, 2006).

DPROE: desvio padrão dos últimos três retornos sobre o patrimônio líquido (anual) para a empresa i. A literatura apresenta evidências de que o aumento na variável DPROE está associado a uma acuraria menor e uma maior dispersão das estimativas (Lang \& Lundholm, 1996; Jiao, Koning, Meterns, \& Roosenboom, 2012).

LNRISCO: logaritmo natural do índice EMBI+Brasil no período t. Tem por função harmonizar os efeitos do risco de mercado na relação entre as variáveis dependentes e as de interesse. Assim como Gatsio (2013), optou-se por acrescentar esta variável em função da crise financeira internacional. A inclusão também é sugerida por Tan, Wang e Welker (2011) pois o mesmos 
encontraram evidências indicando uma relação entre as variáveis analisadas e a volatilidade do mercado.

De acordo com literatura investigada, a Tabela 3 mostra os resultados esperados para cada variável analisada.

Tabela 3 - Resultados esperados para cada variável

\begin{tabular}{|c|c|c|c|}
\hline Modelo & Variável & Coeficiente & Pesquisas Base \\
\hline \multirow{14}{*}{ Acurácia } & COMPM & $(+)$ & $\begin{array}{l}\text { De Franco, Kothari e Verdi } \\
\text { (2011) }\end{array}$ \\
\hline & COMPT & Não utilizado & \\
\hline & QANALIST & $(-) /(+)$ & $\begin{array}{l}\text { Jiao, Koning, Meterns, \& } \\
\text { Roosenboom ( 2012); Dalmácio } \\
(2009) .\end{array}$ \\
\hline & LNATIVO & $(-)$ & $\begin{array}{l}\text { (Cotter, Tarca, \& Wee (2012); } \\
\text { Jiao, Koning, Meterns, \& } \\
\text { Roosenboom (2012). }\end{array}$ \\
\hline & PTB & $(+)$ & Dalmácio (2009) \\
\hline & PERDA & $(+) /(-)$ & $\begin{array}{l}\text { Cotter, Tarca, \& Wee (2012) } \\
\text { Dalmácio (2009) }\end{array}$ \\
\hline & $\mathrm{VP}$ & $(-)$ & Dalmácio (2009) \\
\hline & DESTIMAT & $(-)$ & Dalmácio (2009) \\
\hline & DROE & $(+)$ & $\begin{array}{l}\text { Gatsios (2013); Cotter, Tarca, \& } \\
\text { Wee (2012); Jiao, Koning, } \\
\text { Meterns, \& Roosenboom } \\
\text { 2012). }\end{array}$ \\
\hline & LNRISCO & $(+)$ & Gatsios (2013) \\
\hline & SETOR & $(-) /(+)$ & Martinez (2004a) \\
\hline & IFRSANT & Não utilizado & \\
\hline & IFRSTRANS & $(+)$ & Gatsios (2013) \\
\hline & IFRSOBR & $(-)$ & $\begin{array}{l}\text { (Cotter, Tarca, \& Wee (2012); } \\
\text { Jiao, Koning, Meterns, \& } \\
\text { Roosenboom ( 2012). }\end{array}$ \\
\hline
\end{tabular}

Nota: Para (-) espera-se uma relação negativa, para (+), espera-se uma relação positiva

\subsubsection{Informatividade}

O modelo utilizado para mensurar a informatividade é derivado de estudos anteriores realizados por Easton e Harris (1991), Francis e Schipper (1999), Bushman et al (2004) Sarlo Neto (2009), Silva, Sarlo Neto, Costa Junior e Reina (2016), e Sarlo Neto, Bassi e Almeida, 2011). Esses autores mencionam que a relação entre o lucro contábil e o retorno das ações é representada por 
uma equação em que o retorno das ações (variação dos preços em um determinado período) é definido como uma variável explicativa/dependente do lucro contábil, assim é possível identificar o poder de explicação da informação contábil sobre a variação dos preços das ações. A partir desta definição, os autores mencionam que a relação entre o retorno das ações e o lucro contábil assume a seguinte especificação:

$$
R_{i t}=\alpha_{0}+\alpha_{1} \cdot L C_{i t}+\varepsilon
$$

onde:

$\mathrm{R}_{\mathrm{it}}=$ Retorno da ação da empresa i no período t;

$\mathrm{LC}_{\mathrm{it}}=$ Lucro contábil da empresa i no período t;

$\alpha_{0}=$ Intercepto;

$\alpha_{1}=$ Coeficiente angular entre o lucro contábil e o retorno; $\varepsilon=$ Erro

Segundo Wang (2014) a comparabilidade das demonstrações financeiras é reconhecida como uma característica importante dos relatórios financeiros que melhoram a utilidade da informação contábil, pois em termos gerais o processo de tomada de decisão pelos usuários perpassa pelos valores evidenciados nos demonstrativos contábeis. Libby e Curto (2009) cita que é impossível analisar os dados financeiros de uma empresa sem uma base de comparação, enfatizando assim, a importância da comparabilidade das demonstrações financeiras nas técnicas de avaliação utilizadas por bancos de investimentos, investidores e analistas de mercado.

Considerando as informações contábeis como forma de transmitir informação aos usuários e a comparabilidade como uma característica que melhora a qualidade da informação, fez-se uma adaptação ao modelo original acima mencionado empregando-se o mesmo raciocínio subjacente, porém, ao invés de utilizar o lucro contábil variável explicativa/dependente utilizouse a variável comparabilidade. Com isso, o modelo estruturado com a finalidade de investigar a influência dos demonstrativos financeiros sobre a informatividade segue a lógica das pesquisas lucro-retorno substituindo a medida de resultados contábeis pela comparabilidade sendo apresentado na seguinte forma:

$$
R A_{i, t}=\alpha_{0}+\alpha_{1} . I C_{i t}+\sum_{j}^{K} \varpi_{j} . I C_{i t} . V C_{i t}+\varepsilon_{i t}
$$


Sendo:

$\mathrm{RA}_{i, t}=$ medida de retorno da ação da empresa i no período $\mathrm{t}$ (retorno anormal);

$\mathrm{IC}_{\mathrm{it}}=$ variáveis independentes da informação contábil da empresa $\mathrm{i}$ no período $\mathrm{t}$ : Comparabilidade COMPM e COMPT;

$\mathrm{VC}_{i, t}^{j}=$ variáveis de controle $\mathrm{j}$, de um total de $\mathrm{k}$ variáveis para a empresa i no período t: Tamanho (TAM), Market-to-Book (MTB), Endividamento (END) Endividamento, PERDA, Setor de atividade (DSETOR), IFRSANT, IFRSTRANS, IFRSPOS.

O modelo acima parte do pressuposto de que a mensuração da informatividade é condicionada à influência da comparabilidade. Segundo (Sarlo Neto, 2009) a informatividade condicionada é mensurada por intermédio da aplicação de uma variável multiplicativa sobre a informação contábil ( $\mathrm{IC}_{i t}$. Comparabilidade).

Retorno Anormal (RA): como medida para o retorno das ações utilizou-se o retorno anormal (RA) para tanto, adotou-se o retorno da ação ${ }^{4}$ ajustado pelo retorno do mercado ${ }^{5}$, procedimento similar ao adotado por Fan e Wang (2002); Francis et. al. (2005); Sarlo Neto (2009), e Sarlo Neto, Bassi e Almeida (2011). O retorno anormal representa o excesso de retorno da empresa em relação ao mercado em determinado período.

$$
R A_{i, t}=R_{i, t}-R I B O V_{t}
$$

Em que:

$\mathrm{RA}_{i, t}=$ é o retorno anormal da ação da empresa i no período t;

$\mathrm{R}_{i, t}=$ é o retorno da ação da empresa i no período t; e

$\mathrm{RIBOV}_{t}=$ é o retorno do mercado para o período $\mathrm{t}$ (como medida para o retorno de mercado foi utilizada a variação do Ibovespa (IBOV).

4 O retorno da ação foi calculado da seguinte forma (Soares, 2002):

$$
R_{i, t}=P_{i, t}-P_{i, t-1} / P_{i, t-1}
$$

Onde, $\mathrm{R}_{i, t}=$ taxa de retorno da ação i no período $(\mathrm{t}, \mathrm{t}-1) ; \mathrm{P}_{\mathrm{i}, \mathrm{t}}=$ preço da ação i na data $\mathrm{t}$; e, $\mathrm{P}_{\mathrm{i}, \mathrm{t}-1}=$ preço da ação $\mathrm{i}$ na data $\mathrm{t}-1$.

${ }^{5} \mathrm{O}$ retorno de mercado foi calculado de forma semelhante ao retorno da ação:

$$
R I B O V_{t}=I B O V_{t}-I B O V_{t-1} / I B O V_{t-1}
$$

Onde, $\mathrm{RIBOV}_{\mathrm{t}}=$ taxa de retorno do Ibovespa no período (t, t-1); IBOV $\mathrm{t}=$ preço do Ibovespa na data $t$; e, IBOV,t${ }_{1}=$ preço do Ibovespa na data $\mathrm{t}-1$. 
As variáveis de controle utilizadas são as seguintes:

Tamanho (TAM): Representa o logaritmo natural do valor de mercado da empresa i no período t.

Market-to-Book (MTB): relação entre o valor de mercado dos ativos divididos pelo valor contábil do patrimônio líquido.

Endividamento (END): relação entre o indicador dívida bruta e o passivo total da empresa i no período t. Para as companhias que apresentaram o patrimônio líquido negativo, o indicador não foi calculado, ficando como missing value.

PERDA: variável dummy que assume valor igual a 1 em caso de prejuízo e 0 em caso de lucro no exercício divulgado para a empresa.

Setor de atividade (DSETOR): representado por um conjunto de variáveis binárias (dummies), que assumem valor igual a 1 para as empresas que participam de determinado setor e igual a 0 para as empresas de outros setores

De acordo com literatura investigada, a Tabela 4Tabela 3 mostra os resultados esperados para cada variável analisada.

\begin{tabular}{|c|c|c|c|}
\hline Modelo & Variável & Coeficiente & Pesquisa Base \\
\hline \multirow{7}{*}{ Informatividade } & COMPM & Não utilizado & \\
\hline & COMPT & Não utilizado & \\
\hline & PERDA & $(-)$ & $\begin{array}{l}\text { (Almeida, Sarlo Neto, } \\
\text { Gomes, \& Novaes, 2014) }\end{array}$ \\
\hline & TAM & $(+) /(-)$ & $\begin{array}{l}\text { (Atiase, 1985; Freeman, } \\
\text { 1987; Collins \& Kothari, } \\
\text { 1989). }\end{array}$ \\
\hline & MTB & $(+)$ & $\begin{array}{l}\text { (Collins; \& Kothari, } \\
\text { 1989; Sarlo Neto, Bassi, } \\
\text { \& Almeida, 2011) }\end{array}$ \\
\hline & END & $(-)$ & Collins \& Kothari (1989) \\
\hline & SETOR & $?$ & Sarlo Neto (2009) \\
\hline
\end{tabular}

Tabela 4 - Resultados esperados variáveis modelo informatividade

\subsection{Abordagem Estatística}

Para a análise dos dados, foram utilizados modelos de regressão para dados em painel. Optouse por utilizar esta técnica devido à característica da amostra desta pesquisa, pois os dados observados nesta pesquisa são compostos pelo mesmo indivíduo ao longo do tempo. Assim, 
para a aceitação ou não das hipóteses elaboradas, serão utilizadas as três abordagens para os modelos de regressão com dados em painel que são:1) POOLED - dados em painel com efeito combinado; 2) RE - dados em painel com efeitos aleatórios; e 3) FE - dados em painel com efeitos fixos.

Gujarati e Porter (2011, p. 588) apresentam as seguintes vantagens da utilização dos modelos de regressão com dados em painel:

- como os dados em painel se relacionam com empresas e com o tempo, tende a haver heterogeneidade nessas unidades. As técnicas de estimação utilizada nos dados em painel podem levar em consideração a heterogeneidade, permitindo variáveis específicas ao sujeito.

- combinando séries temporais com observações os dados em painel proporcionam dados mais informativos, maior variabilidade, menos colinearidade entre variáveis, mais graus de liberdade e mais eficiência.

- os dados em painel possibilitam detectar e medir melhor os efeitos que simplesmente não podem ser observados em um corte transversal puro ou em uma série temporal pura.

- investigando repetidas observações em corte transversal, os dados em painel são mais adequados para examinar a dinâmica da mudança.

A expressão geral de um modelo de regressão para a análise de dados em painel é representada pela seguinte equação:

$$
\eta_{i t}=\alpha_{i}+\beta_{1} \cdot X_{1 i t}+\beta_{2} \cdot X_{2 i t}+\ldots+\beta_{k} \cdot X_{k i t}
$$

Em que o y é conhecido por função de ligação canônica, $\alpha$ representa os termos do intercepto, $\beta_{\mathrm{j}}(\mathrm{j}=1,2, \ldots, \mathrm{K})$ são os coeficientes de cada variável explicativa e correspondem aos parâmetros a serem estimados e $\mathrm{X}_{\mathrm{j}}$ são as variáveis explicativas (métricas ou dummies), que variam entre os indivíduos ao longo do tempo. Os subscritos i representam cada um dos indivíduos da amostra ( $i=1,2, \ldots, n$, em que $n$ é o tamanho da amostra) e $t$, os períodos em que são coletados os dados (Fávero, 2015).

Desenhado como uma regressão linear, faz-se necessário aprimorar as especificações dos modelos, bem como definir o melhor modelo. Para tanto, são aplicados vários testes estatísticos que serão abordados a seguir. 
O teste de LM de Breusch-Pagan avalia a adequação dos modelos de efeitos aleatórios com base na análise dos resíduos do modelo estimado por mínimos quadrados ordinários (POLS) (Fávero, Belfiore, Silva, \& Chan, 2009). As hipóteses para o teste são:

$\mathrm{H}_{0}$ : a variância dos resíduos que refletem diferenças individuais é igual a zero (POLS).

$\mathrm{H}_{1}$ : a variância dos resíduos que refletem diferenças individuais é diferente de zero (efeitos aleatórios).

Para escolher entre os modelos de efeitos fixos e os de efeitos aleatórios, utiliza-se o teste de Hausman, que observa se o modelo de correção dos erros é adequado para a regressão proposta (Wooldridge, 2010).

$\mathrm{H}_{0}$ : modelo de correção dos erros é adequado (efeitos aleatórios).

$\mathrm{H}_{1}$ : modelo de correção dos erros não é adequado (efeitos fixos).

Para avaliar a adequação entre o POLS e o modelo de efeitos fixos, utiliza-se o teste de Chow. Este, teste representa um teste $\mathrm{F}$ que pode ser utilizado para determinar se os parâmetros de duas funções de regressão múltiplas diferem entre os grupos (Fávero, Belfiore, Silva, \& Chan, 2009). A seguir apresentam-se as hipóteses para o teste:

$\mathrm{H}_{0}$ :os interceptos são iguais para todas as cross-sections (POLS).

$\mathrm{H}_{1}$ :os interceptos são diferentes para todas as cross-sections (efeitos fixos).

Uma das proposições exigidas para poder comparar duas ou mais populações é a homogeneidade das variâncias, que pode ser obtida a partir do teste de Levene (Fávero, Belfiore, Silva, \& Chan, 2009), cujas hipóteses são:

$\mathrm{H}_{0}$ : as variâncias populacionais, estimadas a partir de $\mathbf{k}$ amostras representativas, são homogêneas ou iguais.

$\mathrm{H}_{1}$ : pelo menos uma variância populacional é diferente das demais.

O teste de RESET (Regression Specification Error Test) tem por função avaliar a existência de erros de especificação do modelo pela omissão de variáveis relevantes, evitando assim um dos grandes problemas de violação aos pressupostos na análise de regressão (Fávero, 2015).

Segundo Fávero (2015), o problema de multicolinearidade ocorre quando há correlações muito elevadas entre variáveis explicativas e, em alguns casos, essas correlações podem ser perfeitas, 
indicando uma relação linear entre as variáveis. O método mais simples de diagnosticar a multicolinearidade é por meio da análise da matriz de correlação, por meio da identificação de altas correlações entre as variáveis explicativas. Outra forma de identificar a multicolinearidade é por meio da estimação de regressões auxiliares, pois se para cada regressão auxiliar for observado que um ou mais $\mathrm{R}_{\mathrm{k}}{ }^{2}$ auxiliares forem elevados, poderemos considerar a existência de multicolinearidade, assim podemos definir, as estatísticas Tolerance e VIF (Variance Inflation Factor). Nesse sentido, se a Tolerance for muito baixa para uma regressão e a estatística VIF alta, há indícios de problemas de multicolinearidade (Fávero, 2015).

Como nos modelos utilizados nesta pesquisa foram analisadas variáveis de natureza qualitativa e quantitativa, torna-se necessária a utilização da técnica estatística ANOVA, de um fator tem por função verificar o efeito de uma variável independente de natureza qualitativa (fator) em uma variável dependente de natureza quantitativa. A hipótese consiste em testar se as médias das populações são iguais. Para que essas médias sejam rejeitadas, basta que pelo menos uma das médias seja diferente das demais (Fávero, Belfiore, Silva, \& Chan, 2009).

Para cada uma das equações estimadas para os modelos de Acurária e os modelos de Informatividade; adota-se as seguintes estratégias: 1) estimou-se, inicialmente, um modelo pooled (POLS) para verificar as hipóteses de homogeneidade [pelo Teste Breusch-Pagan $\left(\chi^{2}\right)$ ], especificação [pelo Teste RESET de $\operatorname{Ramsey}(F)$ ] e multicolinearidade [pelo exames do fator de inflação da variância (VIF)]; 2) com os problemas identificados no passo anterior fez-se a estimação de todos os outros modelos [POLS, efeitos aleatórios (RE) e efeitos fixos (FE)] tendo em vista as soluções para os problemas; 3) executou-se o Teste LM de Breusch-Pagan para definir entre os modelos POLS, efeitos aleatórios e/ou o Teste de Hausman para escolher entre os modelos efeitos aleatórios, efeitos fixos e/ou o Teste de Chow (Teste LM de restrição de modelos) para decidir entre os modelos POLS e efeitos fixos; e, 4) execução dos passos anteriores com adoção do seguinte procedimento para exclusão dos outliers multivariados: cálculos das estatísticas $d f$ its para cada resíduo padronizado e utilização dos pontos de corte sugeridos por Baum (2006), cujo critério reside em excluir as observações com $\mid$ difts $\mid>$ $2,5(\mathrm{k} / \mathrm{N})^{1 / 5}$, onde $\mathrm{k}=$ número parâmetros no modelo, e $\mathrm{N}=$ número de observações. 


\begin{tabular}{|l|l|l|}
\hline CÓDIGO & DESCRIÇÃO & VALORES \\
\hline ANO & Ano & 2005 a 2015 \\
\hline EMPRESA & Empresa & $\begin{array}{l}\text { Variável categórica nominal com identificação das } 37 \\
\text { empresas }\end{array}$ \\
\hline ACURACIA & Acurácia & Medida escalar calculada conforme metodologia \\
\hline RA & Retorno anormal & Medida escalar calculada conforme metodologia \\
\hline COMPM & Comparabilidade média & Medida escalar calculada conforme metodologia \\
\hline COMPT & $\begin{array}{l}\text { Comparabilidade } \\
\text { temporal }\end{array}$ & Medida escalar calculada conforme metodologia \\
\hline IFRS & Período do IFRS & $1=$ Antes IFRS; 2 = Período Transição; 3 = Pós IFRS \\
\hline PERDA & Prejuízo no exercício & $1=$ prejuízo no período; 0 = caso contrário \\
\hline LNATIVO & Ln do Ativo Total & Logaritmo natural do ativo total \\
\hline VP & Viés de previsão & $1=$ previsão otimista; 0 = previsão pessimista \\
\hline PTB & Price-to-book & Valor de mercado / Valor patrimonial \\
\hline $\begin{array}{l}\text { DVPESTIMA } \\
\text { T }\end{array}$ & Dispersão das estimativas & Desvio-padrão das estimativas (previsões) \\
\hline DPROE & Desvio-padrão do ROE & Desvio-padrão dos últimos três ROE \\
\hline QANALIST & Cobertura dos analistas & Quantidade de analistas que acompanham a empresa \\
\hline LNRISCO & Ln do EMBI+Brasil & Logaritmo natural do EMBI+Brasil \\
\hline LLA & Lucro líquido ajustado & Lucro líquido / Valor de mercado no período anterior \\
\hline MTB & Market-to-book & Valor de mercado dos ativos / Valor contábil do PL \\
\hline END & Endividamento & Dívida bruta / passivo total \\
\hline TAM & Ln do valor de mercado & Logaritmo natural do valor de mercado \\
\hline SETOR & Setor & Variável categórica nominal com identificação dos 10 setores \\
\hline
\end{tabular}

Figura 3 - Codificação das variáveis utilizadas na pesquisa 


\section{APRESENTAÇÃO E ANÁLISE DOS RESULTADOS}

Neste capítulo, encontram-se as estatísticas descritivas das variáveis, a correlação existente entre elas e também a apresentação e análise dos resultados obtidos em cada um dos modelos utilizados.

\subsection{Análise Descritiva dos Dados}

Nesta seção, serão apresentados os resultados das estatísticas descritivas das variáveis utilizadas nos modelos de acurácia das previsões dos analistas e informatividade, no Brasil. Além disso, serão discutidas as matrizes de correlação entre as variáveis apresentadas na metodologia.

A Tabela 5 sumariza a estatística descritiva para as principais variáveis desta pesquisa.

Tabela 5- Estatística descritiva das principais variáveis utilizadas na pesquisa

\begin{tabular}{c|c|c|c|c|c}
\hline Variáveis & $\mathbf{N}$ & Média & Min & Max & Desv.Pad \\
\hline COMPM & 407 & -1.099958 & -6.450897 & -.0014495 & .9301324 \\
COMPT & 407 & -.8572454 & -8.029384 & -.0024976 & 1.075772 \\
ACURÁCIA & 407 & -.0738074 & -.9206408 & 0 & .1500215 \\
RA & 407 & 5.74769 & -1.330902 & 466.9526 & 41.2973 \\
PERDA & 407 & .1326781 & 0 & 1 & .3396441 \\
LNATIVO & 407 & 15.75794 & 12.14771 & 19.53772 & 1.419423 \\
VP & 407 & .5454545 & 0 & 1 & .4985424 \\
PTB & 407 & 1.75968 & -.7338169 & 13.12852 & 1.675004 \\
DVESTIMAT & 407 & .4393761 & 0 & 18.06404 & 1.913718 \\
DPROE & 407 & .0818572 & 0 & 1.159094 & .1252143 \\
QANALIST & 407 & 7.17199 & 1 & 18 & 5.121663 \\
LLA & 407 & .0004976 & -16.23337 & 1.017665 & .8871038 \\
MTB & 407 & 1.760601 & 0 & 12.04523 & 1.565433 \\
END & 407 & .5951329 & 0 & 5.201158 & .8193302 \\
LNRISCO & 407 & 5.497749 & 4.955827 & 6.259581 & .3666678 \\
TAM & 407 & 15.34916 & 0 & 19.4394 & 1.983063 \\
\hline
\end{tabular}

Os resultados obtidos para a variável (COMPM) comparabilidade individual média, com base nas empresas do mesmo setor é de -1,09. As empresas investigadas nesta pesquisa possuem um nível de COMPM sensivelmente maior do que as investigadas no contexto nacional por Ribeiro (2014) que encontrou média de -2,634 e de pesquisas realizadas no contexto internacional por Choi, Choi, Myers e Ziebart (2015), Sohn, (2016), Fang, Li e Zhang (2016) e De Franco, Kothari e Verdi (2011) que encontraram médias de -1,71, -1,90, -2,03, -2,7 respectivamente.

A variável que mensura a comparabilidade de uma mesma empresa ao longo do tempo (COMPT) é sensivelmente maior do que a medida de comparabilidade entre empresas do mesmo setor (COMPM). Entretanto, esse resultado era esperado pois a diferença entre os 
eventos econômicos para as empresas do mesmo setor é maior do que para a mesma empresa ao longo do tempo, pois outras variáveis (tais como, o tamanho, o risco, o endividamento e etc.) que podem influenciar essa relação possuem um efeito menor ao longo do tempo para a mesma empresa do que para empresas diferentes (De Franco, Kothari \& Verdi, 2011; Ribeiro, 2014).

O valor da variável comparabilidade média da mesma empresa ao longo do tempo (COMPT) obtido nesta pesquisa é de $-0,85$, tal resultado difere do estudo de Ribeiro, (2014) que foi de 0,48 , evidenciando uma melhora, uma vez que as empresas da amostra se mostraram mais comparáveis ao longo do tempo. 

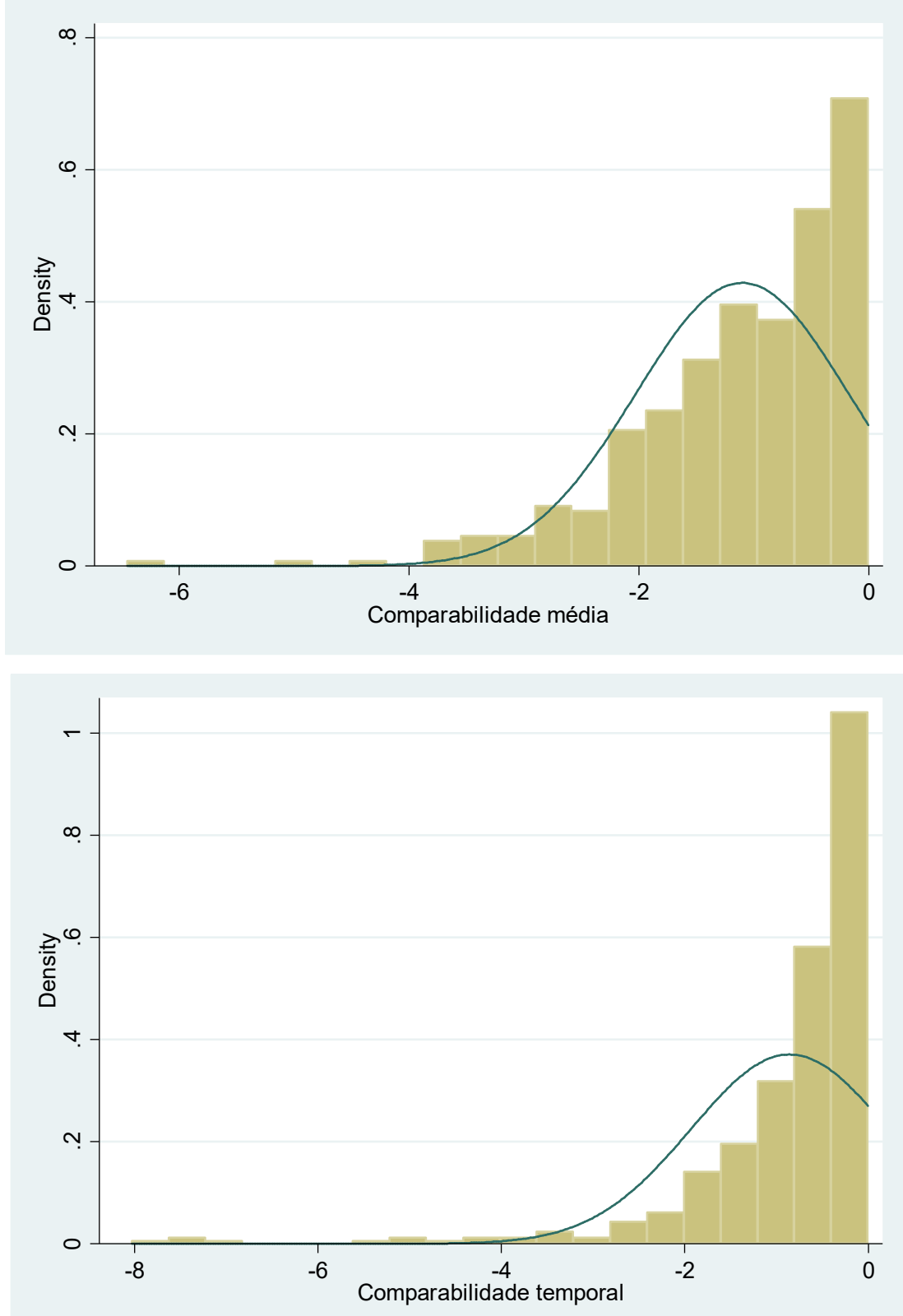

Figura 4 - Distribuição das variáveis COMPM e COMPT

A Figura 4 apresenta a distribuição das variáveis COMPM e COMPT em relação à linha da distribuição normal. O comportamento das variáveis foi similar ao observado por De Franco, Kothari e Verdi (2011), e Ribeiro (2014). Partindo do zero, ambas as variáveis apresentaram uma distribuição assimétrica para a esquerda.Conforme apresentado na Figura 4 a distribuição da comparabilidade individual média ficou concentrada entre -2 e zero (quanto mais próximo de zero, maior o nível de comparabilidade).Para a medida de comparabilidade temporal ficou concentrada entre -1,5 e zero. Portanto, não foi observada uma variância muito grande entre as variáveis COMPM e COMPT . 
Tabela 6 - Correlação entre as principais variáveis quantitativas

\begin{tabular}{|c|c|c|c|c|c|c|c|c|c|c|c|c|c|}
\hline & & RA & Acurácia & COMPT & COMPM & LNATIVO & PTB & DVPESTIMAT & DPROE & QANALIST & END & MTB & TAM \\
\hline \multirow{3}{*}{ RA } & Coeficiente & 1 & , 009 & ,069 &,- 030 & ,043 &,- 035 &,- 031 &,- 050 & ,028 &,- 049 &,- 037 & ,036 \\
\hline & $p$-valor & & 851 &, 166 & ,548 & ,384 & ,480 & ,530 & ,319 & ,567 & ,328 & ,455 &, 465 \\
\hline & $\mathrm{N}$ & 407 & 407 & 407 & 407 & 407 & 407 & 407 & 407 & 407 & 407 & 407 & 407 \\
\hline \multirow{3}{*}{ Acurácia } & Coeficiente & ,009 & 1 & 037 & $129^{* *}$ & $289^{* *}$ &, $157^{* *}$ &,- 036 &,$- 222^{* *}$ & $332^{* *}$ & ,011 &, $165^{* *}$ &, $257^{* *}$ \\
\hline & $p$-valor & ,851 & & 455 & ,009 &, 000 &, 002 & ,470 & ,000 & ,000 & ,831 & ,001 &, 000 \\
\hline & $\mathrm{N}$ & 407 & 407 & 407 & 407 & 407 & 407 & 407 & 407 & 407 & 407 & 407 & 407 \\
\hline \multirow{3}{*}{ COMPT } & Coeficiente &, 069 & 037 & 1 & $192^{* *}$ & ,083 & $175^{* *}$ &,- 059 &,$- 266^{* *}$ & $130^{* *}$ &,- 027 &, $163^{* *}$ &, $156^{* *}$ \\
\hline & $p$-valor & , 166 & 455 & &, 000 & ,094 & ,000 & ,233 &, 000 & ,009 & ,586 & ,001 &, 002 \\
\hline & $\mathrm{N}$ & 407 & 407 & 407 & 407 & 407 & 407 & 407 & 407 & 407 & 407 & 407 & 407 \\
\hline \multirow{3}{*}{ COMPM } & Coeficiente &,- 030 & $129^{* *}$ & $192^{* *}$ & 1 &,- 047 & 058 & ,003 &,$- 104^{*}$ &,- 030 &, $179^{* *}$ & ,020 &,- 020 \\
\hline & $p$-valor & ,548 & ,009 & ,000 & & ,345 & ,245 & ,960 & ,036 & ,552 & ,000 & ,692 &, 683 \\
\hline & $\mathrm{N}$ & 407 & 407 & 407 & 407 & 407 & 407 & 407 & 407 & 407 & 407 & 407 & 407 \\
\hline \multirow{3}{*}{ LNATIVO } & Coeficiente & ,043 &, $289^{* *}$ &, 083 &,- 047 & 1 &,- 025 &,- 001 &,- 057 & $499^{* * *}$ &, $163^{* *}$ &,- 025 &, $722^{* *}$ \\
\hline & $p$-valor & , 384 & ,000 & , 094 & ,345 & & ,612 & ,980 & ,255 & , 000 & ,001 & ,615 & , 000 \\
\hline & $\mathrm{N}$ & 407 & 407 & 407 & 407 & 407 & 407 & 407 & 407 & 407 & 407 & 407 & 407 \\
\hline \multirow{3}{*}{ PTB } & Coeficiente &,- 035 & $157^{* *}$ & $175^{* *}$ &, 058 &,- 025 & 1 &,$- 105^{*}$ &,- 020 & $227^{* * *}$ & $214^{* *}$ & ,894** & $273^{* *}$ \\
\hline & $\mathrm{p}$-valor & ,480 &, 002 &, 000 & ,245 &, 612 & & 035 &, 684 &, 000 & , 000 & ,000 &, 000 \\
\hline & $\mathrm{N}$ & 407 & 407 & 407 & 407 & 407 & 407 & 407 & 407 & 407 & 407 & 407 & 407 \\
\hline \multirow{3}{*}{ DVPESTIMAT } & Coeficiente &,- 031 &,- 036 &,- 059 &, 003 &,- 001 &,$- 105^{*}$ & 1 &, 045 &,- 073 & ,009 &,- 068 &,- 090 \\
\hline & p-valor & ,530 & ,470 & ,233 & ,960 & ,980 & ,035 & & ,366 & , 139 & ,850 & ,173 & 071 \\
\hline & $\mathrm{N}$ & 407 & 407 & 407 & 407 & 407 & 407 & 407 & 407 & 407 & 407 & 407 & 407 \\
\hline \multirow{3}{*}{ DPROE } & Coeficiente &,- 050 &,$- 222^{* *}$ &,$- 266^{* *}$ &,$- 104^{*}$ &,- 057 &,- 020 & ,045 & 1 &,$- 106^{*}$ & $397^{* *}$ & ,044 &,$- 134^{* *}$ \\
\hline & p-valor & ,319 & 000 & 000 &, 036 & ,255 & ,684 & ,366 & & ,033 & ,000 &, 376 &, 007 \\
\hline & $\mathrm{N}$ & 407 & 407 & 407 & 407 & 407 & 407 & 407 & 407 & 407 & 407 & 407 & 407 \\
\hline \multirow{3}{*}{ QANALIST } & Coeficiente & ,028 & $332^{* *}$ & $130^{* *}$ &,- 030 & ,499** & $227^{* *}$ &,- 073 &,$- 106^{*}$ & 1 &, $155^{* *}$ &, $252^{* *}$ &, $506^{* *}$ \\
\hline & $p$-valor & ,567 &, 000 & ,009 & ,552 &, 000 &, 000 &, 139 & ,033 & &, 002 & ,000 &, 000 \\
\hline & $\mathrm{N}$ & 407 & 407 & 407 & 407 & 407 & 407 & 407 & 407 & 407 & 407 & 407 & 407 \\
\hline \multirow{3}{*}{ END } & Coeficiente &,- 049 & 011 &,- 027 & $179^{* *}$ &, $163^{* *}$ &, $214^{* *}$ & ,009 &, $397^{* *}$ &, $155^{* *}$ & 1 & $272^{* *}$ &, 078 \\
\hline & $\mathrm{p}$-valor &, 328 & 831 &, 586 &, 000 &, 001 &, 000 &, 850 &, 000 &, 002 & &, 000 &, 116 \\
\hline & $\mathrm{N}$ & 407 & 407 & 407 & 407 & 407 & 407 & 407 & 407 & 407 & 407 & 407 & 407 \\
\hline \multirow{3}{*}{ MTB } & Coeficiente &,- 037 &, $165^{* * *}$ &, $163^{* * *}$ & ,020 &,- 025 &, $894^{* *}$ &,- 068 &, 044 & $252^{* *}$ & $272^{* *}$ & 1 &, $274^{* *}$ \\
\hline & p-valor & ,455 & ,001 & ,001 & ,692 & ,615 & , 000 & ,173 & ,376 & ,000 & ,000 & & , 000 \\
\hline & $\mathrm{N}$ & 407 & 407 & 407 & 407 & 407 & 407 & 407 & 407 & 407 & 407 & 407 & 407 \\
\hline \multirow{3}{*}{ TAM } & Coeficiente &, 036 & $257^{* *}$ & $156^{* *}$ &,- 020 &, $722^{* *}$ &, $273^{* *}$ &,- 090 &,$- 134^{* * *}$ &, $506^{* *}$ & ,078 &, $274^{* *}$ & 1 \\
\hline & p-valor & ,465 &, 000 & ,002 & ,683 & , 000 &, 000 & ,071 & ,007 & , 000 & ,116 & , 000 & \\
\hline & $\mathrm{N}$ & 407 & 407 & 407 & 407 & 407 & 407 & 407 & 407 & 407 & 407 & 407 & 407 \\
\hline
\end{tabular}

Obs: * /**/ denotam significância bi-caudal nos níves $0,05 / 0,01$ respectivamente. 
Ao analisar a correlação entre as variáveis, conforme mostra a Tabela 6 observa-se que a variável COMPM possui uma correlação positiva e significativa embora não muito forte, em relação às variáveis ACURÁCIA e END e uma correlação negativa significativa não muito forte com a variável DPROE. Já a variável COMPT apresentou correlação positiva e significativa, porém não muito forte com as variáveis PTB, QANALIST, MTB e TAM, e com as variáveis COMPM, que também apresentou uma correlação negativa significativa não muito forte com a variável DPROE. Dentre as variáveis de controle observou-se uma correlação forte e positiva entre MTB e PTB.

\subsubsection{Análise comparabilidade individual média entre empresas diferentes do mesmo setor}

Nesta seção analisou-se a comparabilidade individual média entre empresas por setor de atividade econômica e por período. Primeiramente apresenta-se na Tabela 7 o comportamento da variável COMPM ao longo do período de 2005 a 2015. As medidas apresentadas foram calculadas com base nas comparabilidades individuais médias de todas as empresas que compõem a amostra. $\mathrm{O}$ percentil (P10\%) reflete a média dentro do intervalo de $10 \%$ das menores comparabilidades (significa que 10\% das empresas apresentaram COMPM igual ou inferior ao observado), já o percentil (P90\%) representa que 90\% das empresas apresentaram COMPM igual ou inferior ao observado.

Tabela 7 - Comportamento ao longo do tempo da COMPM

\begin{tabular}{l|r|r|r|r|r}
\hline Ano & Média & \multicolumn{1}{c|}{ Desv.Padrão } & \multicolumn{1}{c}{ P10\% } & \multicolumn{1}{c}{ Mediana } & \multicolumn{1}{c}{ P90\% } \\
\hline 2005 & $-1,0781$ &, 85330 & $-2,2585$ & $-1,0031$ &,- 1833 \\
\hline 2006 & $-1,2000$ &, 94249 & $-2,7230$ & $-1,0197$ &,- 1145 \\
\hline 2007 & $-1,1927$ &, 81616 & $-2,4198$ & $-1,1067$ &,- 1808 \\
\hline 2008 & $-1,2535$ & 1,03827 & $-2,8974$ & $-1,0823$ &,- 2071 \\
\hline 2009 & $-1,1942$ & 1,14734 & $-2,8614$ &,- 8092 &,- 1259 \\
\hline 2010 & $-1,0155$ &, 89261 & $-2,4113$ &,- 5721 &,- 1303 \\
\hline 2011 & $-1,0062$ &, 81940 & $-2,3646$ &,- 9166 &,- 0691 \\
\hline 2012 & $-1,0637$ & 1,17135 & $-2,3325$ &,- 8051 &,- 1402 \\
\hline 2013 &,- 9687 &, 84182 & $-2,3110$ &,- 6030 &,- 1431 \\
\hline 2014 & $-1,0899$ &, 91811 & $-2,4739$ &,- 9532 &,- 1883 \\
\hline 2015 & $-1,0371$ &, 77176 & $-2,0746$ &,- 9290 &,- 0450 \\
\hline
\end{tabular}


Ao analisar as informações apresentadas na Tabela 7 e na Figura 5 pode ser observado, em termos gerais, que a COMPM se manteve entre os anos de 2005 a 2007. Em 2008 houve um pequeno declínio (redução) na medida, entretanto, no período de 2010 a 2015 houve um ligeiro aumento na comparabilidade média individual, esse período coincide com o período pós adoção às normas internacionais de contabilidade no Brasil. Esses resultados diferem de forma parcial dos resultados da pesquisa de Ribeiro (2014) que identificou um ligeiro aumento na comparabilidade individual média entre os anos de 2004 a 2005, esse crescimento foi seguido por um declínio revertido a partir de 2008.

A partir da Figura 5 é possível notar também que as medidas concentradas no percentil $90 \%$ aparentemente sofreram maior variação no período de 2010 a 2015, em média geral tem-se que 90\% das empresas apresentaram COMPM igual ou inferior a $-0,12$, sendo que no ano de 2015 o valor foi de -0,045 (o menor valor observado no período de 2005 a 2015). Esse comportamento foi também observado para as medidas concentradas no percentil $10 \%$, em média geral 10\% das empresas apresentaram COMPM igual ou inferior a $-2,32$ no período de 2010 a 2015, e de $-2,07$ para o ano de 2015 (o menor valor observado no período de 2005 a 2015)

Pode-se concluir, a partir de tais resultados que, de modo geral e sem considerar outros fatores que poderiam influenciar a relação da comparabilidade individual média, houve uma perda na comparabilidade no período de transição (anos de 2008 e 2009) e uma melhora na comparabilidade média individual no período pós adoção das IFRS (anos de 2010 a 2015).

Cabe ressaltar que a crise do subprime ocasionada pela queda no preço dos imóveis nos Estados Unidos que desencadeou uma crise financeira internacional, pode ter, de alguma forma, impactado nos resultados da medida de comparabilidade (tendo em vista que esta medida utilizou o retorno de mercado e o lucro líquido na sua composição). Santos e Calixto (2010), ao investigarem os efeitos da convergência ao padrão IFRS no Brasil, constataram que os períodos de 2007 e 2008 foram afetados pelos impactos da crise financeira global. Costa, Reis e Teixeira (2012), ao investigarem se a relevância da informação contábil sofre impacto de crises financeiras no Brasil. Os resultados indicam que no período de 2007 e 2008, a relevância do lucro foi significativamente inferior em relação aos demais anos sem crise. Corroborando com os evidências desta pesquisa, Ribeiro (2014) também menciona que possívelmente houve um efeito da crise financeira sobre a medida de comparabilidade. 

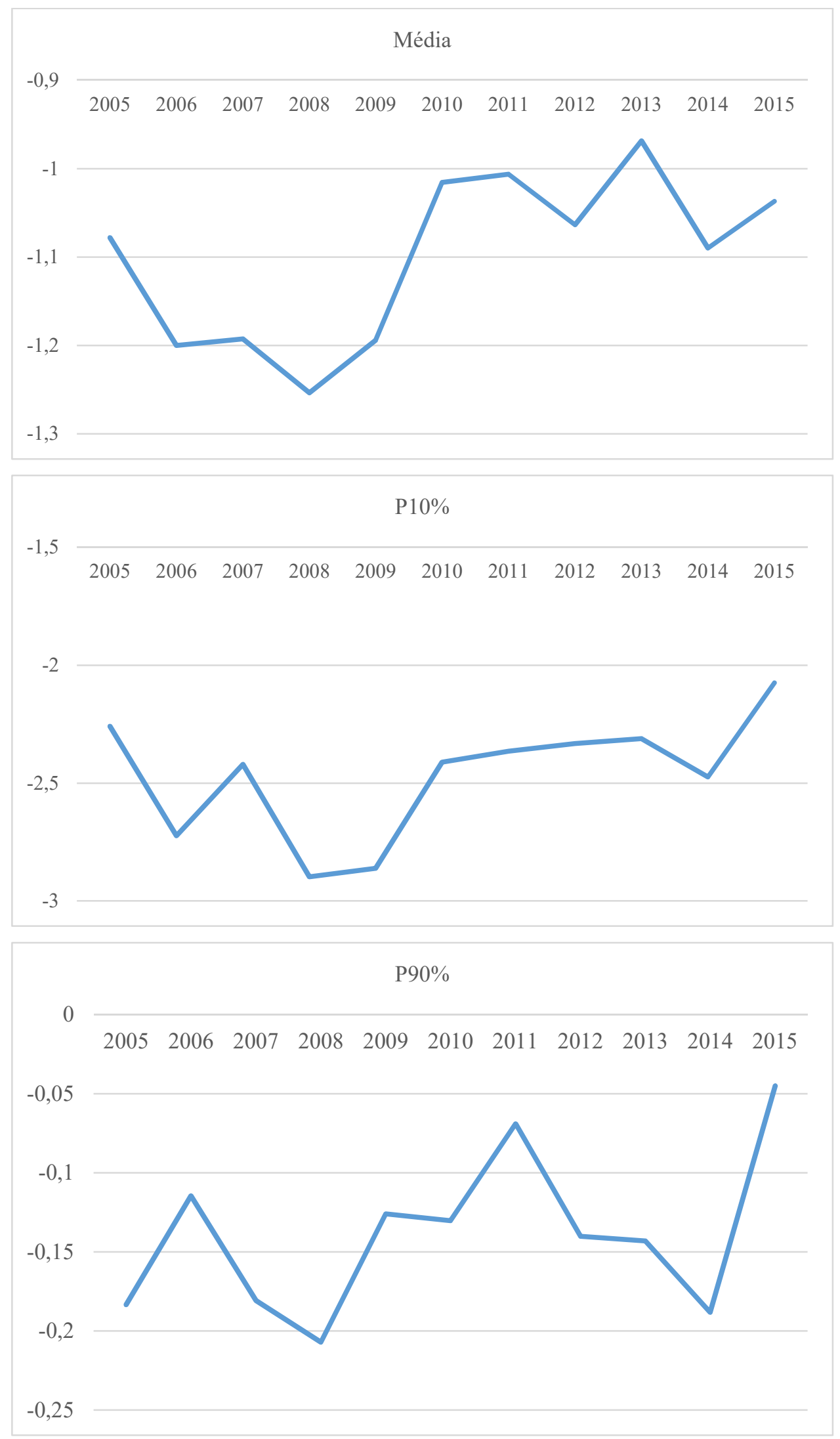

Figura 5 -Comportamento COMPM no período de 2005 a 2015 
A próxima análise foi em relação ao comportamento da variável COMPM por setor de atividade econômica.

Tabela 8 - Comportamento e diferenças na variável COMPM entre os setores

\begin{tabular}{|c|c|c|c|c|c|c|}
\hline Setor & Média & Desv.Padrão & $\mathbf{P} 10 \%$ & Variância & Mediana & $\mathbf{P 9 0 \%}$ \\
\hline Energia, gás e água & $-1,4480$ & 1,05747 & $-2,8150$ & 1,118 & $-1,3181$ &,- 2387 \\
\hline Siderurgia &,- 9381 & ,90242 & $-2,1882$ & 0,814 &,- 6057 &,- 1268 \\
\hline Ind. Prod. Metal &,- 8404 & ,71452 & $-1,8965$ & 0,511 &,- 9035 &,- 0206 \\
\hline Telecomunicações & $-1,1142$ & ,70122 & $-1,8551$ & 0,492 & $-1,0596$ &,- 1972 \\
\hline Equi. Transporte &,- 6570 & ,37227 & $-1,1781$ & 0,139 &,- 6794 &,- 1653 \\
\hline Ind. Química & $-1,2840$ & ,54791 & $-2,0409$ & 0,300 & $-1,2378$ &,- 6368 \\
\hline Papel e Celulose &,- 3623 & ,25222 &,- 7934 & 0,064 &,- 3309 &,- 0528 \\
\hline Calçados &,- 5769 & ,34365 & $-1,0873$ & 0,118 &,- 4626 &,- 0759 \\
\hline Tec. e Vestuário & $-1,8100$ & ,79653 & $-2,9148$ & 0,634 & $-1,9121$ &,- 4830 \\
\hline Lojas geral &,- 1967 &, 14540 &,- 4386 & 0,021 &,- 1673 &,- 0507 \\
\hline Total & $-1,1000$ & ,93013 & & 0,865 &,- 9098 & \\
\hline \multicolumn{7}{|l|}{ Análise de variância } \\
\hline & SS & DF & MS & $\mathbf{F}$ & \multicolumn{2}{|c|}{ Prob $>$ F } \\
\hline Entre grupos & 73,972 & 9 & 8,219 & 11,768 & & 0,000 \\
\hline Dentro dos grupos & 277,277 & 397 & 0,698 & & & \\
\hline Total & 351,249 & 406 & & & & \\
\hline
\end{tabular}

Analisando os dados da Tabela 8 pode ser constatado que, aparentemente, existem diferenças consideráveis em relação à COMPM entre os diferentes setores. Os setores com a maior média para COMPM foram os de lojas em geral, papel e celulose, calçados e equipamento de transporte, respectivamente. O setor que apresentou a menor média foi o de tecidos e vestuário. Os setores que apresentaram medidas menos dispersas foram os mesmos que apresentaram a maior média para o COMPM. Para testar se as diferenças aparentes são significativas estatisticamente, foi realizada a análise de variância. O teste de ANOVA permite concluir que existem diferenças estatisticamente significativas nos níveis de comparabilidade entre as empresas de acordo com a sua distribuição por setor de atividade econômica.

\subsubsection{Análise comparabilidade da mesma empresa ao longo do tempo}

Nesta seção analisou-se a comparabilidade da mesma empresa ao longo do tempo por período e por setor de atividade econômica. A Tabela 9 apresenta os resultados do comportamento da variável COMPT ao longo do período de 2005 a 2015. As medidas apresentadas, foram 
calculadas com base no aspecto temporal individuais de todas as empresas que compõem a amostra.

Tabela 9 - Comparabilidade temporal da COMPT

\begin{tabular}{l|r|r|r|r|r}
\hline Ano & Média & \multicolumn{1}{c|}{ Desv.Padrão } & \multicolumn{1}{c}{ P10\% } & \multicolumn{1}{c}{ Mediana } & \multicolumn{1}{c}{ P90\% } \\
\hline 2005 &,- 9007 &, 87513 & $-2,2874$ &,- 6448 &,- 1435 \\
\hline 2006 &,- 5484 &, 49170 & $-1,4798$ &,- 4009 &,- 0654 \\
\hline 2007 &,- 7488 &, 74329 & $-2,0627$ &,- 4131 &,- 0416 \\
\hline 2008 & $-1,3531$ & 1,59580 & $-3,7737$ &,- 6872 &,- 0303 \\
\hline 2009 & $-1,2049$ & 1,58853 & $-3,4038$ &,- 6459 &,- 0561 \\
\hline 2010 &,- 6968 &, 63642 & $-1,6008$ &,- 4788 &,- 0634 \\
\hline 2011 &,- 6934 &, 63482 & $-1,7379$ &,- 5141 &,- 1612 \\
\hline 2012 &,- 9507 & 1,45777 & $-2,0505$ &,- 4153 &,- 1024 \\
\hline 2013 &,- 8039 & 1,19193 & $-1,4649$ &,- 5027 &,- 0831 \\
\hline 2014 &,- 6085 &, 76662 & $-1,7955$ &,- 4506 &,- 0787 \\
\hline 2015 &,- 8179 & 1,02018 & $-1,9300$ &,- 5607 &,- 0842 \\
\hline
\end{tabular}

Conforme as informações apresentadas na Tabela 9 pode ser observado em termos gerais, que a COMPT no período de 2005 a 2007 obteve uma sensível melhora na comparabilidade no ano de 2006 voltando a aumentar no ano de 2007. Já nos anos de 2007 e 2008 (período de transição para as normas internacionais) a COMPT aumentou consideravelmente, inclusive com valores maiores que o período de 2005 a 2007.No período pós adoção às normas internacionais de contabilidade no Brasil (anos de 2010 a 2015) a comparabilidade temporal reduz voltando à tendência observada no período anterior à adoção. Esses resultados corroboram com a pesquisa de Ribeiro (2014) em que a comparabilidade temporal aparentemente não demonstrou uma tendência discriminatória ao longo dos anos, exceto no ano de 2008.

A variação sofrida no comportamento da COMPT em 2008 e 2009 pode não possui relação com a adoção das IFRS, pois houve uma queda acentuada na variável neste período, sendo o mesmo revertido no ano seguinte. Uma provável explicação para essa variação pode estar relacionada à crise subprime ocorrida no período. Essa variação foi observada também por Ribeiro (2014).

A partir da Figura 6 é possível notar que as medidas concentradas no percentil 90\%, aparentemente, sofreram pouca variação no período de 2005 a 2015, exceto para os anos de 2008 e 2009. 
Com base nessas informações, é possível inferir que aparentemente não houve diferenças significativas entre as médias da COMPT, esse comportamento é observado também nas empresas localizadas nos percentis menores e maiores.
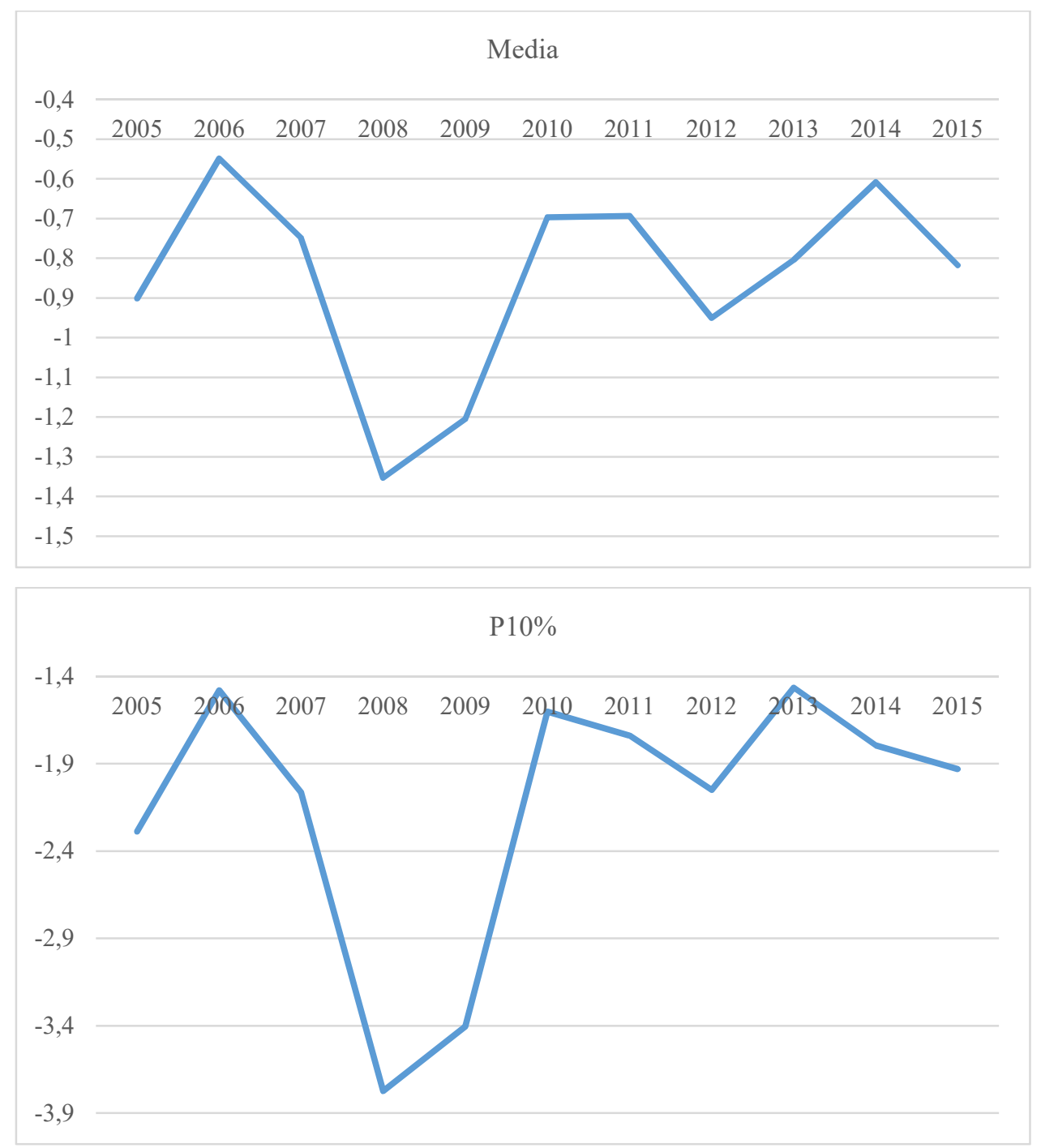


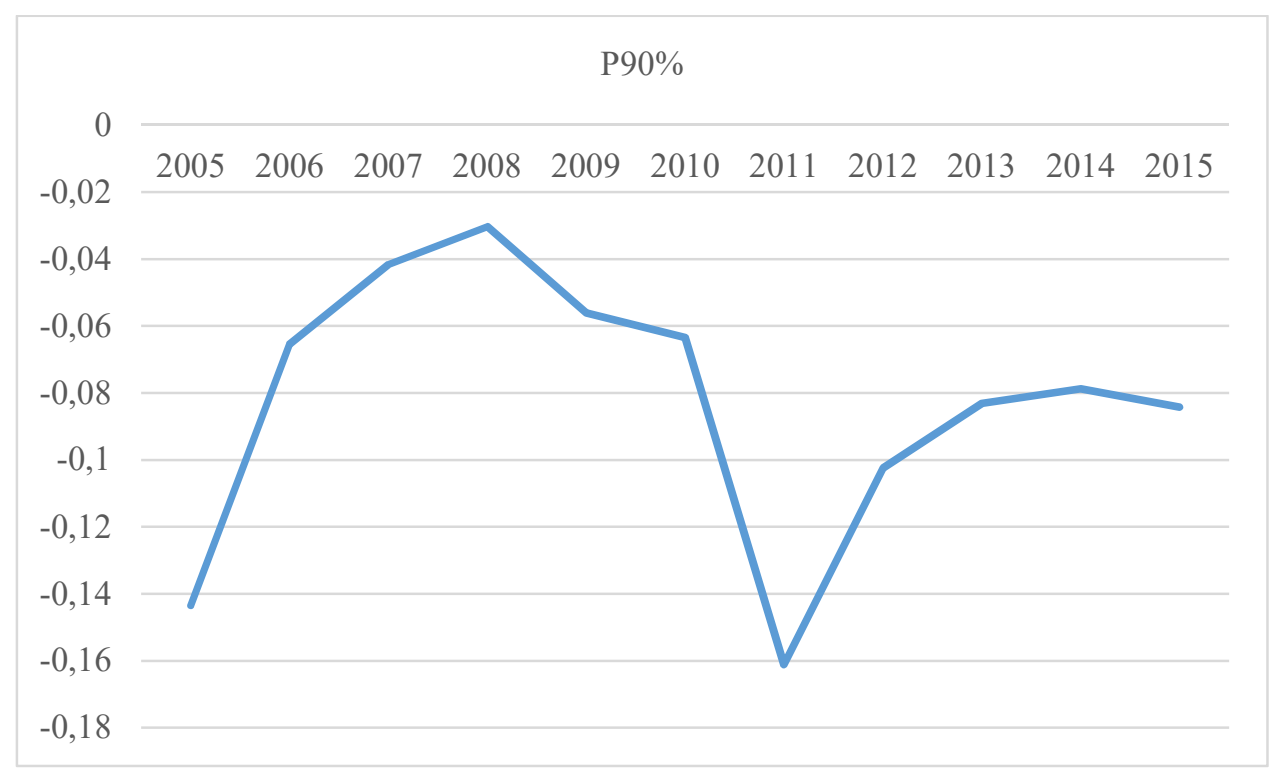

Figura 6-Comportamento COMPM no período de 2005 a 2015

A seguir analisou-se o comportamento da variável COMPT por setor de atividade econômica.

Tabela 10-Comportamento e diferenças na variável COMPT entre os setores

\begin{tabular}{|c|c|c|c|c|c|c|}
\hline Setor & Mean & Std. Deviation & $\mathrm{P} 10 \%$ & Variância & Median & $\mathrm{P} 90 \%$ \\
\hline Energia, gás e água &,- 8172 & 1,02637 & $-1,8532$ & 1,053 &,- 5084 &,- 0779 \\
\hline Siderurgia &,- 8654 & ,99233 & $-2,1747$ & 0,880 &,- 5897 &,- 0944 \\
\hline Ind. Prod. Metal & $-1,3433$ & 1,36236 & $-3,9819$ & 1,856 &,- 9173 &,- 1110 \\
\hline Telecomunicações &,- 7258 & ,77294 & $-1,8534$ & 0,597 &,- 4878 &,- 0735 \\
\hline Equi. Transporte &,- 5528 & ,38374 & $-1,0594$ & 0,147 &,- 5336 &,- 1142 \\
\hline Ind. Química & $-1,7399$ & 2,34049 & $-6,5567$ & 5,478 &,- 8681 &,- 1444 \\
\hline Papel e Celulose &,- 9413 & ,92888 & $-2,6463$ & 0,863 &,- 7346 &,- 0454 \\
\hline Calçados &,- 7222 & ,75402 & $-1,5946$ & 0,569 &,- 5184 &,- 1094 \\
\hline Tec. e Vestuário &,- 6770 & ,71556 & $-1,9283$ & 0,512 &,- 3217 &,- 0393 \\
\hline Lojas geral &,- 3049 &, 21540 &,- 6555 & 0,046 &,- 2768 &,- 0587 \\
\hline Total &,- 8479 & 1,08316 & & 1,157 &,- 5041 & \\
\hline \multicolumn{7}{|l|}{ Análise de variância } \\
\hline & SS & DF & MS & $\mathbf{F}$ & \multicolumn{2}{|c|}{ Prob $>$ F } \\
\hline Entre grupos & 33,460 & 9 & 3,718 & 3,382 & & 0,001 \\
\hline Dentro dos grupos & 436,398 & 397 & 1,099 & & & \\
\hline Total & 469,858 & 406 & & & & \\
\hline
\end{tabular}

De acordo com os dados apresentados na Tabela 10, pode ser observado que, aparentemente, existem diferenças consideráveis em relação à COMPT entre os diferentes setores. Os setores com a menor média para COMPM foram os de Indústria Química e Indústria de produtos de metal. O setor que apresentou a maior média foi o de lojas em geral. O setor que evidenciou 
medida menos dispersa foi o mesmo que apresentou a maior média para o COMPT, e o mesmo ocorre com o setor de indústria química que apresentou a maior dispersão e também a maior média. Para testar se as diferenças aparentes são significativas estatisticamente foi realizada a análise de variância. O teste de ANOVA permite concluir que existem diferenças estatisticamente significativas nos níveis de comparabilidade entre a mesma empresa conforme sua distribuição por setor de atividade econômica.

\subsubsection{Acurácia dos analistas}

As informações apresentadas na Tabela 5 evidenciam que as previsões dos analistas se distanciam do resultado real dos lucros reportados, com valores de média e desvio padrão diferentes. Essa constatação pode ser explicada pela variabilidade entre os valores de mínimos e máximos da variável ACURÁCIA.

Tabela 11 - Comparação das variáveis antes e após a adoção do IFRS

\begin{tabular}{|c|c|c|c|c|c|}
\hline \multicolumn{6}{|c|}{ PERÍODO ANTERIOR À ADOÇÃO OBRIGATÓRIA DO IFRS } \\
\hline VARIÁVEIS & $N$ & Média & Min & $\max$ & Desv.Pad. \\
\hline COMPM & 111 & -1.1569 & -3.50 & -0.01 & 0.86611 \\
\hline COMPT & 111 & -0.7326 & -3.31 & -0.01 & 0.72910 \\
\hline ACURÁCIA & 111 & -.07486 & -0.862 & 0.00 & 0.148081 \\
\hline PERDA & 111 & 0.06 & Não & Sim & 0.244 \\
\hline LNATIVO & 111 & 15.3897 & 12.15 & 18.58 & 1.37485 \\
\hline VP & 111 & 0.59 & Não & Sim & 0.493 \\
\hline РTB & 111 & 1.9306 & 0.00 & 6.87 & 1.37072 \\
\hline DVPESTIMAT & 111 & 1.2295 & 0.00 & 18.06 & 3.45478 \\
\hline DPROE & 111 & 0.0715 & 0.00 & 0.55 & 0.06758 \\
\hline QANALIST & 111 & 5.89 & 1 & 14 & 3.878 \\
\hline LNRISCO & 111 & 5.4652 & 5.26 & 5.74 & 0.20343 \\
\hline \multicolumn{6}{|c|}{ PERÍODO DE TRANSIÇÃO À ADOÇÃO OBRIGATÓRIA DO IFRS } \\
\hline VARIÁVEIS & $N$ & Média & Min & $\max$ & Desv.Pad. \\
\hline COMPM & 74 & -1.2238 & -5.00 & 0.00 & 1.08706 \\
\hline COMPT & 74 & -1.2790 & -8.03 & -0.01 & 1.58298 \\
\hline ACURÁCIA & 74 & -0.09867 & -0.921 & 0.00 & 0.205497 \\
\hline PERDA & 74 & 0.09 & Não & Sim & 0.295 \\
\hline LNATIVO & 74 & 15.62667 & 12.24 & 18.96 & 1.39416 \\
\hline VP & 74 & 0.55 & Não & Sim & 0.500 \\
\hline PTB & 74 & 1.7932 & 0.00 & 12.69 & 1.7539 \\
\hline DVPESTIMAT & 74 & 0.1521 & 0.00 & 5.68 & 0.68559 \\
\hline DPROE & 74 & 0.0968 & 0.01 & 1.13 & 0.15099 \\
\hline QANALIST & 74 & 7.28 & 1 & 16 & 4.934 \\
\hline LNRISCO & 74 & 5.6583 & 5.26 & 6.06 & 0.40355 \\
\hline
\end{tabular}


Continuidade Tabela 11 - Comparação das variáveis antes e após a adoção do IFRS

\begin{tabular}{c|ccccc}
\hline \multicolumn{5}{c}{ PERÍODO DE ADOÇÃO OBRIGATÓRIA DO IFRS } \\
\hline VARIÁVEIS & $\boldsymbol{N}$ & Média & Min & max & Desv.Pad. \\
\hline COMPM & 222 & -1.0302 & -6.45 & 0.00 & 0.90222 \\
COMPT & 222 & -0.7790 & -7.32 & 0.00 & 0.97991 \\
ACURÁCIA & 222 & -0.06499 & -0.853 & 0.00 & 0.127270 \\
PERDA & 222 & 0.18 & Não & Sim & 0.385 \\
LNATIVO & 222 & 15.9858 & 12.62 & 19.54 & 1.41154 \\
VP & 222 & 0.55 & Não & Sim & 0.500 \\
PTB & 222 & 1.6631 & -0.73 & 13.13 & 1.78171 \\
DVPESTIMAT & 222 & 0.1400 & 0.00 & 3.35 & 0.44812 \\
DPROE & 222 & 0.0821 & 0.00 & 1.16 & 0.13737 \\
QANALIST & 222 & 7.77 & 1 & 18 & 5.610 \\
LNRISCO & 222 & 5.4605 & 4.96 & 6.26 & 0.40254 \\
\hline
\end{tabular}

Ao comparar os períodos de adoção do IFRS, observa-se que em termos gerais, a média da variável ACURÁCIA se manteve estável nos períodos antes e após a adoção obrigatória do IFRS. Também se observou uma pequena redução da medida no período de transição, uma vez que quanto mais próximo de zero o resultado da ACURÁCIA maior a acurácia. Ressalta-se que esse comportamento também foi observado em relação ao desvio padrão da variável, que aumentou no período de transição e que, em termos gerais manteve-se nos períodos antes e após a adoção obrigatória do IFRS. Os resultados observados corroboram com os achados de Pessotti e Costa (2013) e Gatsio (2013).

A variáveis PERDA apresentaram um aumento significativos médio nos períodos investigados, esse fato pode indicar previsões menos acuradas pois empresas que evidenciam lucros tendem a ter previsões mais acuradas (Martinez, 2004; Dalmácio, 2009; Gatsios, 2013).

O desvio padrão do retorno (DPROE), em média, apresentou uma leve variação no período de transição à adoção das IFRS. O fato de a variável DPROE possuir valores médios menores nos períodos anteriores e de adoção obrigatória das IFRS pode estar associado com uma maior acurácia nas estimativas dos analistas de mercado (Lang \& Lundholm, 1996; Jiao, Koning, Meterns, \& Roosenboom, 2012).

A variável LNATIVO, apesar de evidenciar as características das diferentes empresas analisadas, não apresentou variação em termos médios durante o período investigado.

O price-to-book (PTB) apresentou leve variação média durante o período investigado. Como a média diminuiu ao longo do período, espera-se que esse fator possa influenciar negativamente 
a acurácia das previsões, pois a literatura evidencia que quanto maior o price-to-book, maior a acurácia (Martinez, 2004).

A variável QANALIST mostra que a quantidade de analistas aumentou no período de transição e no período de adoção obrigatória. Cumpre ressaltar que as pesquisas anteriores constataram que as previsões de consenso são mais acuradas, quanto maior for o número de analistas que participam na apuração do consenso (Martinez, 2004)

A variável LNRISCO evidencia a alta volatilidade no mercado. Em termos médios não houve variação significativa no período investigado, fato este que pode indicar que a crise financeira internacional não influenciou na acurácia.

A dispersão das estimativas (DVPESTIMAT) apresentou uma redução ao longo do período investigado. Há evidencias na literatura de que quanto maior a dispersão das estimativas, menor a acurácia (Conroy \& Harris, 1987; Martinez \& Salim, 2004; Martinez, 2004; Byard, Li , \& Weintrop, 2006), ou seja, há indícios de que as previsões sejam mais acuradas no período após a adoção das IFRS.

Com o intuito de verificar se as diferenças na acurácia são significativas, utilizou-se a metodologia estatística do teste de diferenças de médias.

Tabela 12 - Análise de diferença de médias variável ACURÁCIA

\begin{tabular}{l|r|r|r|r|r}
\multicolumn{1}{l}{ Análise de variância da ACURÁCIA no período anterior a adoção obrigatória do IFRS } \\
\hline & \multicolumn{1}{c|}{ SS } & DF & \multicolumn{1}{c}{ MS } & \multicolumn{1}{c}{ F } & \multicolumn{1}{c}{ Prob>F } \\
\hline Entre grupos & 0,000 & 1 & 0,000 & 0,008 & 0,931 \\
\hline Dentro dos grupos & 9,137 & 405 & 0,023 & & \\
\hline Total & 9,138 & 406 & & & \\
\hline
\end{tabular}

Análise de variância da ACURÁCIA no período de transição a adoção obrigatória do IFRS

\begin{tabular}{l|r|r|r|r|r}
\hline & SS & DF & \multicolumn{1}{c|}{ MS } & \multicolumn{1}{c}{ F } & \multicolumn{1}{c}{ Prob>F } \\
\hline Entre grupos & 0,056 & 1 & 0,056 & 2,493 & 0,115 \\
\hline Dentro dos grupos & 9,082 & 405 & 0,022 & & \\
\hline Total & 9,138 & 406 & & & \\
\hline
\end{tabular}

Análise de variância da ACURÁCIA no período de adoção obrigatória do IFRS

\begin{tabular}{l|r|r|r|r|r}
\hline & SS & DF & \multicolumn{1}{c|}{ MS } & \multicolumn{1}{c}{ F } & \multicolumn{1}{c}{ Prob $>$ F } \\
\hline Entre grupos & 0,038 & 1 & 0,038 & 1,689 & 0,194 \\
\hline Dentro dos grupos & 9,100 & 405 & 0,022 & & \\
\hline Total & 9,138 & 406 & & & \\
\hline
\end{tabular}


A partir dos resultados apresentados na Tabela 12 percebe-se que não há diferenças significativas entre os períodos, pois o $p$-value obtido com o teste de variância em todos os períodos foi muito maior do que o intervalo discriminante de 0,05 .

Ao analisa o teste ANOVA em relação a acurácia e os setores, constatou-se que há diferenças entre as médias da acurácia entre os setores analisados, no entanto, ao investigar a acurácia entre os anos em termos médio não há diferenças.

Após a análise descritiva das variáveis, apresentam-se na Tabela 13, os coeficientes de correlação. Por meio dos coeficientes de correlação de Pearson, pode-se observar o grau de associação entre as variáveis do modelo de acurácia das previsões do consenso de analistas. Tais valores representam uma referência preliminar das relações existentes entre as variáveis utilizadas na pesquisa.

A partir dos valores apresentados na Tabela 13, observa-se que a variável COMPT possuí correlação positiva, porém não significante com a variável ACURÁCIA, já as variáveis VP, DVPESTIMAT, SETOR e LNRISCO possuem correlações negativas, mas não significantes com ACURÁCIA. As variáveis COMPM, QANALIST, PTB e LNATIVO possuem correlações positivas e significantes, e as variáveis PERDA e DPROE possuem correlações negativas, mas significantes.

Em relação ao QANALIST essa observação indica que a quantidade de analistas se relaciona de maneira positiva com acurácia, como aponta Martinez (2004), de que quanto maior a quantidade de analistas, mais acuradas as previsões.

No que tange à variáveis IFRS: i) o período antes da adoção possui correlações positivas e significantes com PERDA, QANALIST, DVPESTIMAT e LNATIVO; ii) o período de transição apresenta correlações positivas e significantes com as variáveis COMPT e LNRISCO; e, iii) o período de adoção mostra correlações positivas e significantes com as variáveis PERDA, QANALIST, LNRISCO, DVESTIMAT e LNATIVO. 
O fato da variável QANALIST possuir correlação positiva e significante no período anterior e de adoção das IFRS, confirma a informação obtida pela análise estatística que mostra que a quantidade de analistas aumentou no período de transição e no período de adoção obrigatória. 
Tabela 13 - Correlação entre as variáveis do modelo de Acurácia

\begin{tabular}{|c|c|c|c|c|c|c|c|c|c|c|c|c|}
\hline 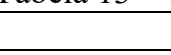 & & Acurácia & COMPM & COMPT & PERDAS & QANALIST & LNRISCO & DPROE & DESTIMAT & PTB & $\mathrm{VP}$ & LNATIVO \\
\hline Acurácia & \begin{tabular}{|l|} 
Pearson \\
Correlation \\
\end{tabular} & 1 & & & & & & & & & & \\
\hline COMPM & \begin{tabular}{|l|} 
Pearson \\
Correlation
\end{tabular} &, $129^{* *}$ & 1 & & & & & & & & & \\
\hline COMPT & \begin{tabular}{|l|} 
Pearson \\
Correlation
\end{tabular} &, 037 &, $185^{* *}$ & 1 & & & & & & & & \\
\hline PERDAS & \begin{tabular}{|l|} 
Pearson \\
Correlation \\
\end{tabular} &,$- 157^{* *}$ &,$- 161^{* *}$ &, $267^{* *}$ & 1 & & & & & & & \\
\hline QANALIST & \begin{tabular}{|l|} 
Pearson \\
Correlation \\
\end{tabular} &, $332^{* *}$ &,- 030 &,$- 136^{* *}$ &,$- 117^{* *}$ & 1 & & & & & & \\
\hline LNRISCO & \begin{tabular}{|l|} 
Pearson \\
Correlation
\end{tabular} &,- 006 &,- 012 &,- 075 &, $131^{* *}$ &,$- 178^{* *}$ & 1 & & & & & \\
\hline DPROE & \begin{tabular}{|l|} 
Pearson \\
Correlation
\end{tabular} &,$- 222^{* *}$ &,$- 104^{*}$ &,$- 268^{* *}$ & , 188** &,$- 106^{*}$ & ,024 & 1 & & & & \\
\hline DESTIMAT & \begin{tabular}{|l|} 
Pearson \\
Correlation
\end{tabular} &,- 036 & ,003 &,- 058 & ,062 &,- 073 &, 005 & ,045 & 1 & & & \\
\hline РTB & \begin{tabular}{|l|} 
Pearson \\
Correlation \\
\end{tabular} &, $157^{* *}$ & ,058 &, $184^{* *}$ &,$- 216^{* *}$ &, $227^{* *}$ &,- 070 &,- 020 &,$- 105^{*}$ & 1 & & \\
\hline VP & \begin{tabular}{|l|} 
Pearson \\
Correlation
\end{tabular} &,- 054 & ,003 &,- 089 &, $182^{* *}$ &,- 009 & ,011 &,- 011 &, $122^{*}$ &,$- 104^{*}$ & 1 & \\
\hline LNATIVO & $\begin{array}{l}\text { Pearson } \\
\text { Correlation } \\
\end{array}$ & ,289** &,- 047 & ,073 & ,050 &, $499^{* *}$ & ,022 &,- 057 &,- 001 &,- 025 &, 015 & 1 \\
\hline
\end{tabular}

Obs: * / **/ denotam significância bi-caudal nos níves 0,05 / 0,01 respectivamente. 


\subsubsection{Informatividade}

Nas informações apresentadas na Tabela 14 observa-se, por meio da medida (RA), um distanciamento entre o retorno anormal e o retorno de mercados das ações. Essa constatação pode ser verificada pela variabilidade em torno da média para a variável RA. Dentre as variáveis analisadas, a que apresenta pouca variabilidade em torno da média é o Market-tobook (MTB). A seguir apresenta-se as diferenças de média da variável RA ao longo do período investigado.

Tabela 14 - Diferenças na RA ao longo do período investigado

\begin{tabular}{lrrr} 
Ano & \multicolumn{1}{c}{ Média } & Desv. Padrão & Mediana \\
\hline 2005 & 10,9958 & 41,10431 &,- 2526 \\
\hline 2006 &, 5232 & 3,67811 &,- 0744 \\
\hline 2007 & 46,1572 & 121,40083 &, 0000 \\
\hline 2008 & 4,7235 & 28,71705 &,- 0870 \\
\hline 2009 &,- 1846 &, 54947 &,- 1310 \\
\hline 2010 &,- 0805 &, 29075 &,- 0246 \\
\hline 2011 &, 0810 &, 30642 &, 0500 \\
\hline 2012 &, 0716 &, 44857 &, 0392 \\
\hline 2013 &, 0641 &, 30414 &, 0861 \\
\hline 2014 &,- 1242 &, 41151 &,- 1103 \\
\hline 2015 &, 9973 & 1,50082 &, 7248 \\
\hline Total & 5,7477 & 41,29730 &, 0000 \\
\hline
\end{tabular}

A partir da 14 é possível observar que, em termos médios, o RA variou consideravelmente durante o período investigando. Com o intuito de verificar se as diferenças no retorno anormal são significativas, utilizou-se a metodologia estatística do teste de diferenças de médias, conforme apresentado abaixo

Tabela 15 - Análise de diferença de media variável RA

\begin{tabular}{l|r|r|r|r|r}
\hline Análise de variância & \multicolumn{1}{c|}{ SS } & DF & MS & F & Prob $>$ F \\
\hline Entre grupos & 70731,243 & 10 & 7073,124 & 4,505 &, 000 \\
\hline Dentro dos grupos & 621688,293 & 396 & 1569,92 & & \\
\hline Total & 692419,536 & 406 & & & \\
\hline
\end{tabular}

Os resultados da Tabela 15 indicam que existem diferenças significativas nos anos avaliados, ou seja, as diferenças médias no RA durante o período investigado são estatisticamente significativas. 
A partir da correlação entre as variáveis, na Tabela 16, observa-se que a variável IFRSANT, IFRSPOS e o setor de lojas em geral possuem correlações positivas e significantes com a variável RA.

As variáveis PERDA, IFRSPOS e os setores de energia, gás e água, equipamento de transporte, papel e celulose; calçados; tecidos e vestuário; e lojas em geral apresentam correlações positivas e significantes com a variável COMPM. Já a variável COMPT possuí correlação positivas, e significantes com a TAM, MTB, PERDA, IFRSTRANS e os setores de indústria de produção de metais e químicos.

Em relação ao END, o mesmo possui correlações positivas e significantes com PERDA, IFRSANT, IFRSPOS e os setores de energia, gás e água, indústria química; papel e celulose; calçados; tecidos e vestuário; e lojas em geral.

A variável PERDA apresenta correlações positivas e significantes com MTB, IFRSANT, IFRSPOS e com os setores de energia, gás e água; indústria de produtos de metais; papel e celulose; calçados; tecidos e vestuários; e lojas em geral. 
Tabela 16 - Analise correlação entre as variáveis da informatividade

\begin{tabular}{|c|c|c|c|c|c|c|c|c|c|c|c|c|c|c|c|c|c|c|c|c|}
\hline & RA & $\begin{array}{l}\underset{\mathrm{M}}{\mathrm{COMP}} \\
\mathrm{M}\end{array}$ & $\begin{array}{c}\text { COMP } \\
\mathrm{T}\end{array}$ & TAM & \begin{tabular}{|l|l|} 
END \\
\end{tabular} & MTB & $\begin{array}{c}\text { PERD } \\
\text { A }\end{array}$ & \begin{tabular}{|c|} 
IFRSAN \\
$\mathrm{T}$
\end{tabular} & \begin{tabular}{|c|} 
IFRSTRA \\
NS
\end{tabular} & $\begin{array}{c}\text { IFRSPO } \\
\mathrm{S}\end{array}$ & $\begin{array}{l}\text { Energi } \\
\text { a, gás } \\
\mathrm{e} \text { água }\end{array}$ & $\begin{array}{c}\text { Siderurg } \\
\text { ia }\end{array}$ & \begin{tabular}{|c|} 
Ind. \\
Prod \\
$\dot{\text { Met }}$ \\
al
\end{tabular} & $\begin{array}{c}\text { Telecomunicą̧ } \\
\text { ões }\end{array}$ & $\begin{array}{c}\text { Equi. } \\
\text { Transpor } \\
\text { te }\end{array}$ & \begin{tabular}{|c|} 
Ind. \\
Quími \\
ca
\end{tabular} & \begin{tabular}{|c} 
Papel e \\
Celulo \\
se
\end{tabular} & $\begin{array}{l}\text { Calçad } \\
\text { os }\end{array}$ & $\begin{array}{c}\text { Tec. e } \\
\text { Vestuár } \\
\text { io }\end{array}$ & \begin{tabular}{|c} 
Loja \\
s \\
gera \\
1
\end{tabular} \\
\hline RA & 1 & & & & & & & & & & & & & & & & & & & \\
\hline COMPM &, 030 & 1 & & & & & & & & & & & & & & & & & & \\
\hline COMPT &, 071 &, $185^{* *}$ & 1 & & & & & & & & & & & & & & & & & \\
\hline TAM &, 036 &,- 020 &, $155^{* *}$ & 1 & & & & & & & & & & & & & & & & \\
\hline END &, 049 &, $179^{* *}$ &,- 021 &, 078 & 1 & & & & & & & & & & & & & & & \\
\hline MTB &, 037 & ,020 &, $172^{* *}$ & 274 & ,272 & 1 & & & & & & & & & & & & & & \\
\hline PERDA &, 046 &,$- 161^{* *}$ &, $267^{* *}$ & 284 &, 136 & , 204 & 1 & & & & & & & & & & & & & \\
\hline IFRSANT &, 200 &,- 038 & ,071 & 003 & , 090 & 088 &, $126^{* *}$ & 1 & & & & & & & & & & & & \\
\hline IFRSTRANS &, 040 &,- 063 &, $185^{* *}$ & 006 & , 014 &, 022 &,- 053 &,$- 289^{* *}$ & 1 & & & & & & & & & & & \\
\hline IFRSPOS &, 148 &, $082^{*}$ & , 080 & ,001 & , 091 & ,062 &, $153^{* *}$ &,$- 671^{* *} \mid$ &,$- 516^{* *}$ & 1 & & & & & & & & & & \\
\hline $\begin{array}{l}\text { Energia, gás e } \\
\text { água }\end{array}$ & 049 &,$- 292^{* *}$ & ,029 & 095 & \begin{tabular}{|l|}
, 179 \\
$* *$
\end{tabular} & , 097 &,$- 111^{*}$ & , 000 & , 000 & ,000 & 1 & & & & & & & & & \\
\hline Siderurgia &, 051 &, 077 &,- 027 & $\begin{array}{r}225 \\
* *\end{array}$ & ,040 & 032 &,- 015 &, 000 &, 000 & ,000 &, $343^{* *}$ & 1 & & & & & & & & \\
\hline $\begin{array}{l}\text { Ind. Prod. } \\
\text { Metal }\end{array}$ &, 032 & ,067 &,$- 108^{*}$ &, 581 & , 024 & , 104 &, $195^{* *}$ & , 000 & , 000 & , 000 &, $187^{* *}$ &,$- 105^{*}$ & 1 & & & & & & & \\
\hline $\begin{array}{l}\text { Telecomunicaç } \\
\text { ões }\end{array}$ &, 041 &,- 005 & ,036 & $\begin{array}{l}, 189 \\
* * *\end{array}$ & \begin{tabular}{|l|l|}
, 054 \\
\end{tabular} & 044 & ,016 & , 000 & , & ,000 &, $232^{* *}$ &,$- 131^{* *}$ & ,071 & 1 & & & & & & \\
\hline $\begin{array}{l}\text { Equi. } \\
\text { Transporte }\end{array}$ &, 033 & , $114^{*}$ & ,068 &, 113 & , 041 & ,068 &,- 061 & , & , 000 & ,000 &, $187^{* *}$ &,$- 105^{*}$ & ,057 &,- 071 & 1 & & & & & \\
\hline Ind. Química &, 005 &,- 051 &, $207^{* *}$ & 071 & ,244 & 026 & ,072 &, 007 & ,005 &,- 010 &, $182^{* *}$ &,$- 103^{*}$ &, 056 &,- 069 &,- 056 & 1 & & & & \\
\hline $\begin{array}{l}\text { Papel e } \\
\text { Celulose }\end{array}$ &, 031 & , $188^{* *}$ &,- 012 & ,039 & ,214 & , 017 &, $124^{* *}$ &,- 007 &,- 005 & ,010 &, $191^{* *}$ &,$- 108^{*}$ &, 059 &,- 073 &,- 059 &,- 057 & 1 & & & \\
\hline
\end{tabular}




\begin{tabular}{|c|c|c|c|c|c|c|c|c|c|c|c|c|c|c|c|c|c|c|c|c|}
\hline Calçados &, 020 &, $135^{* *}$ & , 030 & 057 & ,135 &, 071 &,$- 093^{*}$ &, 000 &, 000 &, 000 &, $187^{* *}$ &,$- 105^{*}$ &, 057 &,- 071 &,- 057 &,- 056 &,- 059 & 1 & & \\
\hline $\begin{array}{l}\text { Tec. e } \\
\text { Vestuário }\end{array}$ &, 023 & $-183^{* *}$ & ,040 &, 136 & , 102 &, 189 &, $099^{*}$ & ,000 & ,000 & ,000 &, $187^{* *}$ &,$- 105^{*}$ &, 057 &,- 071 &,- 057 &,- 056 &,- 059 &,- 057 & 1 & \\
\hline Lojas geral &, 121 & ,232** &, $123^{* *}$ & ,118 & ,276 & , 132 &,$- 093^{*}$ &, 000 &, 000 &, 000 &, $187^{-*}$ &,$- 105^{*}$ & 057 &,- 071 &,- 057 &,- 056 &,- 059 &,- 057 &,- 057 & 1 \\
\hline
\end{tabular}

Obs: * / ** / denotam significância bi-caudal nos níves 0,05 / 0,01 respectivamente. 


\subsection{Modelo de Acurácia dos Analistas}

Este modelo tem por objetivo analisar se o aumento da comparabilidade dos demonstrativos financeiros está associado a um aumento na acurácia das estimativas de consenso dos analistas de mercado após a adoção das normas internacionais de contabilidade. Para tanto o primeiro modelo a ser investigado é o da comparabilidade individual média das empresas do mesmo setor de atividade econômica.

$$
\text { Acuráci }_{i, t}=\alpha_{i}+\beta_{1} \text { COMPM }_{i t}+\beta_{2} \text { DSETOR }_{i t}+\beta_{3} \text { IFRS }_{i t}+\Upsilon \text { Controle }_{i t}+\varepsilon_{i t+1}
$$

O segundo modelo a ser investigado é o da comparabilidade intertemporal, ou seja, a comparabilidade da mesma empresa ao longo do tempo.

$$
\begin{aligned}
& \text { Acurácia }_{i, t} \\
& =\alpha_{i}+\beta_{1} \text { COMPT }_{i t}+\beta_{2} \text { DSETOR }_{i t}+\beta_{3} \text { IFRS }_{i t} \\
& +\Upsilon \text { Controle }_{i t}+\varepsilon_{i t+1}
\end{aligned}
$$

Estimando a equação 16 pela abordagem pooled, realizou-se o teste de Breusch-Pagan para heterocedasticidade, rejeitando fortemente a hipótese de homogeneidade dos resíduos $\left(\chi^{2}=436,04 ; p\right.$-valor $\left.<0,000\right)$, indicando dessa forma, que os modelos deverão ser estimados considerando erros-padrão robustos quanto à heterocedasticidade.

O Teste RESET de Ramsey indicou a rejeição de que o modelo esteja bem especificado $(F=5,39 ; \mathrm{p}$-valor $<0,01)$. O VIF médio das variáveis do modelo foi de 1,44 , sendo que nenhuma passou de 3 , bem abaixo do valor 10 recomendado.

A estimativa da equação 17 por POLS resultou nos mesmos achados da equação 16 quanto à verificação das hipóteses do modelo: i) Teste Breusch-Pagan para heterocedasticidade significativo $\left(\chi^{2}=386,93\right.$; $\mathrm{p}$-valor $\left.<0,000\right)$; ii) Teste RESET de Ramsey significativo $(F=8,47$; p-valor $<0,000$ ); e iii) VIF médio igual a 1,42 . 
Executando as estimativas das equações acima por POLS com o procedimento descrito na seção 3.4 para a exclusão dos outliers multivariados, obtiveram-se os mesmos resultados quanto às hipóteses dos modelos, qual seja: deve-se utilizar os modelos com erros robustos quanto à heterocedasticidade e preferir os modelos de efeitos fixos devido aos problemas de especificação.

$\underline{\text { Tabela } 17 \text { - Teste para efeitos aleatórios, fixos e modelo pooled (modelos Acurácia) }}$

\begin{tabular}{|c|c|c|c|c|c|}
\hline & Modelo & $\begin{array}{l}\text { Teste Breusch- } \\
\text { Pagan LM }\left(\chi^{2}\right)\end{array}$ & $\begin{array}{c}\text { Teste de } \\
\text { Hausman }\left(\chi^{2}\right) \\
\end{array}$ & $\begin{array}{c}\text { Teste de } \\
\text { Chow }\left(\chi^{2}\right) \\
\end{array}$ & Conclusão \\
\hline \multirow[t]{4}{*}{ Acurácia } & Com outliers e COMPM & $52,17 * * *$ & 9,26 & $121,41 * * *$ & RE \\
\hline & Com outliers e COMPT & $52,08 * * *$ & 11,55 & $124,64 * * *$ & RE \\
\hline & Sem outliers e COMPM & $7,85 * * *$ & 13,51 & $81,89 * * *$ & RE \\
\hline & Sem outliers e COMPT & $12,58 * * *$ & $17,91 *$ & $90,09 * * *$ & RE \\
\hline
\end{tabular}

Nota: $* * *$ p-valor $<0,01 ; * *$ p-valor $<0,05 ; *$ p-valor $<0,10$. O Teste Breusch Pagan LM examina $\mathrm{H}_{0}$ : POLS

contra $\mathrm{H}_{1}$ : RE; O Teste de Hausman examina $\mathrm{H}_{0}$ : $\mathrm{RE}$ contra $\mathrm{H}_{1}$ : FE; O Teste de Chow examina $\mathrm{H}_{0}$ : POLS

A Tabela 17, com os testes para efeitos aleatórios, fixos e o modelo POLS com adição da Tabela 18, com os critérios de informação possibilitam decidir qual modelo deve ser considerando para avaliar a Hipótese $\mathrm{H} 1$ desta pesquisa.

Tabela 18 -Critérios de informação para os modelos com efeitos fixos e pooled

\begin{tabular}{l|cccc}
\hline \multicolumn{2}{c}{ Modelo } & Estimador & AIC & BIC \\
\hline Acurácia & Com outliers e & POLS & $-476,604$ & $-392,418$ \\
& COMPM & EF & $-614,643$ & $-570,546$ \\
& Com outliers e & POLS & $-469,069$ & $-384,884$ \\
& COMPT & EF & $-610,869$ & $-566,772$ \\
& Sem outliers e & POLS & $-927,054$ & $-843,982$ \\
& COMPM & EF & $-1000,000$ & $-982,080$ \\
& Sem outliers e & POLS & $-913,406$ & $-830,279$ \\
& COMPT & EF & $-1000,000$ & $-975,400$ \\
\hline
\end{tabular}

$\overline{\mathrm{AIC}}=$ Critérios de informação de Akaike; $\mathrm{BIC}=$ Critério de informação bayesiano. Quanto menor melhor o modelo, no entanto, comparáveis em modelos aninhados e com mesmo tamanho amostral.

Para análise da acurácia o modelo que apresentou uma melhor performance foi o de efeitos aleatórios (RE).

Tabela 19 - Resultado do modelo de COMPM

\begin{tabular}{l|c|c|c}
\hline & $\begin{array}{c}\text { POLS } \\
\text { ACURACIA }\end{array}$ & $\begin{array}{c}\text { Efeito Aleatório_ } \\
\text { ACURACIA }\end{array}$ & $\begin{array}{c}\text { Efeito fixo } \\
\text { ACURACIA }\end{array}$ \\
\hline \multirow{2}{*}{ COMPM } & $0.004^{*}$ & $0.001^{*}$ & -0.001 \\
& $(0.00587)$ & $(0.00449)$ & $(0.00480)$ \\
& -0.0218 & -0.0177 & \\
& $(0.0227)$ & $(0.0344)$ &
\end{tabular}




\begin{tabular}{|c|c|c|c|}
\hline 3.Prod. Metal & $\begin{array}{c}-0.120 \\
(0.0744)\end{array}$ & $\begin{array}{l}-0.146 \\
(0.172)\end{array}$ & \\
\hline \multirow[t]{2}{*}{ 4.Telecomunicações } & 0.0114 & 0.0148 & \\
\hline & $(0.0143)$ & $(0.0191)$ & \\
\hline \multirow[t]{2}{*}{ 5.Equi. Transporte } & $0.0415^{*}$ & $0.035 * *$ & \\
\hline & $(0.0211)$ & $(0.0296)$ & \\
\hline \multirow[t]{2}{*}{ 6.Ind. Química } & 0.0138 & 0.00894 & \\
\hline & $(0.0237)$ & $(0.0171)$ & \\
\hline \multirow[t]{2}{*}{ 7.Papel e celuloce } & -0.0150 & -0.0100 & \\
\hline & $(0.0206)$ & $(0.0164)$ & \\
\hline \multirow[t]{2}{*}{ 8.Calçados } & -0.0228 & -0.0282 & \\
\hline & $(0.0429)$ & $(0.0324)$ & \\
\hline \multirow[t]{2}{*}{ 9.Tecidos e Vestuário } & $-0.131 * *$ & -0.131 & \\
\hline & $(0.0576)$ & $(0.0973)$ & \\
\hline \multirow[t]{2}{*}{ 10.Lojas geral } & -0.0182 & -0.00287 & \\
\hline & $(0.0188)$ & $(0.0220)$ & \\
\hline \multirow[t]{2}{*}{ 2.IFRSTRANS } & -0.0303 & -0.0290 & -0.0230 \\
\hline & $(0.0255)$ & $(0.0237)$ & $(0.0227)$ \\
\hline \multirow[t]{2}{*}{ 3.IFRSPOS } & -0.000530 & -0.000549 & 0.0127 \\
\hline & $(0.0159)$ & $(0.0151)$ & $(0.0280)$ \\
\hline \multirow[t]{2}{*}{ QANALIST } & $0.00542 * * *$ & $0.00467 * *$ & $0.00418 *$ \\
\hline & $(0.00139)$ & $(0.00193)$ & $(0.00207)$ \\
\hline \multirow[t]{2}{*}{ LNATIVO } & 0.0103 & 0.00559 & -0.0163 \\
\hline & (0.00989) & $(0.0174)$ & $(0.0384)$ \\
\hline \multirow[t]{2}{*}{ PTB } & $0.00848 * *$ & 0.00231 & -0.000329 \\
\hline & $(0.00394)$ & $(0.00419)$ & $(0.00342)$ \\
\hline \multirow[t]{2}{*}{ PERDA } & 0.00178 & 0.0149 & 0.0191 \\
\hline & $(0.0301)$ & $(0.0368)$ & $(0.0372)$ \\
\hline \multirow[t]{2}{*}{ VP } & -0.00144 & $-0.021 * *$ & -0.0121 \\
\hline & $(0.0144)$ & $(0.0235)$ & $(0.0231)$ \\
\hline \multirow[t]{2}{*}{ DVPESTIMAT } & 0.000631 & 0.000325 & 0.000892 \\
\hline & $(0.00264)$ & $(0.00232)$ & $(0.00241)$ \\
\hline \multirow[t]{2}{*}{ DPROE } & $-0.222 *$ & $-0.224 * *$ & $-0.230 * *$ \\
\hline & $(0.118)$ & $(0.0904)$ & $(0.0966)$ \\
\hline \multirow[t]{2}{*}{ LNRISCO } & 0.0201 & 0.0149 & 0.0150 \\
\hline & $(0.0207)$ & $(0.0218)$ & $(0.0224)$ \\
\hline \multirow[t]{2}{*}{ Constant } & $-0.359 * *$ & -0.237 & 0.0905 \\
\hline & $(0.171)$ & $(0.213)$ & $(0.536)$ \\
\hline Observations & 407 & 407 & 407 \\
\hline R-squared & 0.271 & & 0.089 \\
\hline r2_a & 0.233 & 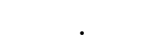 & 0.0632 \\
\hline $\mathrm{r} 2-\mathrm{w}$ & . & 0.0849 & 0.0886 \\
\hline $\mathrm{r} 2-\mathrm{b}$ & . & 0.531 & 0.0284 \\
\hline r2_- o & . & 0.263 & 0.0576 \\
\hline $\mathrm{F}$ & 3.192 & 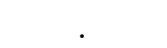 & 5.328 \\
\hline chi2 & 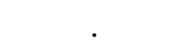 & 116.6 & . \\
\hline $\mathrm{P}$ & $6.09 \mathrm{e}-06$ & 0 & $6.03 e-05$ \\
\hline Number of EMPRESA & & 37 & 37 \\
\hline
\end{tabular}

Robust standard errors in parentheses

$* * * \mathrm{p}<0.01, * * \mathrm{p}<0.05, * \mathrm{p}<0.1$

Ao analisar a influência das variáveis na acurácia das previsões de consenso dos analistas de investimento no mercado brasileiro observou-se: 
- uma relação positiva e estatisticamente significante (10\%) entre a variável ACURÁCIA e a variável COMPM. Corroborando com as evidencias encontradas por De Franco, Kothari e Verdi (2011). O resultado indica que a melhoria na comparabilidade possibilita aos analistas entenderem melhor os eventos econômicos as partir das informações contábeis.

- variável quantidade de analistas (QANALIST) apresentou valor positivo e significante (5\%), corroborando com as evidencias já encontradas de que quanto maior o número de analistas que acompanham a empresa, maior a acurácia do consenso Conroy e Harris (1987); Brown (1997); Martinez e Salim (2004); Martinez (2004); Dalmácio (2009).

- a variável viés de previsão evidenciou valor negativo e significante (5\%), indicando que as previsões otimistas foram menos acuradas. Esse resultado corrobora com achados de Dalmácio (2009), entretanto, evidências contrárias foram encontradas por Martinez e Salim (2004); e Martinez (2004).

- a variação dos resultados das empresas (DPROE) apresentou resultado negativo e significante (5\%), esta observação apresenta evidências contrárias aos achados de Gatsio (2013) e Jiao, Koning, Meterns e Roosenboom (2012), indicando que o erro de previsão dos analistas é maior quando a volatilidade dos resultados é alta.

- o setor de equipamento de transporte evidenciou resultado positivo e significante $(5 \%)$ corroborando com os achados de Martinez (2004), evidenciando que o consenso dos analistas é pouco acurado.

- As demais variáveis não foram estatisticamente significantes

O segundo modelo a ser investigado é o da comparabilidade intertemporal, ou seja, a comparabilidade da mesma empresa ao longo do tempo.

Tabela 20 - Resultado do modelo de COMPT

\begin{tabular}{l|c|c|c}
\hline VARIAVEIS & $\begin{array}{c}\text { POLS } \\
\text { ACURACIA }\end{array}$ & $\begin{array}{c}\text { Efeito Aleatório } \\
\text { ACURACIA }\end{array}$ & $\begin{array}{c}\text { Efeito fixo } \\
\text { ACURACIA }\end{array}$ \\
\hline \multirow{2}{*}{ COMPT } & -0.00560 & $-0.00698^{*}$ & $-0.00718^{*}$ \\
& $(0.00518)$ & $(0.00373)$ & $(0.00382)$ \\
2.Siderurgia & -0.0132 & -0.00948 & \\
3.Prod. Metal & $(0.0224)$ & $(0.0366)$ & \\
& -0.119 & -0.146 &
\end{tabular}




\begin{tabular}{|c|c|c|c|}
\hline \multirow{3}{*}{ 4.Telecomunicações } & $(0.0735)$ & $(0.164)$ & \\
\hline & 0.0175 & 0.0198 & \\
\hline & $(0.0145)$ & $(0.0208)$ & \\
\hline \multirow[t]{2}{*}{ 5.Equi. Transporte } & 0.0321 & 0.0306 & \\
\hline & $(0.0201)$ & $(0.0278)$ & \\
\hline \multirow[t]{2}{*}{ 6.Ind. Química } & 0.0259 & 0.0184 & \\
\hline & $(0.0226)$ & $(0.0185)$ & \\
\hline \multirow[t]{2}{*}{ 7.Papel e celulose } & -0.0150 & -0.00977 & \\
\hline & $(0.0209)$ & $(0.0187)$ & \\
\hline \multirow[t]{2}{*}{ 8.Calçados } & -0.0301 & -0.0348 & \\
\hline & $(0.0434)$ & $(0.0353)$ & \\
\hline \multirow[t]{2}{*}{ 9.Tecidos e Vestuário } & $-0.143 * *$ & -0.140 & \\
\hline & $(0.0585)$ & $(0.108)$ & \\
\hline \multirow[t]{2}{*}{ 10.Lojas geral } & -0.0277 & -0.00671 & \\
\hline & $(0.0196)$ & $(0.0227)$ & \\
\hline \multirow[t]{2}{*}{ 2.IFRSTRANS } & -0.0293 & -0.0269 & -0.0210 \\
\hline & $(0.0258)$ & $(0.0241)$ & $(0.0230)$ \\
\hline \multirow[t]{2}{*}{ 3.IFRSPOS } & 0.00464 & 0.00449 & 0.0154 \\
\hline & $(0.0166)$ & $(0.0148)$ & $(0.0273)$ \\
\hline \multirow[t]{2}{*}{ QANALIST } & $0.00663 * * *$ & $0.00530 * *$ & $0.00431 *$ \\
\hline & $(0.00140)$ & $(0.00206)$ & $(0.00222)$ \\
\hline \multirow[t]{2}{*}{ LNATIVO } & 0.00391 & 0.000919 & -0.0162 \\
\hline & $(0.00924)$ & $(0.0171)$ & $(0.0374)$ \\
\hline \multirow[t]{2}{*}{ PTB } & $0.0118 * * *$ & 0.00428 & 0.000587 \\
\hline & $(0.00434)$ & $(0.00503)$ & $(0.00363)$ \\
\hline \multirow[t]{2}{*}{ PERDA } & -0.00522 & 0.0143 & 0.0210 \\
\hline & $(0.0298)$ & $(0.0381)$ & $(0.0381)$ \\
\hline \multirow[t]{2}{*}{ VP } & -0.00153 & -0.00916 & -0.0101 \\
\hline & $(0.0152)$ & $(0.0238)$ & $(0.0235)$ \\
\hline \multirow[t]{2}{*}{ DVPESTIMAT } & 0.000300 & 0.000122 & 0.000642 \\
\hline & $(0.00273)$ & $(0.00245)$ & $(0.00250)$ \\
\hline \multirow[t]{2}{*}{ DPROE } & $-0.254 * *$ & $-0.255^{* * *}$ & $-0.258 * *$ \\
\hline & $(0.120)$ & $(0.0953)$ & $(0.0999)$ \\
\hline \multirow[t]{2}{*}{ LNRISCO } & 0.0290 & 0.0211 & 0.0186 \\
\hline & $(0.0212)$ & $(0.0212)$ & $(0.0215)$ \\
\hline \multirow[t]{2}{*}{ Constant } & $-0.322 *$ & -0.208 & 0.0662 \\
\hline & $(0.170)$ & $(0.214)$ & $(0.530)$ \\
\hline Observations & 407 & 407 & 407 \\
\hline R-squared & 0.257 & & 0.080 \\
\hline r2_a & 0.219 & . & 0.0545 \\
\hline $\mathrm{r} 2_{-}^{-} \mathrm{w}$ & . & 0.0760 & 0.0801 \\
\hline $\mathrm{r} 2-\mathrm{b}$ & . & 0.502 & 0.0118 \\
\hline r2_o & . & 0.245 & 0.0457 \\
\hline $\mathrm{F}$ & 2.901 & . & 4.341 \\
\hline $\operatorname{chi} 2$ & . & 87.10 & . \\
\hline $\mathrm{P}$ & $3.70 \mathrm{e}-05$ & $2.37 \mathrm{e}-10$ & 0.000386 \\
\hline Number of EMPRESA & & 37 & 37 \\
\hline
\end{tabular}

Robust standard errors in parentheses

$* * * \mathrm{p}<0.01, * * \mathrm{p}<0.05, * \mathrm{p}<0.1$

- uma relação positiva e estatisticamente significante (10\%) entre a variável ACURÁCIA e a variável COMPT. Corroborando com as evidencias encontradas por De Franco, Kothari e Verdi (2011). O resultado indica que a melhoria na comparabilidade possibilita aos analistas entender melhor os eventos econômicos as partir das informações contábeis.

- variável quantidade de analistas (QANALIST) apresentou valor positivo e significante (5\%), corroborando com as evidências já encontradas de que quanto maior o número de analistas que 
acompanham a empresa, maior a acurácia do consenso Conroy e Harris (1987); Brown (1997); Martinez e Salim (2004); Martinez (2004); e Dalmácio (2009).

- a variação dos resultados das empresas (DPROE) apresentou resultado negativo e significante (5\%). Esta observação apresenta evidências contrárias aos achados de Gatsio (2013) e Jiao, Koning, Meterns e Roosenboom (2012), indicando que o erro de previsão dos analistas é maior quando a volatilidade dos resultados é alta.

- As demais variáveis não foram estatisticamente significantes

A partir dos resultados apresentados para o Modelo COMPM e COMPT, pode-se inferir que a comparabilidade influenciou positivamente a ACURÁCIA das estimativas de consenso dos analistas de mercado. Nesse contexto aceita-se a Hipótese H1 desta pesquisa.

\subsection{Modelo de informatividade}

Estes modelos têm por objetivo investigar a influência da comparabilidade em relação à informatividade. Assim, o primeiro modelo a ser investigado é o da comparabilidade média individual das empresas do mesmo setor de atividade econômica.

$$
R A_{i, t}=\alpha_{0}+\beta_{1} . \operatorname{COMPM}_{i t}+\sum_{j}^{K} \varpi_{j} . \operatorname{COMPM}_{i t} . V C_{i t}+\varepsilon_{i t}
$$

O segundo modelo a ser investigado é o da comparabilidade intertemporal, ou seja, a comparabilidade da mesma empresa ao longo do tempo.

$$
R A_{i, t}=\alpha_{0}+\beta_{1} \cdot \operatorname{COMPT}_{i t}+\sum_{j}^{K} \varpi_{j} . \mathrm{COMPT}_{i t} . V C_{i t}+\varepsilon_{i t}
$$

Estimando a equação 18, pela abordagem pooled realizou-se o teste de Breusch-Pagan para heterocedasticidade, rejeitando hipótese de homogeneidade dos resíduos $\left(\chi^{2}=1,88\right.$; pvalor $<0,1705$ ), indicando dessa forma, que os modelos deverão ser estimados considerando erros-padrão robustos quanto à heterocedasticidade. 


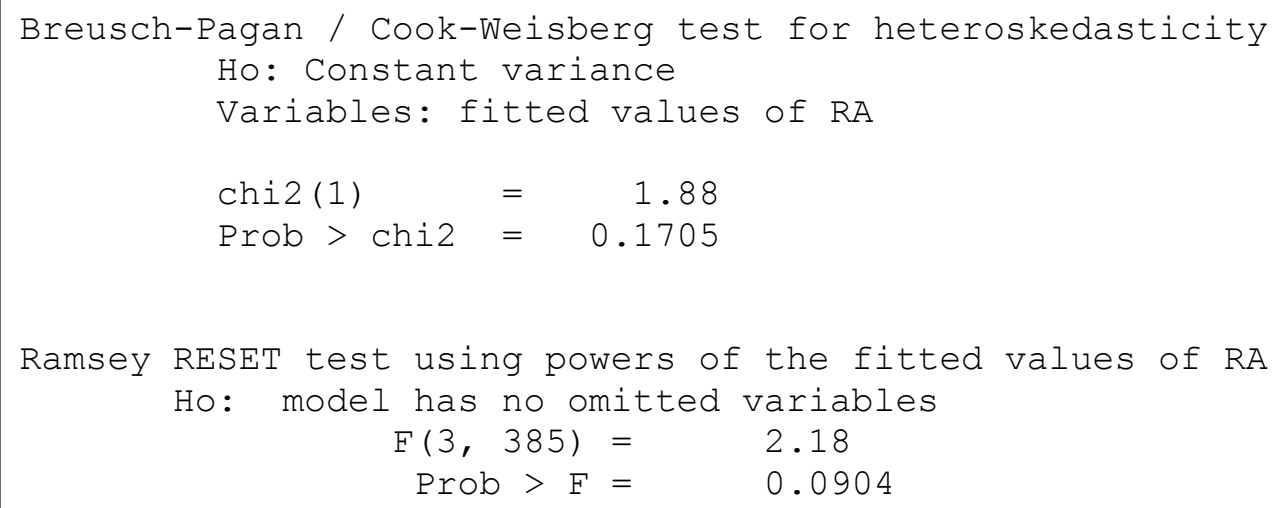

Figura 7 - Teste Breusch-Pagan e RESET modelo informatividade

O Teste RESET de Ramsey indicou a rejeição de que o modelo esteja bem especificado $(F=2,18$; p-valor $<0,0904)$.

A estimativa da equação 19 por POLS, resultou nos mesmos achados da equação 18 , quanto à verificação das hipóteses do modelo: i) Teste Breusch-Pagan para heterocedasticidade significativo $\left(\chi^{2}=386,93\right.$; $p$-valor $\left.<0,000\right)$; e ii)teste $\operatorname{RESET}$ de Ramsey significativo $(F=8,47$; p-valor $<0,000)$.

Para este modelo, todas as estimativas das equações supracitadas foram testadas conforme procedimento apresentado na seção 3.4 (os testes estão no apêndice). Para a exclusão dos outliers multivariados obteve-se os mesmos resultados quanto às hipóteses dos modelos, quais sejam: deve-se utilizar os modelos com erros robustos quanto à heterocedasticidade e preferir os modelos de efeitos fixos devido aos problemas de especificação.

Para os modelos da informatividade o estimador de efeitos fixos (FE) mostrou-se como de melhor performance.

Para estes modelos de informatividade, espera-se que o coeficiente de interesse $\beta_{1}$ seja positivo e significativo para explicar/prever os retornos das ações.

A Figura 8 evidencia que a variável explicativa COMPM possui coeficiente positivo e estatisticamente significativo (5\%) no modelo, evidenciando que a COMPM explica o retorno das ações. Em relação à variável COMPM.TAM, é negativo e significativo, ao nível de confiança de 5\%, corroborando com os achados de Sarlo Neto, Bassi e Almeida (2011). 
A variável COMPM $\square *$ MTB é negativo e não significativo este achado difere das pesquisas de Collins e Kothari (1989) e de Sarlo Neto, Bassi e Almeida (2011).

Já a variável COMPM $\square *$ END apresentou coeficiente negativo e não significativo, não sendo, portanto, observada relação conforme Sarlo Neto, Bassi e Almeida (2011).

A variável $\mathrm{COMPM}_{\square} \mathrm{PERDA}$ apresentou coeficiente negativo e significativo (5\%), corroborando com Almeida, Sarlo Neto, Gomes e Novaes (2014) e que as empresas com prejuízo possuem conteúdo menos informativo.

Com as evidências apresentadas encontra-se indícios de que a comparabilidade média individual exerce influência positiva na sobre a capacidade informacional do preço das ações, não rejeita-se $\mathrm{H} 2 \mathrm{a}$ 


\begin{tabular}{|c|c|c|c|}
\hline & POLS COMPM (CO) & RE_COMPM (CO) & FE_COMPM (CO) \\
\hline VARIABLES & RA & RA & RA \\
\hline COMPM & 0.289 & $0.289^{*}$ & $0.810^{* *}$ \\
\hline c.TAM\#c.COMPM & -0.013 & -0.013 & $-0.047 * *$ \\
\hline c.MTB\#c.COMPM & -0.013 & $-0.013 *$ & -0.013 \\
\hline c.END\#c.COMPM & -0.021 & -0.021 & 0.028 \\
\hline $\begin{array}{l}\text { 0b.PERDA\#co.COMPM } \\
\text { Sim }\end{array}$ & $-.090^{*}$ & $-.090 * *$ & $-0.128^{* *}$ \\
\hline cons & $0.079^{*}$ & $-0.090 * *$ & 0.060 \\
\hline Observations & 394 & 394 & 394 \\
\hline R-squared & 0.017 & & 0.030 \\
\hline r2_w & . & 0.021 & 0.020 \\
\hline $\mathrm{r} 2 \mathrm{~b}$ & . & 0.012 & 0.022 \\
\hline r2_o & & 0.017 & 0.030 \\
\hline $\mathrm{F}$ & 1.756 & & 3.365 \\
\hline chi2 & & 15.185 & \\
\hline Aic & 615.848 & & 586.357 \\
\hline Biv & 639.706 & & 606.239 \\
\hline
\end{tabular}

Figura 8 - Modelo COMPM e Retorno anormal 
Abaixo apresenta-se o Modelo de COMPT

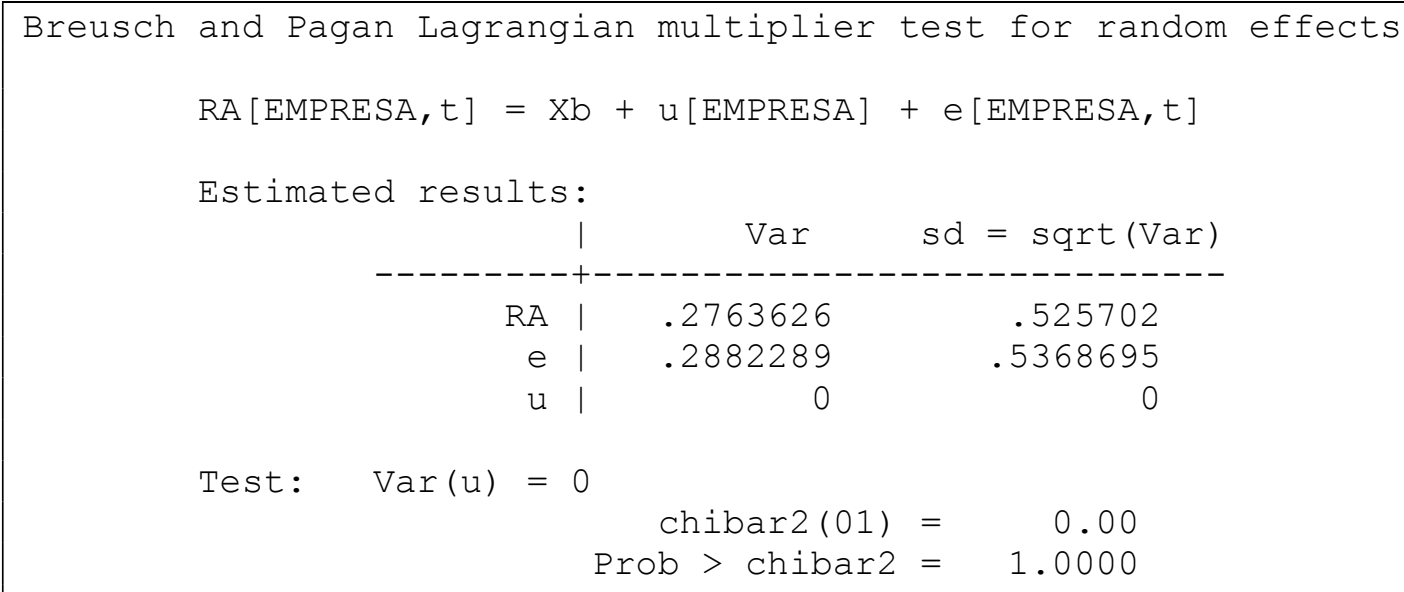

Figura 9 - Teste Breusch Pagan COMPT

O Teste RESET de Ramsey indicou a rejeição de que o modelo esteja bem especificado $(F=2,18$; p-valor $<0,0904)$.

A estimativa da equação 19 por POLS resultou nos mesmos achados da equação 18 quanto à verificação das hipóteses do modelo: i) Teste Breusch-Pagan para heterocedasticidade significativo $\left(\chi^{2}=0,00\right.$; p-valor $\left.<1,000\right)$; e ii) Teste $\operatorname{RESET}$ de $\operatorname{Ramsey}$ significativo $(F=8,47$; pvalor $<0,000)$.

Analisando a Figura 10, a variável explicativa COMPT possui coeficiente positivo e estatisticamente significativo (5\%) no modelo, evidenciando que a COMPT explica o retorno das ações. Em relação à variável COMPT.TAM apresentou coeficiente negativo e significativo, ao nível de confiança de 1\%, corroborando com os achados de Sarlo Neto, Bassi e Almeida (2011).

A variável COMPT. MTB é negativo e não significativo este achado difere da pesquisa de Collins e Kothari (1989) e de Sarlo Neto, Bassi e Almeida (2011).

Já a variável COMPT. END apresentou coeficiente negativo e não significativo, não sendo, portanto, observada relação conforme Sarlo Neto, Bassi e Almeida (2011). 
104

A variável COMPM.PERDA apresentou coeficiente negativo e não significativo, corroborando com Almeida, Sarlo Neto, Gomes e Novaes (2014) e que as empresas com prejuízo possuem conteúdo menos informativo.

Com as evidências apresentadas encontra-se indícios de que a comparabilidade intertemporal exerce influência positiva na sobre a capacidade informacional do preço das ações, não rejeitase $\mathrm{H} 2 \mathrm{a}$ 


\begin{tabular}{l|c|c|c}
\hline & POLS COMPT (CO) & RE_COMPT (CO) & FE_COMPT (CO) \\
\hline VARIABLES & RA & RA & RA \\
\hline & & & \\
\hline COMPT & 0.060 & 0.060 & $0.338^{* *}$ \\
\hline c.TAM\#c.COMPT & 0.001 & 0.001 & $-0.021^{*}$ \\
\hline c.MTB\#c.COMPT & -0.033 & -0.033 & -0.024 \\
\hline c.END\#c.COMPT & -0.019 & $-0.019^{*}$ & -0.006 \\
\hline 0b.PERDA\#co.COMPT & -0.031 & -0.031 & -0.035 \\
Sim & & & \\
\hline cons & 0.037 & 0.037 & 0.020 \\
\hline & & & \\
\hline Observations & 394 & 394 & 394 \\
\hline R-squared & 0.011 & & 0.012 \\
\hline r2_w & $\cdot$ & 0.011 & 0.004 \\
\hline r2_b & $\cdot$. & 0.013 & 0.012 \\
\hline r2_o & $\cdot$ & 0.005 & 0.012 \\
\hline F & 0.769 &. & 1.363 \\
\hline chi2 &. & 15.185 &. \\
\hline Aic & 618.095 & & 583.576 \\
\hline Biv & 641.953 & & 613.458 \\
\hline & Nota:** $<<0.05, * \mathrm{p}<0.1$ &
\end{tabular}

Figura 10 -Modelo COMPT e Retorno Anormal 


\section{CONSIDERAÇÕES FINAIS}

O presente estudo teve como objetivo investigar o impacto da comparabilidade dos demonstrativos financeiros sobre a acurácia na previsão de consenso dos analistas de investimento do mercado brasileiro e na informatividade das empresas listadas na BM\&FBovespa no período de 2005 a 2015. Dentre os principais eixos que nortearam esta pesquisa destacam-se: comparabilidade, acurácia na previsão dos analistas, e sua influência sobre a informatividade .

As hipóteses e os testes estatísticos foram parametrizados essencialmente com base nos estudos dos autores a seguir: Franco, Kothari e Verdi (2011); Conroy e Harris (1987); Brown (1997); Martinez e Salim (2004); Martinez (2004); Dalmácio (2009); Gatsio (2013) e Jiao, Koning, Meterns e Roosenboom (2012), Watts e Zimmerman (1990); Sarlo Neto, Losss, Nossa e Teixeira (2003); Silva, Sarlo Neto, Reina e Formentini (2015); Ball e Brow (1968); Beaver (1968); Lopes e Iudicibus (2012); Acker, Horton e Tonks (2002); Black e Carnes (2006); Bae, Tan, e Welker, (2008); Ashbaugh e Pincus (2001); Martinez, 2007; Martinez \& Dumer (2013); Ribeiro (2014) e Freri e Salotti (2013).

Quanto aos objetivos esta pesquisa teve como foco: i) calcular o nível de comparabilidade média de cada companhia analisada com base em seus pares do setor; ii) mensurar a acurácia na previsão dos analistas financeiros; iii) avaliar a influência da comparabilidade sobre a informatividade; e iv) examinar a relação entre a comparabilidade e a acurácia na previsão realizada pelos analistas.

De acordo com as evidências encontradas pela aplicação da metodologia estabelecida sobre as observações das amostras selecionadas, apresenta-se o seguinte resumo dos resultados relativos às hipóteses de trabalho levantadas:

\begin{tabular}{l|l|l}
\hline & Hipóteses & Resultados \\
\hline $\mathrm{H}_{1}$ & $\begin{array}{l}\mathrm{O} \text { aumento da comparabilidade dos } \\
\text { demonstrativos financeiros está associado ao } \\
\text { aumento na acurácia das estimativas de consenso } \\
\text { dos analistas de mercado. }\end{array}$ & \\
\hline $\mathrm{H}_{2}$ & $\begin{array}{l}\text { A comparabilidade dos demonstrativos } \\
\text { financeiros está associada ao aumento na } \\
\text { informatividade. }\end{array}$ & Confirmada. \\
\hline
\end{tabular}

Tabela 21 - Resultados encontrados para cada hipótese 
Para responder ao problema de pesquisa e testar as hipóteses, foram apresentados dois modelos bases de análise em painel: i) modelo de acurácia das previsões de consenso dos analistas, e ii) modelo de informatividade.

As evidências obtidas por esta pesquisa em relação à comparabilidade são apresentadas a partir de duas perspectivas: a comparabilidade individual média entre as empresas diferentes, mas do mesmo setor (COMPM), e a comparabilidade da mesma empresa ao longo do tempo (COMPT). No que tange à COMPM constatou-se aparentes diferenças de comportamento na comparabilidade entre os setores de atividade econômica, entretanto, em termos gerais houve uma melhora na comparabilidade da mesma empresa ao longo do tempo após o período de adoção ao IFRS. Em relação à comparabilidade da mesma empresa ao longo do tempo não se observou variações significativas. Ribeiro (2014) encontrou evidência similar em sua pesquisa em relação à comparabilidade da mesma empresa ao longo do tempo.

Em relação a acurácia não foi observada alterações significantes nos períodos antes e após a transição regulatório. No entanto, observou-se que as variáveis COMPM e COMPT influenciam a acurácia de forma significativa e negativa. Em relação a acurácia esse resultado diverge dos achados de Jiao, Koning, Meterns, e Roosenboom (2012), pois a previsão dos analistas se tornaram mais precisas após a doção das IFRS nos paises europeus. Também no contexto internacional De Franco, Kothari, e Verdi (2011) encontram evidencias de que a comparabilidade melhora a acurácia dos analistas, envidenciando assim, que a adoção as normas IFRS possibilitam melhorias na qualidade dos demontrativos financeiros. No contexto nacional ao investigar a melhoria na acurácia após a adoção do IFRS, Gatsio (2013) encontrou evidências que corroboram parcialmente com os achados desta pesquisa, uma vez, que em ambos os estudos não foram encontraram evidencias significativas de alteração no padrão da acurácia dos analistas, entretanto, tais resultados divergem ao encontrado por Pessotti e Costa (2013) também no contexto brasileiro.

As variáveis COMPM e COMPT mostrou-se positivo e estatisticamente significativo, como a principal variável que impacta no retorno das ações, este resultado é condizente com a teoria (Ball \& Brow, 1968; Beaver, 1968; Sarlo Neto, 2009). Assim, pode se inferir que a comparabilidade afeta a informatividade do preço das ações, tal associação existe principalmente porque a comparabilidade possibilita aos investidores compreender melhor o 
desempenho econômico de uma empresa ao longo do período bem como comparar com outras empresas do setor, facilitando assim a decisão de alocação de capital.

O tamanho da empresa e o índice de Market-to-book apresentaram-se significativos, no modelo de informatividade, resultado condizente com teoria internacional (Atiase, 1985; FREEMAN, 1987; COLLINS; KOTHARI, 1989; CHANEY; JETER, 1992).

Conclui-se como resultados que esta pesquisa encontrou evidencias que permite inferir que a comparabilidade proporciona melhoria na qualidade e na capacidade informacional das informações contábeis por meio da acurácia nas previsões dos analistas e da informatividade do preço das ações. Entretanto, esses resultados podem melhorar, tendo em vista que o Brasil saiu de padrões contábeis baseado em regras para padrões baseados em principios, além deste fato um dos poucos países que realizou a adoção de forma completa, assim, pode-se inferir a necessidade de um período maior para adaptação.

De forma geral, esta pesquisa contribui para que os usuários, reguladores e educadores ampliem seus conhecimentos e debate sobre as adoção dos padrões IFRS no que tange a: i) apesar de não ser observado melhoria significativa na acurácia da previsão dos analistas locais, pode se inferir que a qualidade da informação contábil melhorou em relação á proxy comparabilidade. O fato de não observarmos uma melhora significativa em relação à acurácia pode ser justificada pois a maioria das pesquisas realizadas utilizam como amostra paises europeus, no qual, a principal fonte de captação de recursos é o mercado financeiro.; ii) mesmo com as inovações trazidas para o ambiente e normas contábeis praticadas ao adotarmos padrões baseados em principios e não em regras foi possível constatar uma melhora na qualidade e na capacidade informacional da contabilidade. Esse é um fator muito importante, pois Lopes (2012) menciona a resistência à aceitação da filosofia da Primazia da Essência sobre a Forma, em virtude do apego à regra escrita, ao que esta apresentado de forma detalhada, ocasionando uma em sua aceitação. Entretanto, apesar dessa lentidão na aceitação dessa nova filosofia observa-se uma evolução na qualidade das informações contábeis. Outro ponto que merece destaque ao observarmos os resultados dessa pesquisa é a necessidade de melhoria na qualidade da formação do profissional contábil bem como sua educação continuada, pois o mercado irá exigir cada vez mais profissionais que tenham o conhecimento e a capacidade necessária para realiza a análise da substância do que de fato ocorreu e tomar decisões com base em julgamento. Leva a todos a 
refletirmos sobre a mudança de postura necessária para que tenhamos exito como educadores, profissionais e normatizadores.

Por intermédio das informações apresentadas, observa-se que o Brasil apesar das dificuldades e dos diversos pontos que merecem refleções e discussões, a adoção das normas internacional vem apresentando melhoria na qualidade e capacidade informacional da contabilidade beneficiando assim os analistas, os investidores, as corretoras, os bancos de investimentos e outros usuários da contabilidade.

Esta pesquisa apresenta as seguintes limitações: i) a amostra desta pesquisa é não probabilística, o que impede a generalização dos resultados; ii) no período investigado o mercado financeiro passou por um período de grande volatilidade; iii) a utilização do lucro contábil como produto final dos demonstrativos contábeis; e iv) o modelo utilizado não é imune à utilização da uniformidade pelas empresas, conforme conceito apresentado no item 2.1. 


\section{Bibliografia}

Almeida, A. A., Sarlo Neto, A., Gomes, L. L., \& Novaes, P. V. (2014). A influência do private equity venture capital sobre a informatividade dos lucros no mercado brasiliero. Advances in Scientific and Applied Acconting, pp. 7 (2), pp. 266-292.

Amato, J. G., Lima, F. G., Gatsios, R. C., \& Assaf Neto, A. (2016). Acurácia dos analistas na previsão de lucros das instituições financeiras no Brasil: impacto da adoção do padrão IFRS. X Congresso Anpcont, Ribeirão Preto.

Antunes, G. A., \& Mendonça, M. M. (2008). Impacto da adesão aos níveis de governaça da Bovespa na qualidade da informação contábil:uma investigação acerca da oportunidade, relevância e do conservadorismo contábil utilizando dados em painel. Congresso da Associação Nacional dos Programas de Pós-Graduação em Ciências Contábeis, Salvador .

Ashbaugh, H., \& Pincus, M. (2001). Domestic accounting standards, international accounting standards, and the predictability of earnings. The Accounting Review, pp. 83 (3), pp.593-628.

Atiase, R. (1985). Predisclosure information, firm capitalization and security price behavior around earnings announcements. Jounal of Accounting Research, pp. 21-36.

Bae, K. H., Tan, H., \& Welker, M. (2008). International GAAP differences: the impact foreign analysts. The Accountin Review, pp. 83 (3), pp.593-628.

Ball, R., \& Brow, P. (1968). An empirical evaluation of accounting income numbers. Journal of Accounting Research, pp. 6. p.159-178.

Barth, M. E. (2013, April 27). Global Comparability in Financial Reporting: What, Why, How, and When? China Journal of Accounting Studies, pp. 2-12.

Barth, M. E. (2014). Measurement in financial reporting: The need for concepts. Accounting Horizons, 331-352.

Barth, M. E., Landsman, W. R., \& Lang, M. H. (2008). International accounting standards and accouting quality. Journal of Accounting Research, 467-498.

Barth, M. E., Landsman, W. R., Lang, M., \& Williams, C. (2012). Are IFRS-based and US GAAP-based accounting amounts comparable? Journal of Accounting and Economics, pp. 68-93.

Beaver, W. (1968). The information content of annual earnings announcements. Journal of Accounting Research, pp. 62-92. 
Bernardo, H. P. (2001). Avaliação empírica do efeito dos anúncios trimestrais de resultado sobre o valor das ações no mercado brasileiro de capitais: um estudo de evento. Tese de Mestrado. Faculdade de Econômia, Administração e Contabilidade, Universidade de são Paulo, São Paulo.

Bernardo, H. P. (2001). Avaliação empírica dos efeitos dos anúncios trimestrais de resultado sobre o valor das ações no mercado brasileiro de capitais: um estudo de evento. Tese de Mestrado. Faculdade de Economia, Administração e Contabilidade. Universidade de São Paulo., p. São Paulo.

Bhat, G., Hope, O.-K., \& Kang, T. (2006). Does corporate governance transparency affect the accuracy of analyst forecast? Accounting and Finance, 46, pp. 715-732.

Boff, L. H., Procianoy, J. L., \& Hoppen, N. (2006). O uso de informação por analistas de investimento na avaliação de empresas: à procura de padrões. Revista de Administração Contemporânea, 169-192.

Bradshaw, M. T., \& Miller, G. S. (2008). Will harmonizing accounting standards really harmonize accounting? evidence from non-U.S. firms adopting U.S. GAAP. Journal of Accounting, Auditing \& Finance, 233-264.

Brochet, F., Jagolinzer, A. D., \& Riedl, E. J. (2013). Mandatory IFRS adoption and financial statement comparability. Contemporary Accounting Research, pp. 1373-1400.

Brown, L. (1997). Analyst forecast errors: additional evidence. Financial Analyst Journal, 53, pp. 81-88.

Brugni, T. V., Sarlo Neto, A., Bastianello, R. F., \& Paris, P. K. (2012). Influência de dividendos sobre a informatividade dos lucros:evidências empíricas na BM\&FBovespa. Revista Universo Contábil, Blumenau.

Byard, D., Li , Y., \& Weintrop, J. (2006). Corporate governance and the quality of financial analysts'information. Journal of Accounting and Economics, 609-625.

Byard, D., Li, Y., \& Weintrop, J. (2006). Corporate governance and the quality of financial analysts' information. Journal of Accounting and Public policy, 609-625.

Cairns, D., Massoudi, D., Taplin, R., \& Tarca, A. (2011). IFRS fair value measurement and accounting policy choice in the United Kingdom and Australia. The British Accounting Review, 1-21.

Carvalho, N., \& Salotti, B. M. (2013). Adoption of IFRS in Brazil and the consequences to accounting education. Issues in Accounting Education, 235-242. 
Choi, F. D., Frost, C. A., \& Meek, G. K. (2001). International Accounting. Upper Sanddle River: Pearson Education.

Choi, J.-H., Choi, S., Myers, L. A., \& Ziebart, D. (2015). Financial Statement Comparability and the Informativeness of Stock Prices about Future Earnings. Working Paper.

Clement, M. B. (1999). Analyst forecast accuracy: do ability, resources, and portfolio complexity matter? Journal of Accounting and Economics, 285-3030.

Collins, D. W., \& Kothari, S. (1989). An analysis of intertemporal and cross-sectional determinants of ERCs. Jounal of Accounting and Economics, pp. 11 (2-3) 143-183.

Comitê de Pronunciamentos Contábeis. (2011). Fonte: Pronunciamentos Técnico CPC 00 Estrutura Conceitual para Elaboração e Divulgação de Relatório Contábil-Financeiro: Http://static.cpc.mediagroup.com.br/Documentos/147_CPC00_R1.pdf

Conroy, R., \& Harris, R. (1987). Consensus forecast of corporate earnings analysts' forecast and time series methods. Management Science, 33(6), pp. 725-738.

Costa, F. M., Reis, D. J., \& Teixeira, A. M. (2012). Implicações de crises econômicas na relevância da Infomação contábil das empresas brasileiras. $R E P e C, 141-153$.

Cotter, J., Tarca, A., \& Wee, M. (2012). IFRS adoption an analysts'earnings forecasts: Australian evidence. Accounting and Finance, pp. 52 (2), pp. 395-419.

Cotter, J., Tarca, A., \& Wee, M. (2012). IFRS adoption and analysts' earnings forecasts: Australian evidence. Accounting and Finance, 395-419.

Dalmácio, F. Z. (2009). Mecanismos de governança e acurácia das previsões dos analistas do mercado brasileiro:uma análise sob a perspectiva da teoria de sinalização. Tese de doutorado Universidade de São Paulo.

Dantas, J. A., Medeiros, O. R., \& Lustosa, P. R. (2006). Reação do mercado à alavancagem operacional: um estudo empírico no Brasil. Revista Contabilidade e Finanças, pp. 41, pp. 72-86.

De Fond, M., Hu, X., Hung, M., \& Li, S. (2011). The impact of mandatory IFRS adoption on foreign mutual fund ownership: The role of comparability. Journal of Accounting and Economics, 240-258. 
De Found, M., Hu, X., Hung, M., \& Li, S. (2011). The impact of mandatory IFRS adoption on foreign mutual fund ownership: The role of comparability. Journal of Accounting and Economics, pp. 240-258.

De Franco, G., Kothari, S., \& Verdi, R. S. (2011). The benefits of financial statement comparability. Journal of Accounting Research, 895-931.

Demirakos, E. G., Strong, N. C., \& Walker, M. (2004). What valuation models do analyst use? Accounting Horizons, pp. 18 (4), pp. 221-240.

Durnev, A., Morck, R., Yeung, B., \& Zarowin, P. (2003). Does greater firm-specific return variation mean more or less informed stock pricing? Jounal of Accounting Research, pp. 41 (5), pp. 797-836.

Ernstbergerger, J., \& Krotter, S. (2008). Analysts' forecast accuracy in Germany: the effect of different accounting principles and changes of accounting principles. Business Research, pp. 1 (1), pp.26-53.

Fabiano, D. (2012). O nível de comparabilidade contábil dos países do BRIC. Dissertação de Mestrado. Faculdade de Gestão e Negócios. Universidade Federal de Uberlândia., Uberlândia.

Fang, X., Li, Y., \& Zhang, W. (2016). Financial Statement Comparability and Debt Contracting Evidence from the Syndicated Loan Market. Accounting Horizons, 277303.

Fávero, L. P. (2015). Análise de dados. Rio de Janeiro: Elsevier.

Fávero, L. P., Belfiore, P., Silva, F. L., \& Chan, B. L. (2009). Análise de dados: modelagem multivariada para tomada de decisões. Rio de Janeiro: Elsevier.

Freeman, R. (1987). The association between accounting earnings and security returns for large and small firms. Journal of Accounting and Economics, pp. 9, 195-228.

Freri, M. R., \& Salotti, B. M. (2013). Comparabilidade de empresas administradoras de shoppings centers do mercado de capitais brasileiro. Revista de Contabilidade do Mestrado em Ciências Contabeis da UERJ, 26-45.

Gatsios, R. C. (2013). Acurácia e dispersão das estimativas dos analistas no mercado de capitais brasileiro:impacto da adoção do padrão IFRS sobre a qualidade preditiva da informação contábil. Dissertação defendida no Departamento de Contabilidade e Atuária da Universidade de São Paulo, 105.

Gil, A. C. (2010). Como elaborar projetos de pesquisa. São Paulo: Atlas. 
Gujarati, D. N., \& Porter, D. C. (2011). Economotria básica. Porto Alegre: AMGH Editora Ltda.

Hail, L., Leuz, C., \& Wysocki, P. (2010). Global accounting convergence and the potential adoption of IFRS by the U.S (Part.I): Conceptual underpinnings and economics analysis. Accounting Horizons, 355-394.

Haw, I.-M., Hu, B., Lee, J. J., \& Wu, W. (2012). Investor protection and price informativeness about future earnings:international evidence. Review of Accounting Studies, pp. 17 (2), pp. 389-419.

Hendriksen, E. S., \& Van Breda, M. F. (2007). Teoria da Contabilidade. São Paulo: Atlas.

Horton, J., Serafeim, G., \& Serafeim, I. (2013). Does mandatory IFRS adoption improve th information environment? Contemporary Accounting Researcg, 388-423.

Iudícibus, S. d. (2015). Teoria da Contabilidade. São Paulo: Editora Atlas.

Jiao, T., Koning, M., Meterns, G., \& Roosenboom, P. (2012). Mandatory IFRS adoption and its impact on analysts' forecasts. Internationa Review of Financial Analysis, 56-63.

Kang, J.-K., \& Stulz, R. M. (1997). Why is there a home bias? An analysis of foreigh portfolio equity ownership in Japan. Journal of Financial Economics, 3-28.

Lang, M. H., \& Lundholm, R. J. (1996). Corporate disclosure policy and analyst behavior. The Accounting Review, 467-492.

Lima, J. B., \& Terra, P. R. (2004). A reação do mercado de capitais brasileiro à divulgação das informações contábeis. XXVIII Encontro da Associação Nacional de Pós-Graduação em Administração (EnANPAD), Curitiba .

Lima, J. B., \& Terra, P. S. (2004). A reação do mercado de capitais brasileiro à divulgação das informações contábeis. XXVIII Encontro Nacional de Programas de Pós-Graduação em Administração (ENANPAD). , p. Curitiba.

Lopes, A. B. (2001). A relevância da informação contábil para o mercado de capitais:modelo de Ohlson aplicado à Bovespa. Tese de Doutorado. Faculdade de Economia, Administração e Contabilidade, São Paulo.

Lopes, A. B. (2012). Contabilidade e finanças no Brasil: estudos em homenagem ao professor Eliseu Martins. São Paulo: Atlas. 
Lopes, A. B., \& Iudicibus, S. (. (2012). Teoria Avançada da Contabilidade. São Paulo: Atlas.

Lopes, A. B., \& Martins, E. (2005). Teoria da contabilidade: uma nova abordagem . São Paulo: Atlas.

Marconi, M. d., \& Lakatos, E. M. (2015). Técnicas de Pesquisa. São Paulo: Atlas.

Martinez, A. L. (2001). Gerenciamento dos resultados contábeis:estudo empírico das companhias abertas brasileiras. Tese de Doutorado. Faculdade de Economia Administração e Contabilidade.

Martinez, A. L. (2004). Analisando os analistas: estudo empírico das projeções de lucros e das recomendações dos analistas de mercado de capitais para as empresas brasileiras de capital aberto. Tese de doutorado Escola de Administração de Empresas de São Paulo da Fundação Getúlio Vargas.

Martinez, A. L. (2007). Otimismo e viés de seleção dos analistas. Brazilian Business Review, pp. 104-118.

Martinez, A. L. (2009). Cobertura de analistas, erros de previsão e earnings management no Brasil. XXXIII Encontro da ANPAD, São Paulo.

Martinez, A. L., \& Dumer, M. C. (2013). Adoção das IFRS e as propriedades das previsões de lucros dos analistas: caso brasileiro. Revista Mineira de Contabilidade, pp. 14 (52), pp. 53-62.

Martinez, A. L., \& Salim, J. J. (2004). Analisando as previsões de resultados contábeis dos analistas de empresas brasileiras. Encontro da ANPAD, 28.

Martins, G. d., \& Theóphilo, C. R. (2009). Metodologia da investigação científica para Ciências Sociais Aplicadas. São Paulo: Atlas.

Parker, R. H., \& Morris, R. D. (2001). The influence of U.S GAAP on the harmony of accounting measurement policies of large companies in the U.K. and Australia. Abacus, 297-378.

Pessotti, T. J., \& Costa, F. M. (2013). Impacto da convergências às normas internacionais de contabilidade sobre a acurácia dos analistas do mercado de capitais brasileiro. $X X X V I I$ Encontro da ANPAD, Rio de Janeiro.

Petaibanlue, J., Walker, M., \& Lee, E. (2015). When did analust forecast accuracy benefit from increased cross-border comparability following IFRS adoption in the EU? International Review of Financial Analysis, pp. 42, pp. 278-291. 
Prux Junior, J. L. (1998). Assimetria informacional e precificação das ações das empresas negociadas na bolsa de valores de São Paulo:evidências a partir da faculdade de divulgar demonstrações contábeis em moeda constante a partir de 1996. Tese de Mestrado. Faculdade de Ciências Econômicas., p. Rio Grande do Sul.

Reina, D. R., Reina, D., \& Silva, S. F. (2014). Comparabilidade da informação contábil em empresas brasileiras após a adoção das normas internacionais de contabilidade. Revista Contemporânea de Contabilidade, 77-94.

Ribeiro, A. M. (2014). Poder discricionário do gestor e comparabilidade dos relatórios financeiros: Uma análise dos efeitos da convergência do Brasil às IFRS. Tese de Doutoramento. Faculdade de Economia, Administração e Contabilidade, Universidade de São Paulo, São Paulo.

Richardson, R. J. (2008). Pesquisa Social: métodos e técnicas. São Paulo: Atlas.

Saiki, T. G., \& Antunes, M. T. (2010). Reconhecimento de ativos intangíveis em situações de business combinations:um exemplo prático da aplicação dos CPC 04 e CPC 15. Boletim IOB - Temátic Contábil e Balanços, (46).

Santos, E. S., \& Calixto, L. (2010). Impactos do início da Harmonização Contábil Internacional (Lei 11.638/2007) nos resultados das empresas abertas. RAE Eletrônica.

Sarlo Neto, A. (2009). Relação entre a estrutura de propriedade e a informatividade dos lucros contábeis no mercado brasileiro. Tese de doutorado Universidade de São Paulo.

Sarlo Neto, A., Bassi, B. R., \& Almeida, A. A. (2011). Um estudo sobre a informatividade dos lucros contábeis na américa latina. Revista Contabilidade e Organizações, pp. 5 (12) $6-22$.

Sarlo Neto, A., Lopes, A. B., \& Dalmácio, F. Z. (2009). Influência da estrutura de propriedade sobre a informatividade dos lucros contábeis divulgados pelas empresas negociadas na Bovespa. ENANPAD Encontro da Associação Nacional de Programas de Pósgraduação em Administração, pp. 1-33.

Schiehll, E. (1996). O efeito da divulgação das demonstrações financeiras no mercado de capitais brasileiro: um estudo sobre a variação no preço das ações. Dissertação de Mestrado. Programa de Pós-graduação em Administração, UFRGS.

Schiehll, E. (1996). O efeito da divulgação das demonstrações financeiras: um estudo sobre a variação das ações. Tese de Mestrado. Programa de Pós-Graduação em Administração, Universidade Federal do Rio Grande do Sul, Porto Alegre. 
Silva, F. d., Sarlo Neto, A., Costa Junior, J., \& Reina, D. (2016). Influência da composição da remuneração aos acionistas sobre a capacidade informacional dos lucro contábeis. XVII Congresso Nacional de Administração - ADCONT.

Silva, H. R. (1998). A capacidade previsionária no mercado acionário brasileiro: um estudo focado nas previsões dos analistas de investimentos. Encontro da ANPAD, Foz do Iguaçu.

Silva, R. L. (2013). Adoção completa das IFRS no Brasil: qualidade das demonstrações contábeis e o custo de capital próprio. Tese de Doutoramento. Faculdade de Economia, Administração e Contabilidade. Universidade de São Paulo, São Paulo.

Silva, S. F., Sarlo Neto, A., Reina, D., \& Formentini, B. F. (2015). Informatividade dos lucros: influência dos dividendos e da governança corporativa nas empresas listadas na BM\&FBovesp. 6 Congresso UFSC de Controladoria e Finanças, Florianópolis.

Sohn, B. C. (2016). The effect of accounting comparability on the accrual-based and earnings management. Journal of Accounting Public Policy, 513-539.

Sousa, E. F., Sousa, A. F., \& Demonier, G. B. (2016). Adoção das IFRS no Brasil: efeitos no caonservadorismo contábil. Revista de Educação e Pesquisa em Contabilidade, 10 (2), p. 126-147.

Tan, H., Wang, S., \& Welker, M. (2011). Analyst following and forecast accuracy after mandated IFRS adoptions. Journal of Accounting Research, pp. 1307-1357.

Taplin, R. H. (2011). The measurement of comparability in accounting research. Abacus, 383409.

Van Der Tas, L. G. (1988). Measuring harmonization of finacial reporting pratice. Accounting and Business Research, 157-169.

Watts, R. L., \& Zimmerman, J. L. (1990). Positive accounting theory: a ten year perspective. The Accounting Review, 131-156.

Wooldridge, J. M. (2010). Introdução à econometria:uma abordagem moderna. São Paulo: Cengage Learning.

Yip, R. W., \& Young, D. (2012). Does Mandatory IFRS Adoption Improve Information Comparability? The Accounting Review, pp. 1767-1789. 


\section{APÊNDICE 1 - RESULTADOS DOS MODELOS ESTIMADOS}

Tabela 22- Compilação dos modelos POLS, efeitos fixos, efeitos aleatórios variável comparabilidade média sem tratamento dos outliers

\begin{tabular}{|c|c|c|c|}
\hline VARIABLES & $\begin{array}{c}\text { POLS } \\
\text { ACURACIA }\end{array}$ & $\begin{array}{c}\text { Efeito Aleatório } \\
\text { ACURACIA }\end{array}$ & $\begin{array}{c}\text { Efeito fixo } \\
\text { ACURACIA }\end{array}$ \\
\hline COMPM & $\begin{array}{c}0.004 * \\
(0.00318)\end{array}$ & $\begin{array}{c}0.001 * \\
(0.00262)\end{array}$ & $\begin{array}{c}-0.001 \\
(0.00267)\end{array}$ \\
\hline 2.Siderurgia & $\begin{array}{c}-0.00903 \\
(0.0127)\end{array}$ & $\begin{array}{c}-0.00998 \\
(0.0159)\end{array}$ & \\
\hline 3.Prod. Metal & $\begin{array}{c}0.0300 \\
(0.0421)\end{array}$ & $\begin{array}{c}0.0144 \\
(0.0448)\end{array}$ & \\
\hline 4.Telecomunicações & $\begin{array}{c}0.00411 \\
(0.00983)\end{array}$ & $\begin{array}{l}0.00392 \\
(0.0128)\end{array}$ & \\
\hline 5.Equi. Transporte & $\begin{array}{c}0.0347 * * * \\
(0.0126)\end{array}$ & $\begin{array}{c}0.0349 * * * \\
(0.0132)\end{array}$ & \\
\hline 6.Ind. Química & $\begin{array}{c}0.0177 \\
(0.0169)\end{array}$ & $\begin{array}{c}0.0166 \\
(0.0142)\end{array}$ & \\
\hline 7.Papel e celuloce & $\begin{array}{l}0.00833 \\
(0.0116)\end{array}$ & $\begin{array}{l}0.00686 \\
(0.0132)\end{array}$ & \\
\hline 8.Calçados & $\begin{array}{r}-0.00306 \\
(0.0230)\end{array}$ & $\begin{array}{r}-0.00181 \\
(0.0164)\end{array}$ & \\
\hline 9.Tecidos e Vestuário & $\begin{array}{c}-0.0537 * * \\
(0.0256)\end{array}$ & $\begin{array}{l}-0.0597 \\
(0.0482)\end{array}$ & \\
\hline 10.Lojas geral & $\begin{array}{r}-0.00910 \\
(0.0157)\end{array}$ & $\begin{array}{r}-0.00479 \\
(0.0240)\end{array}$ & \\
\hline 2.IFRSTRANS & $\begin{array}{l}0.00256 \\
(0.0111)\end{array}$ & $\begin{array}{r}0.000517 \\
(0.0102)\end{array}$ & $\begin{array}{c}-0.000267 \\
(0.0102)\end{array}$ \\
\hline 3.IFRSPOS & $\begin{array}{c}-0.00553 \\
(0.00981)\end{array}$ & $\begin{array}{r}-0.00800 \\
(0.0117)\end{array}$ & $\begin{array}{l}-0.00970 \\
(0.0146)\end{array}$ \\
\hline QANALIST & $\begin{array}{l}0.00240 * * \\
(0.000979)\end{array}$ & $\begin{array}{l}0.00242 * * \\
(0.000996)\end{array}$ & $\begin{array}{c}0.00186 \\
(0.00131)\end{array}$ \\
\hline LNATIVO & $\begin{array}{c}0.0135^{* * *} \\
(0.00487)\end{array}$ & $\begin{array}{l}0.0130 * * \\
(0.00610)\end{array}$ & $\begin{array}{c}0.0139 \\
(0.0170)\end{array}$ \\
\hline PTB & $\begin{array}{c}0.00773 * * * \\
(0.00223)\end{array}$ & $\begin{array}{c}0.00511 \\
(0.00435)\end{array}$ & $\begin{array}{c}0.00239 \\
(0.00328)\end{array}$ \\
\hline PERDA & $\begin{array}{c}-0.0323^{* *} \\
(0.0160)\end{array}$ & $\begin{array}{l}-0.0259 \\
(0.0175)\end{array}$ & $\begin{array}{c}-0.0219 \\
(0.0181)\end{array}$ \\
\hline VP & $\begin{array}{c}-0.0200 * * * \\
(0.00723)\end{array}$ & $\begin{array}{l}-0.0192^{* *} \\
(0.00872)\end{array}$ & $\begin{array}{c}-0.0186^{* *} \\
(0.00876)\end{array}$ \\
\hline DVPESTIMAT & $\begin{array}{l}0.000325 \\
(0.00206)\end{array}$ & $\begin{array}{r}-0.000683 \\
(0.00212)\end{array}$ & $\begin{array}{l}-0.00125 \\
(0.00201)\end{array}$ \\
\hline DPROE & $\begin{array}{c}-0.208^{* * *} \\
(0.0734)\end{array}$ & $\begin{array}{l}-0.215^{* *} \\
(0.0893)\end{array}$ & $\begin{array}{c}-0.221^{* *} \\
(0.0934)\end{array}$ \\
\hline LNRISCO & $\begin{array}{l}0.00581 \\
(0.0123)\end{array}$ & $\begin{array}{l}0.00400 \\
(0.0146)\end{array}$ & $\begin{array}{c}0.000623 \\
(0.0159)\end{array}$ \\
\hline Constant & $\begin{array}{c}-0.295^{* * *} \\
(0.0884)\end{array}$ & $\begin{array}{c}-0.271 * * * \\
(0.0893)\end{array}$ & $\begin{array}{l}-0.256 \\
(0.216)\end{array}$ \\
\hline Observations & 386 & 386 & 386 \\
\hline $\mathrm{R}$-squared & 0.298 & & 0.136 \\
\hline r2_a & 0.260 & . & 0.111 \\
\hline r2_w & . & 0.132 & 0.136 \\
\hline $\mathrm{r} 2-\mathrm{b}$ & . & 0.685 & 0.493 \\
\hline r2_o & . & 0.292 & 0.241 \\
\hline $\mathrm{F}^{-}$ & 5.265 &. & 7.125 \\
\hline $\begin{array}{l}\text { chi2 } \\
\mathrm{P}\end{array}$ & j & $\begin{array}{c}466.2 \\
0\end{array}$ & $3.00 \mathrm{e}-06$ \\
\hline Number of EMPRESA & & 37 & 37 \\
\hline
\end{tabular}

Robust standard errors in parentheses $* * * \mathrm{p}<0.01, * * \mathrm{p}<0.05, * \mathrm{p}<0.1$ 
Tabela 23- Compilação dos modelos POLS, efeitos fixos, efeitos aleatórios variável comparabilidade média com tratamento dos outliers

\begin{tabular}{|c|c|c|c|}
\hline VARIABLES & $\begin{array}{c}\text { POLS } \\
\text { ACURACIA }\end{array}$ & $\begin{array}{c}\text { Efeito Aleatório } \\
\text { ACURACIA }\end{array}$ & $\begin{array}{c}\text { Efeito fixo } \\
\text { ACURACIA }\end{array}$ \\
\hline COMPM & $\begin{array}{c}0.021 * * \\
(0.00587)\end{array}$ & $\begin{array}{c}0.015^{*} \\
(0.00449)\end{array}$ & $\begin{array}{c}0.014 \\
(0.00480)\end{array}$ \\
\hline 2.Siderurgia & $\begin{array}{l}-0.0218 \\
(0.0227)\end{array}$ & $\begin{array}{l}-0.0177 \\
(0.0344)\end{array}$ & \\
\hline 3.Prod. Metal & $\begin{array}{l}-0.120 \\
(0.0744)\end{array}$ & $\begin{array}{l}-0.146 \\
(0.172)\end{array}$ & \\
\hline 4.Telecomunicações & $\begin{array}{c}0.0114 \\
(0.0143)\end{array}$ & $\begin{array}{c}0.0148 \\
(0.0191)\end{array}$ & \\
\hline 5.Equi. Transporte & $\begin{array}{l}0.0415^{*} \\
(0.0211)\end{array}$ & $\begin{array}{c}0.0362 \\
(0.0296)\end{array}$ & \\
\hline 6.Ind. Química & $\begin{array}{c}0.0138 \\
(0.0237)\end{array}$ & $\begin{array}{l}0.00894 \\
(0.0171)\end{array}$ & \\
\hline 7.Papel e celuloce & $\begin{array}{l}-0.0150 \\
(0.0206)\end{array}$ & $\begin{array}{l}-0.0100 \\
(0.0164)\end{array}$ & \\
\hline 8.Calçados & $\begin{array}{l}-0.0228 \\
(0.0429)\end{array}$ & $\begin{array}{l}-0.0282 \\
(0.0324)\end{array}$ & \\
\hline 9.Tecidos e Vestuário & $\begin{array}{l}-0.131 * * \\
(0.0576)\end{array}$ & $\begin{array}{c}-0.131 \\
(0.0973)\end{array}$ & \\
\hline 10.Lojas geral & $\begin{array}{l}-0.0182 \\
(0.0188)\end{array}$ & $\begin{array}{l}-0.00287 \\
(0.0220)\end{array}$ & \\
\hline 2.IFRSTRANS & $\begin{array}{l}-0.0303 \\
(0.0255)\end{array}$ & $\begin{array}{l}-0.0290 \\
(0.0237)\end{array}$ & $\begin{array}{l}-0.0230 \\
(0.0227)\end{array}$ \\
\hline 3.IFRSPOS & $\begin{array}{c}-0.000530 \\
(0.0159)\end{array}$ & $\begin{array}{c}-0.000549 \\
(0.0151)\end{array}$ & $\begin{array}{c}0.0127 \\
(0.0280)\end{array}$ \\
\hline QANALIST & $\begin{array}{c}0.00542 * * * \\
(0.00139)\end{array}$ & $\begin{array}{l}0.00467 * * \\
(0.00193)\end{array}$ & $\begin{array}{l}0.00418^{*} \\
(0.00207)\end{array}$ \\
\hline LNATIVO & $\begin{array}{c}0.0103 \\
(0.00989)\end{array}$ & $\begin{array}{l}0.00559 \\
(0.0174)\end{array}$ & $\begin{array}{l}-0.0163 \\
(0.0384)\end{array}$ \\
\hline PTB & $\begin{array}{l}0.00848 * * \\
(0.00394)\end{array}$ & $\begin{array}{c}0.00231 \\
(0.00419)\end{array}$ & $\begin{array}{l}-0.000329 \\
(0.00342)\end{array}$ \\
\hline PERDA & $\begin{array}{l}0.00178 \\
(0.0301)\end{array}$ & $\begin{array}{c}0.0149 \\
(0.0368)\end{array}$ & $\begin{array}{c}0.0191 \\
(0.0372)\end{array}$ \\
\hline VP & $\begin{array}{l}-0.00144 \\
(0.0144)\end{array}$ & $\begin{array}{l}-0.0106 \\
(0.0235)\end{array}$ & $\begin{array}{l}-0.0121 \\
(0.0231)\end{array}$ \\
\hline DVPESTIMAT & $\begin{array}{l}0.000631 \\
(0.00264)\end{array}$ & $\begin{array}{l}0.000325 \\
(0.00232)\end{array}$ & $\begin{array}{l}0.000892 \\
(0.00241)\end{array}$ \\
\hline DPROE & $\begin{array}{l}-0.222 * \\
(0.118)\end{array}$ & $\begin{array}{l}-0.224 * * \\
(0.0904)\end{array}$ & $\begin{array}{l}-0.230 * * \\
(0.0966)\end{array}$ \\
\hline LNRISCO & $\begin{array}{c}0.0201 \\
(0.0207)\end{array}$ & $\begin{array}{c}0.0149 \\
(0.0218)\end{array}$ & $\begin{array}{c}0.0150 \\
(0.0224)\end{array}$ \\
\hline Constant & $\begin{array}{c}-0.359 * * \\
(0.171)\end{array}$ & $\begin{array}{l}-0.237 \\
(0.213)\end{array}$ & $\begin{array}{l}0.0905 \\
(0.536)\end{array}$ \\
\hline Observations & 407 & 407 & 407 \\
\hline R-squared & 0.271 & & 0.089 \\
\hline r2_a & 0.233 & • & 0.0632 \\
\hline r2_w & . & 0.0849 & 0.0886 \\
\hline $\mathrm{r} 2-\mathrm{b}$ & . & 0.531 & 0.0284 \\
\hline r2_- o & . & 0.263 & 0.0576 \\
\hline F & 3.192 &. & 5.328 \\
\hline chi2 & $\cdot$ & 116.6 & (1) \\
\hline $\begin{array}{l}\text { P } \\
\text { Number of EMPRESA }\end{array}$ & $6.09 \mathrm{e}-06$ & $\begin{array}{c}0 \\
37\end{array}$ & $\begin{array}{c}6.03 e-05 \\
37\end{array}$ \\
\hline
\end{tabular}

Robust standard errors in parentheses ${ }^{* *} \mathrm{p}<0.01,{ }^{* *} \mathrm{p}<0.05,{ }^{*} \mathrm{p}<0.1$ 
Tabela 24 Média acurácia e retorno anormal por ano

\begin{tabular}{|c|c|c|c|c|c|c|}
\hline & \multicolumn{3}{|c|}{ Acurácia } & \multicolumn{3}{|c|}{ Retorno anormal } \\
\hline & Média & Mediana & Desvio padrão & Média & Mediana & Desvio padrão \\
\hline 2005 &,- 066 &,- 019 &, 094 & 11,00 &,- 25 & 41,10 \\
\hline 2006 &,- 066 &,- 015 & ,110 &, 52 &,- 07 & 3,68 \\
\hline 2007 &,- 093 &,- 010 & ,214 & 46,16 & 0,00 & 121,40 \\
\hline 2008 &,- 094 &,- 024 & , 186 & 4,72 &,- 09 & 28,72 \\
\hline 2009 &,- 103 &,- 011 & ,226 &,- 18 &,- 13 &, 55 \\
\hline 2010 &,- 074 &,- 016 &, 156 &,- 08 &,- 02 & ,29 \\
\hline 2011 &,- 077 &,- 013 &, 176 &, 08 &, 05 &, 31 \\
\hline 2012 &,- 066 &,- 017 &, 113 & ,07 &, 04 & ,45 \\
\hline 2013 &,- 063 &,- 013 &, 121 & ,06 & ,09 & ,30 \\
\hline 2014 &,- 039 &,- 010 &, 057 &,- 12 &,- 11 & ,41 \\
\hline 2015 &,- 071 &,- 030 & ,111 & 1,00 &, 72 & 1,50 \\
\hline Total &,- 074 &,- 016 &, 150 & 5,75 & 0,00 & 41,30 \\
\hline Teste $F$ & \multicolumn{3}{|c|}{$0,939^{\mathrm{a}}(\mathrm{p}=0,499)$} & \multicolumn{3}{|c|}{$8,010^{\mathrm{a}}(\mathrm{p}<0,000)$} \\
\hline
\end{tabular}

${ }^{a}$ Teste $\mathrm{F}$ robusto quanto à heterocedasticidade (Teste de Welch) utilizado devido a significância do Teste de Levene; ${ }^{\mathrm{b}}$ Teste F sem ajuste (ANOVA). No caso do retorno anormal, para execução do teste estatístico, foram excluídas 13 observações consideradas outliers. 


\begin{tabular}{lrrrrrr}
\hline & \multicolumn{3}{c}{ Acurácia } & \multicolumn{4}{c}{ Retorno anormal } \\
& Média & Mediana & Desvio padrão & Média & Mediana & Desvio padrão \\
\hline Energia, gás e água &,- 051 &,- 012 &, 096 & 8,36 &, 04 & 51,50 \\
Siderurgia &,- 069 &,- 030 &, 128 & 1,01 &,- 10 & 8,88 \\
Ind. Prod. Metal &,- 247 &,- 119 &, 290 &, 25 &,- 22 & 1,13 \\
Telecomunicações &,- 030 &,- 014 &, 044 &, 02 &, 00 &, 60 \\
Equi. Transporte &,- 024 &,- 008 &, 051 &, 01 &,- 10 &, 37 \\
Ind. Química &,- 117 &,- 061 &, 193 & 6,79 &,- 11 & 29,94 \\
Papel e Celulose &,- 049 &,- 014 &, 068 &, 09 &,- 05 &, 55 \\
Calçados &,- 108 &,- 031 &, 204 & 9,14 &, 00 & 42,84 \\
Tec. e Vestuário &,- 187 &,- 039 &, 286 & 1,85 &,- 13 & 8,50 \\
Lojas em geral &,- 028 &,- 009 &, 047 & 26,64 &, 24 & 99,20 \\
Total &,- 074 &,- 016 &, 150 & 5,75 & 0,00 & 41,30 \\
\hline Teste F & $3,577(\mathrm{p}=0,001)$ & \multicolumn{5}{c}{$1,470(\mathrm{p}=0,171)$} \\
\hline
\end{tabular}

Nota: O teste de Levene rejeitou a homogeneidade de todas as variáveis, e por isso, o Teste F refere-se ao teste robusto de Welch. No caso do retorno anormal, para execução do teste estatístico, foram excluídas 13 observações consideradas outliers.

\begin{tabular}{|c|c|c|c|c|c|c|}
\hline & \multicolumn{3}{|c|}{ Acurácia } & \multicolumn{3}{|c|}{ Retorno anormal } \\
\hline & Média & Mediana & Desvio padrão & Média & Mediana & Desvio padrão \\
\hline Período anterior à adoção obrigatória do IFRS &,- 075 &,- 012 & , 148 & 19,23 &,- 10 & 75,93 \\
\hline Período de transição da adoção do IFRS &,- 099 &,- 018 & ,205 & 2,27 &,- 13 & 20,32 \\
\hline Período de adoção obrigatória do IFRS &,- 065 &,- 016 & 127 & 17 & 05 & ,78 \\
\hline Total &,- 074 &,- 016 &, 150 & 5,75 & 0,00 & 41,30 \\
\hline Teste F & & $0,947^{\mathrm{a}}(\mathrm{p}=$ & $0,390)$ & & $8,205^{\mathrm{b}}(\mathrm{p}$ & $0,000)$ \\
\hline
\end{tabular}

a Teste F robusto quanto à heterocedasticidade (Teste de Welch) utilizado devido a significância do Teste de Levene; ${ }^{\mathrm{b}}$ Teste F sem ajuste (ANOVA). No caso do retorno anormal, para execução do teste estatístico, foram excluídas 13 observações consideradas outliers. 


\begin{tabular}{lcccrrrrrr}
\hline & & \multicolumn{9}{c}{ Acurácia } & \multicolumn{4}{c}{ Retorno anormal } \\
& & Média & Mediana & Desvio padrão & Média & Mediana & Desvio padrão & Média \\
\hline Prezuízo no & Não &,- 065 &,- 013 &, 145 & 6,49 & 0,00 & 44,25 &,- 15 \\
exercício & Sim &,- 134 &,- 082 &, 167 &, 88 &,- 05 & 5,44 & 1,16 \\
\hline Teste $t$ & \multicolumn{3}{c}{$3,198^{\mathrm{b}}(\mathrm{p}=0,001)$} & \multicolumn{5}{c}{$-1,237^{\mathrm{a}}(\mathrm{p}=0,221)$} \\
\hline Viés de & Não &,- 065 &,- 012 &, 155 & 2,13 & 0,00 & 19,53 &,- 17 \\
previsão & Sim &,- 081 &,- 026 &, 146 & 8,76 &,- 02 & 52,87 &, 17 \\
& Total &,- 074 &,- 016 &, 150 & 5,75 & 0,00 & 41,30 &, 02 \\
\hline Teste $t$ & & $1,088^{\mathrm{b}}(\mathrm{p}=0,277)$ & \multicolumn{5}{c}{$0,609^{\mathrm{b}}(\mathrm{p}=0,543)$} \\
\hline
\end{tabular}

a Teste $t$ com variâncias não iguais assumidas utilizado devido a significância do teste de homogeneidade de Levene; ${ }^{\mathrm{b}}$ Teste $t$ com variância iguais assumidas.

\begin{tabular}{|c|c|c|c|c|c|c|}
\hline & $\begin{array}{c}\text { Cobertura dos } \\
\text { analistas }\end{array}$ & Ln do Ativo Total & Price-to-book & $\begin{array}{c}\text { Dispersão das } \\
\text { estimativas }\end{array}$ & $\begin{array}{c}\text { Desvio-padrão do } \\
\text { ROE }\end{array}$ & $\begin{array}{c}\text { Ln do } \\
\text { EMBI+Brasil } \\
\end{array}$ \\
\hline 2005 & 5 & 15,32 & 1,44 & 1,81 &, 08 & 5,74 \\
\hline 2006 & 5 & 15,37 & 1,98 & 1,79 & 07 & 5,26 \\
\hline 2007 & 7 & 15,48 & 2,38 & ,09 &, 06 & 5,40 \\
\hline 2008 & 7 & 15,62 & 1,69 &, 21 &, 08 & 6,06 \\
\hline 2009 & 8 & 15,64 & 1,90 &, 10 &, 11 & 5,26 \\
\hline 2010 & 8 & 15,78 & 1,79 & ,09 &, 11 & 5,24 \\
\hline 2011 & 8 & 15,90 & 1,53 &, 16 &, 08 & 5,34 \\
\hline 2012 & 9 & 15,96 & 1,76 &, 14 & 07 & 4,96 \\
\hline 2013 & 8 & 16,03 & 1,89 & ,20 &, 07 & 5,41 \\
\hline 2014 & 8 & 16,09 & 1,53 &, 14 &, 05 & 5,56 \\
\hline 2015 & 5 & 16,15 & 1,48 &, 10 &, 11 & 6,26 \\
\hline Total & 7 & 15,76 & 1,76 & ,44 &, 08 & 5,50 \\
\hline Teste $\mathrm{F}$ & $3,108^{\mathrm{a}}(\mathrm{p}=0,001)$ & $1,599^{b}(p=0,105)$ & $1,003 b(p=0,440)$ & $1,429^{\mathrm{a}}(\mathrm{p}=0,172)$ & $1,186^{\mathrm{a}}(\mathrm{p}=0,304)$ & - \\
\hline
\end{tabular}

a Teste $\mathrm{F}$ robusto quanto à heterocedasticidade (Teste de Welch) utilizado devido a significância do Teste de Levene; ${ }^{\mathrm{b}}$ Teste $\mathrm{F}$ sem ajuste $(\mathrm{ANOVA})$. 


\begin{tabular}{lccccc}
\hline & $\begin{array}{c}\text { Cobertura dos } \\
\text { analistas }\end{array}$ & Ln do Ativo Total & Price-to-book & $\begin{array}{c}\text { Dispersão das } \\
\text { estimativas }\end{array}$ & $\begin{array}{c}\text { Desvio-padrão do } \\
\text { ROE }\end{array}$ \\
\hline Energia, gás e água & 8 & 15,97 & 1,51 &, 79 &, 06 \\
Siderurgia & 8 & 16,70 & 1,59 &, 04 &, 09 \\
Ind. Prod. Metal & 1 & 13,02 &, 83 & 1,15 &, 09 \\
Telecomunicações & 8 & 16,87 & 1,69 &, 19 &, 07 \\
Equi. Transporte & 7 & 14,48 & 2,08 &, 01 &, 06 \\
Ind. Química & 5 & 15,60 & 1,29 &, 55 &, 33 \\
Papel e Celulose & 11 & 16,40 & 1,96 &, 02 &, 09 \\
Calçados & 2 & 14,44 & 2,30 &, 03 &, 03 \\
Tec. e Vestuário & 7 & 14,39 & 3,08 &, 10 &, 06 \\
Lojas em geral & 12 & 15,99 & 3,16 &, 33 &, 06 \\
Total & 7 & 15,76 & 1,76 &, 44 &, 08 \\
\hline Teste F & - & $106,246(\mathrm{p}<0,000)$ & $5,734(\mathrm{p}<0,000)$ & $7,874(\mathrm{p}<0,000)$ & $5,796(\mathrm{p}<0,000)$ \\
\hline
\end{tabular}

Nota: $\mathrm{O}$ teste de Levene rejeitou a homogeneidade de todas as variáveis, e por isso, o Teste $\mathrm{F}$ refere-se ao teste robusto de Welch.

\begin{tabular}{|c|c|c|c|c|c|c|}
\hline & $\begin{array}{c}\text { Cobertura dos } \\
\text { analistas }\end{array}$ & $\begin{array}{l}\text { Ln do Ativo } \\
\text { Total }\end{array}$ & Price-to-book & $\begin{array}{l}\text { Dispersão das } \\
\text { estimativas }\end{array}$ & $\begin{array}{c}\text { Desvio-padrão do } \\
\text { ROE }\end{array}$ & $\begin{array}{c}\text { Ln do } \\
\text { EMBI+Brasil }\end{array}$ \\
\hline $\begin{array}{l}\text { Período anterior à adoção obrigatória } \\
\text { do IFRS }\end{array}$ & 6 & 15,39 & 1,93 & 1,23 &, 07 & 5,47 \\
\hline $\begin{array}{l}\text { Período de transição da adoção do } \\
\text { IFRS }\end{array}$ & 7 & 15,63 & 1,79 &, 15 &, 10 & 5,66 \\
\hline $\begin{array}{l}\text { Período de adoção obrigatória do } \\
\text { IFRS }\end{array}$ & 8 & 15,99 & 1,66 &, 14 & ,08 & 5,46 \\
\hline Total & 7 & 15,76 & 1,76 & ,44 & ,08 & 5,50 \\
\hline Teste $\mathrm{F}$ & $6,649^{a}(p=0,002)$ & $7,120^{b}(p=0,001)$ & $0,961^{b}(p=0,383)$ & $5,447^{a}(p=0,005)$ & $1,157(\mathrm{p}=0,317)$ & - \\
\hline
\end{tabular}

${ }^{\mathrm{a}}$ Teste $\mathrm{F}$ robusto quanto à heterocedasticidade (Teste de Welch) utilizado devido a significância do Teste de Levene; ${ }^{\mathrm{b}}$ Teste $\mathrm{F}$ sem ajuste (ANOVA). 


\begin{tabular}{lcccccc}
\hline & & QANALIST & Ln do Ativo Total & Price-to-book & Dispersão das estimativas & Desvio-padrão do ROE \\
\cline { 2 - 7 } PERDA & Não & 7 & 15,73 & 1,90 &, 39 &, 07 \\
& Sim & 6 & 15,94 &, 83 &, 74 &, 14 \\
\hline Teste $t$ & & $2,361^{\mathrm{b}}(\mathrm{p}=0,019)$ & $-0,834^{\mathrm{a}}(\mathrm{p}=0,408)$ & $5,650^{\mathrm{a}}(\mathrm{p}<0,00)$ & $-1,257^{\mathrm{b}}(\mathrm{p}=0,210)$ & $-2,786^{\mathrm{a}}(\mathrm{p}=0,007)$ \\
\hline Viés de & Não & 7 & 15,73 & 1,95 &, 18 &, 08 \\
previsão & Sim & 7 & 15,78 & 1,60 &, 65 &, 08 \\
\hline Teste $t$ & & $0,178^{\mathrm{b}}(\mathrm{p}=0,859)$ & $-0,298^{\mathrm{b}}(\mathrm{p}=0,766)$ & $2,106^{\mathrm{b}}(\mathrm{p}=0,036)$ & $-2,680^{\mathrm{a}}(\mathrm{p}=0,008)$ & $0,215^{\mathrm{b}}(0,830)$ \\
\hline
\end{tabular}

${ }^{a}$ Teste $t$ com variâncias não iguais assumidas utilizado devido a significância do teste de homogeneidade de Levene; ${ }^{\mathrm{b}}$ Teste $t$ com variância iguais assumidas.

\begin{tabular}{lrrrrrrrrr}
\hline & \multicolumn{3}{c}{ Ln do valor de mercado } & \multicolumn{3}{c}{ Market-to-book } & \multicolumn{3}{c}{ Endividamento } \\
& Média & Mediana & Desvio padrão & Média & Mediana & Desvio padrão & Média & Mediana & Desvio padrão \\
\hline 2005 & 15,00 & 15,25 & 1,45 & 1,62 & 1,38 & 1,07 &, 56 &, 24 &, 71 \\
2006 & 15,36 & 15,56 & 1,45 & 1,97 & 1,85 & 1,30 &, 49 &, 23 &, 66 \\
2007 & 15,66 & 15,86 & 1,34 & 2,36 & 2,06 & 1,57 &, 38 &, 23 &, 40 \\
2008 & 15,13 & 15,28 & 1,51 & 1,34 & 1,06 &, 94 &, 60 &, 34 &, 85 \\
2009 & 15,61 & 15,76 & 1,40 & 2,03 & 1,84 & 1,45 &, 54 &, 35 &, 69 \\
2010 & 15,64 & 15,86 & 1,42 & 1,76 & 1,43 & 1,34 &, 53 &, 31 &, 72 \\
2011 & 15,55 & 15,73 & 1,59 & 1,53 & 1,28 & 1,16 &, 65 &, 41 &, 84 \\
2012 & 15,66 & 15,86 & 1,56 & 1,75 & 1,43 & 1,41 &, 67 &, 40 &, 94 \\
2013 & 15,31 & 15,78 & 2,93 & 1,89 & 1,30 & 2,07 &, 73 &, 36 &, 93 \\
2014 & 15,10 & 15,86 & 2,97 & 1,59 & 1,11 & 1,92 &, 55 &, 28 &, 68 \\
2015 & 14,82 & 15,44 & 2,97 & 1,52 &, 60 & 2,33 &, 86 &, 40 & 1,29 \\
Total & 15,35 & 15,66 & 1,98 & 1,76 & 1,40 & 1,57 &, 60 &, 29 &, 82 \\
\hline Teste F & $0,837^{\mathrm{b}}(\mathrm{p}=0,593)$ & \multicolumn{3}{c}{$1,258^{\mathrm{b}}(\mathrm{p}=0,253)$} & & $1,123^{\mathrm{a}}(\mathrm{p}=0,348)$ & \\
\hline
\end{tabular}

${ }^{a}$ Teste $\mathrm{F}$ robusto quanto à heterocedasticidade (Teste de Welch) utilizado devido a significância do Teste de Levene; ${ }^{\mathrm{b}}$ Teste $\mathrm{F}$ sem ajuste (ANOVA). 


\begin{tabular}{lrrrrrrrrr}
\hline & \multicolumn{3}{c}{ Ln do valor de mercado } & \multicolumn{3}{c}{ Market-to-book } & \multicolumn{3}{c}{ Endividamento } \\
& Média & Mediana & Desvio padrão & Média & Mediana & Desvio padrão & Média & Mediana & Desvio padrão \\
\hline Energia, gás e água & 15,59 & 15,66 &, 96 & 1,57 & 1,32 & 1,10 &, 41 &, 27 &, 44 \\
Siderurgia & 16,36 & 16,49 & 1,71 & 1,65 & 1,20 & 1,36 &, 52 &, 15 &, 94 \\
Ind. Prod. Metal & 10,54 & 12,00 & 4,36 & 1,08 &, 94 &, 91 &, 51 &, 07 &, 95 \\
Telecomunicações & 16,61 & 16,70 &, 79 & 1,53 & 1,43 &, 69 &, 45 &, 20 &, 61 \\
Equi. Transporte & 14,41 & 14,39 &, 60 & 2,21 & 2,17 & 1,04 &, 73 &, 71 &, 31 \\
Ind. Química & 14,66 & 14,59 & 1,43 & 1,53 & 1,12 & 1,61 & 1,42 & 1,13 & 1,10 \\
Papel e Celulose & 15,79 & 15,72 &, 59 & 1,71 & 1,61 &, 99 & 1,34 & 1,18 &, 60 \\
Calçados & 14,88 & 14,88 &, 54 & 2,22 & 2,11 &, 71 &, 13 &, 11 &, 08 \\
Tec. e Vestuário & 14,22 & 14,31 & 1,52 & 3,00 & 1,76 & 2,86 &, 25 &, 12 &, 28 \\
Lojas em geral & 16,32 & 16,25 &, 51 & 2,63 & 1,67 & 3,76 & 1,54 &, 53 & 1,64 \\
Total & 15,35 & 15,66 & 1,98 & 1,76 & 1,40 & 1,57 &, 60 &, 29 &, 82 \\
\hline Teste F & \multicolumn{3}{c}{$31,326(\mathrm{p}<0,000)$} \\
\hline
\end{tabular}

Nota: O teste de Levene rejeitou a homogeneidade de todas as variáveis, e por isso, o Teste F refere-se ao teste robusto de Welch.

\begin{tabular}{|c|c|c|c|c|c|c|c|c|c|c|}
\hline & \multicolumn{4}{|c|}{ Ln do valor de mercado } & \multicolumn{2}{|c|}{ Market-to-book } & \multicolumn{4}{|c|}{ Endividamento } \\
\hline & Média & Média & Mediana & Desvio padrão & Média & Mediana & Desvio padrão & Média & Mediana & Desvio padrão \\
\hline Período anterior à adoção obrigatória do IFRS & 12 & 15,34 & 15,47 & 1,43 & 1,99 & 1,85 & 1,35 & ,47 & 23 & ,61 \\
\hline Período de transição da adoção do IFRS &, 09 & 15,37 & 15,52 & 1,47 & 1,69 & 1,45 & 1,26 &, 57 &, 35 & ,77 \\
\hline Período de adoção obrigatória do IFRS &,- 09 & 15,35 & 15,78 & 2,35 & 1,67 & 1,22 & 1,74 & ,66 & ,36 & ,92 \\
\hline Total & ,00 & 15,35 & 15,66 & 1,98 & 1,76 & 1,40 & 1,57 & ,60 & ,29 & ,82 \\
\hline Teste $\mathrm{F}$ & & $0,007^{\mathrm{b}}$ & $\mathrm{p}=0,993)$ & & $1,579^{\mathrm{b}}$ & $\mathrm{p}=0,207)$ & & $2,488^{\mathrm{a}}$ & $\mathrm{p}=0,086)$ & \\
\hline
\end{tabular}

${ }^{\mathrm{a}}$ Teste $\mathrm{F}$ robusto quanto à heterocedasticidade (Teste de Welch) utilizado devido a significância do Teste de Levene; ${ }^{\mathrm{b}}$ Teste $\mathrm{F}$ sem ajuste (ANOVA). 


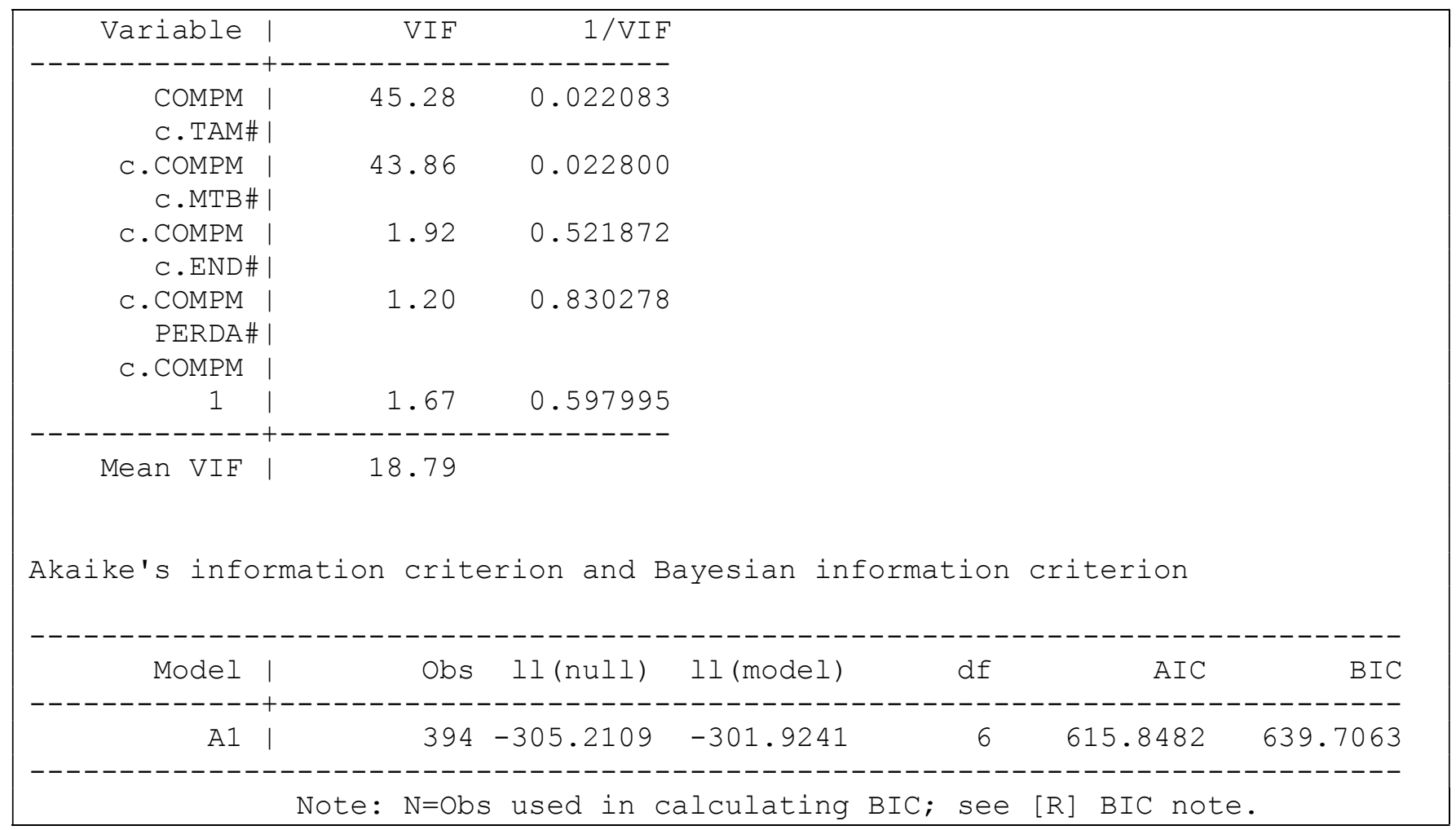




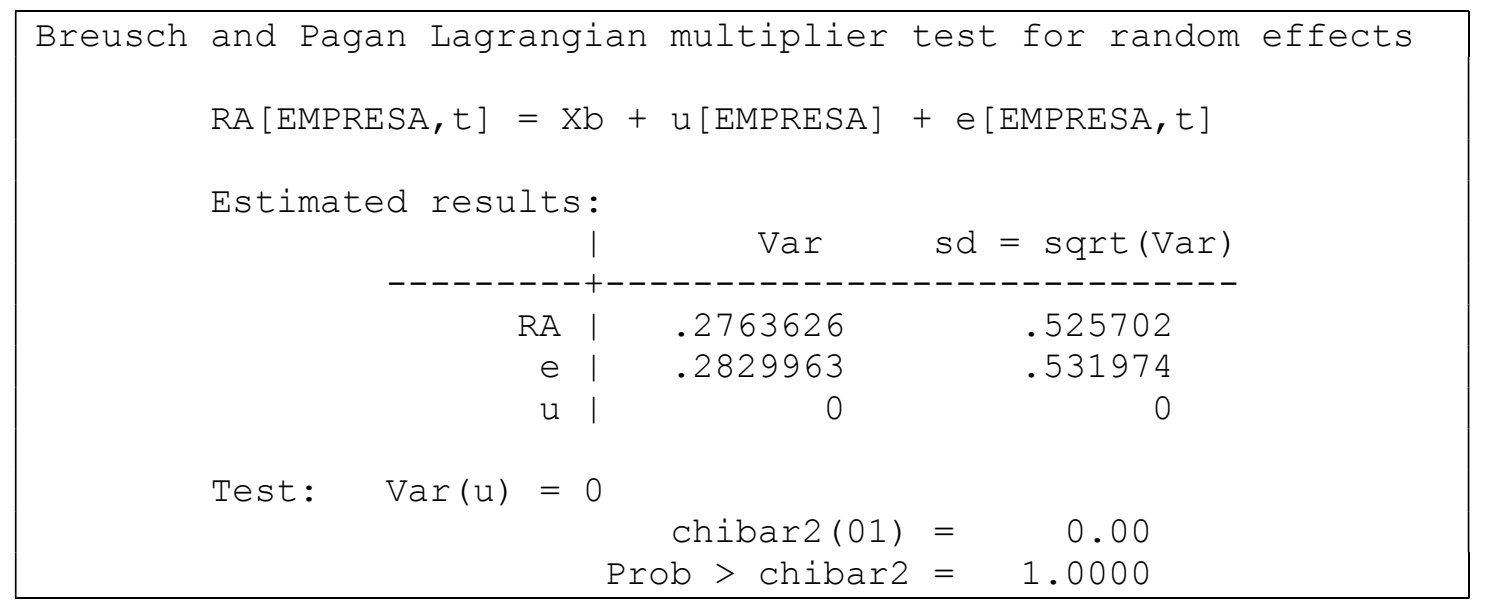

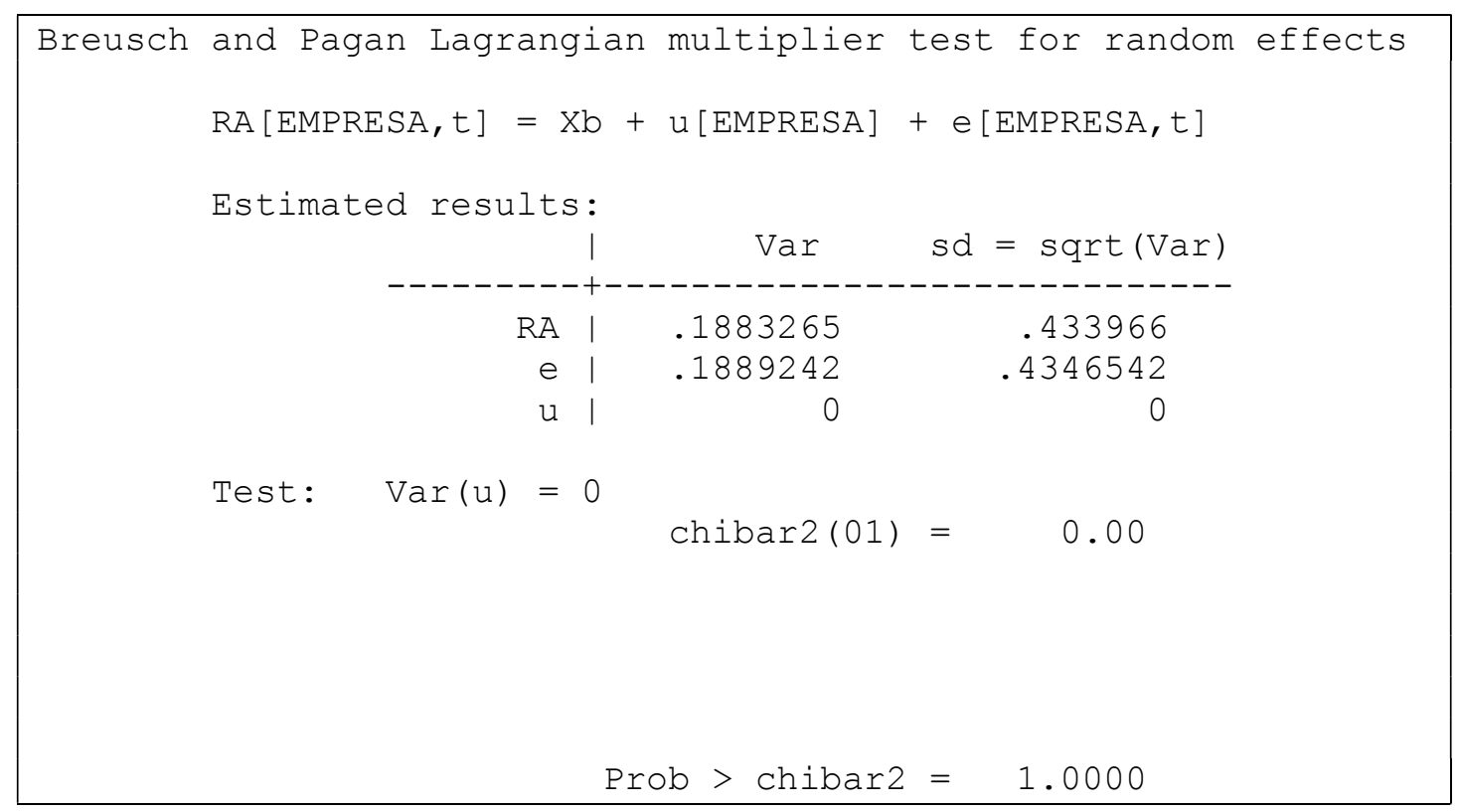




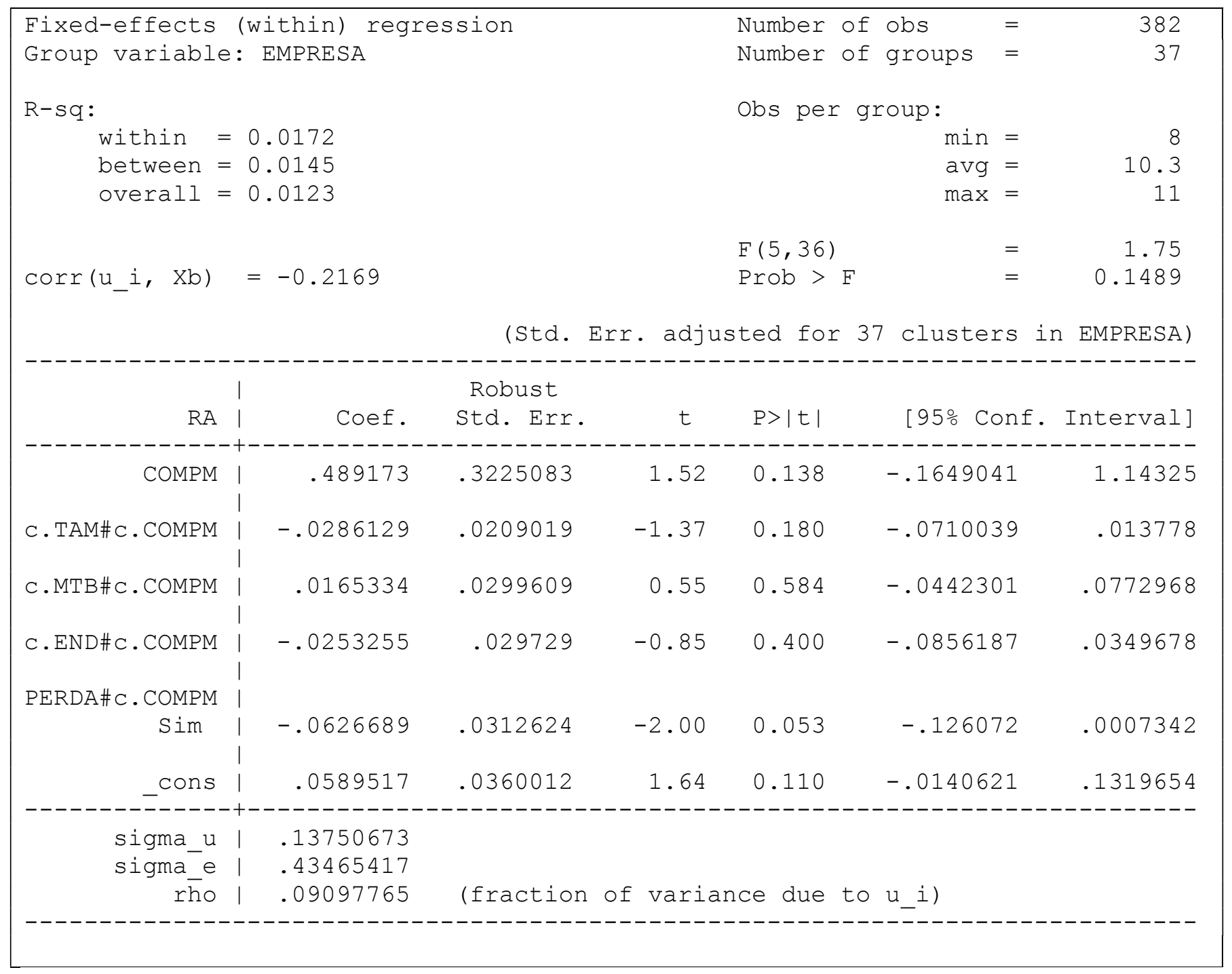




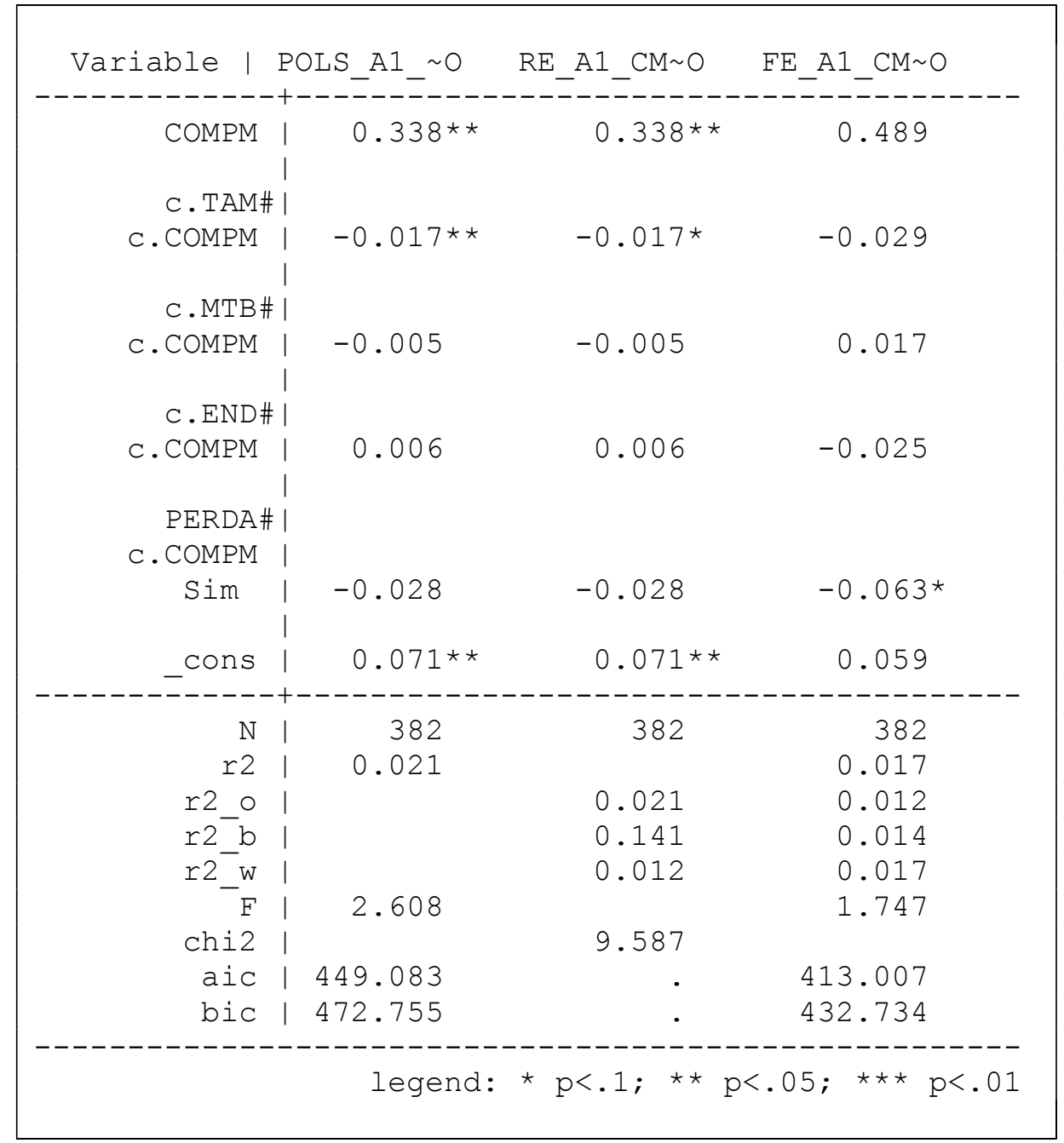


Breusch and Pagan Lagrangian multiplier test for random effects $\mathrm{RA}[\mathrm{EMPRESA}, \mathrm{t}]=\mathrm{Xb}+\mathrm{u}[\mathrm{EMPRESA}]+\mathrm{e}[\mathrm{EMPRESA}, \mathrm{t}]$

Estimated results:

\begin{tabular}{r|rr} 
& $\operatorname{Var}$ & $\mathrm{sd}=\operatorname{sqrt}(\operatorname{Var})$ \\
$\mathrm{RA}$ & .1818389 & .4264258 \\
$\mathrm{e}$ & .1806386 & .425016 \\
$\mathrm{u}$ & 0 & 0
\end{tabular}

Test: $\operatorname{Var}(u)=0$

$$
\text { chibar2 }(01)=0.00
$$

Prob $>$ chibar $=1.0000$ 


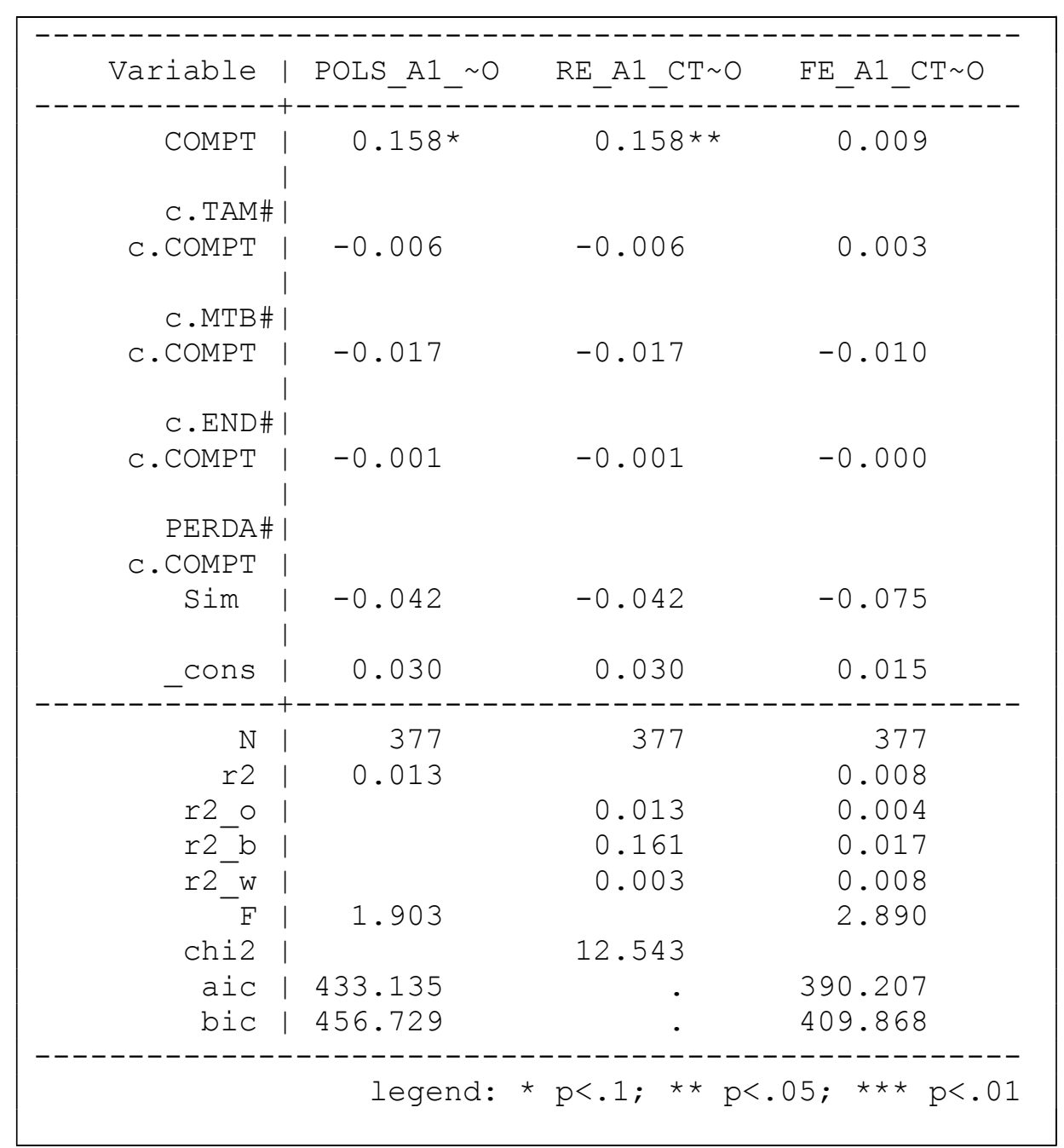


